\title{
Metabolismo del ion hidrógeno. Bases moleculares de las respuestas de compensación de los trastornos primarios del equilibrio ácido-base
}

\author{
Eduardo Arilla Ferreiro \\ Catedrático Universitario de Bioquímica y Biología Molecular; eduardo.arilla@uah.es; ORCID id: \\ https://orcid.org/0000-0001-6744-6056
}

DOI: https://doi.org/10.37536/RIECS.2021.6.1.268

Recibido: 24/02/2020; Aceptado: 12/04/2020; Publicado: 31/05/2021

\section{Importancia fisiológica y clínica de la concentración del ion $\mathbf{H}^{+}$}

La constancia de la concentración del ion $\mathrm{H}^{+}$en el líquido extracelular (e intracelular) es fundamental por los siguientes motivos:

1. Los cambios moderados de la concentración de los protones (ion $\left.\mathrm{H}^{+}\right)(\mathrm{pH})$ afectan el estado iónico de las enzimas y con frecuencia también del sustrato. Además, las enzimas pueden experimentar cambios de conformación con las variaciones del $\mathrm{pH}$.

2. Los cambios en la concentración del ion $\mathrm{H}^{+}$alteran el transporte de oxígeno en la sangre, puesto que, modifica la afinidad de la hemoglobina por el oxígeno.

3. La concentración del ion $\mathrm{H}^{+}$influye sobre la distribución de otros iones entre las células y el líquido extracelular. Así, un aumento de la concentración de los iones $\mathrm{H}^{+}$hace que se desplacen iones $\mathrm{K}^{+}$desde las células hacia el líquido extracelular. Esto puede afectar a la conducción eléctrica del corazón.

4. El aumento de la concentración de iones $\mathrm{H}^{+}$en la sangre, reduce la actividad de hormonas tales como la insulina y la adrenalina y de fármacos como la digital. Asimismo, la concentración del ion $\mathrm{H}^{+}$influye sobre el grado de fijación de algunos fármacos a proteínas plasmáticas $\mathrm{y}$, por lo tanto, sobre la concentración del fármaco libre. Parte de los iones de calcio presentes en el plasma están fijados a las proteínas plasmáticas y su grado de fijación aumenta al disminuir la concentración del ion $\mathrm{H}^{+}$en la sangre. Esto hace que disminuyan los iones de calcio libre, con la consiguiente hiperexcitabilidad de nervios y músculos (tetania).

5. Los trastornos de la concentración del ion $\mathrm{H}^{+}$provocan una amplia variedad de problemas clínicos incluyendo: retardo en el crecimiento en neonatos y niños, náuseas y vómitos, alteraciones electrolíticas, aumento de la susceptibilidad a padecer arritmias, disminución de la sensibilidad a las catecolaminas, particularmente en el sistema cardiovascular, osteoporosis y osteomalacia, nefrolitiasis recurrente, atrofia muscular esquelética, parestesias e incluso coma. Las alteraciones del equilibrio ácido-base son muy frecuente en los pacientes críticos. En muchas ocasiones estos enfermos presentan trastornos complejos que no pueden ser correctamente diagnosticados utilizando el método clásico de Henderson-Hasselbalch de interpretación del equilibrio ácido-base. La teoría de Stewart permite mejorar la identificación de estos trastornos complejos y la comprensión de la fluidoterapia adecuada. 


\section{Modelo fisicoquímico de Stewart para explicar el equilibrio ácido-base}

El conocimiento del equilibrio ácido-base asienta en conceptos derivados de estudios de varios investigadores, incluyendo a Arrhenius, Sørensen, Henderson, Hasselbalch, Brønsted y Lowry, Van Slyke, Lewis, Severinghaus, Astrup, Siggaard-Andersen, Singer, Hastings, Schwartz, Relman y Stewart [1-7].

La aproximación al estudio del equilibrio ácido-base por el Profesor Stewart es diferente de la aproximación convencional basada en la ecuación de Henderson-Hasselbalch y es particularmente útil para el análisis de los trastornos ácido-base metabólicos, así como para su terapia correctora. El modelo de Stewart incluye las aproximaciones tradicionales para describir el equilibrio ácido-base, tales como ecuación de HendersonHasselbalch, la ecuación de Van Slyke y la fórmula de amortiguación de Van Slyke. Así, más que una alternativa, la aproximación o modelo de Stewart creo que puede ser considerada como complementaria al conocimiento de que disponíamos ya sobre el tema. Es decir los dos modelos de abordaje ácido-base no son excluyentes.

1. Principios fundamentales que gobiernan los líquidos corporales

Stewart trata los líquidos corporales como sistemas fisicoquímicos, gobernados por los siguientes principios fundamentales:

a. Ley de electroneutralidad del agua. En una solución acuosa, la suma de todos los iones cargados positivamente(cationes) debe ser igual a la suma de todos los iones cargados negativamente(aniones). La carga neta dentro de un compartimento es cero.

b. Ley de acción de masas. El requerimiento de que todos los equilibrios deben de ser satisfechos simultáneamente para los diversos componentes que constituyen los líquidos corporales.

c. Ley de conservación de la masa. En toda reacción química la masa se conserva, esto es, la masa total de los reactivos es la masa total de los productos. De esta manera la masa no se crea ni se destruye, se transforma.

2. Componentes de los líquidos corporales

Stewart aplicó estos principios a los componentes que constituyen los líquidos corporales.

a. Agua. En el agua pura la concentración de iones hidrógeno $\left[\mathrm{H}^{+}\right]$o hidroxonio $\left[\mathrm{H}_{3} \mathrm{O}^{+}\right]$es igual a la concentración de iones hidroxilo $\left[\mathrm{OH}^{-}\right],\left[\mathrm{H}^{+}\right]=\left[\mathrm{OH}^{-}\right]$. A $25^{\circ} \mathrm{C}$, ambas concentraciones son igual a $10^{-7} \mathrm{M}$. Una solución acuosa se define como ácida si hay más iones hidrógeno que iones hidroxilo $\left[\mathrm{H}^{+}\right]>\left[\mathrm{OH}^{-}\right]$y básica cuando hay más iones hidroxilo que iones de hidrógeno $\left[\mathrm{H}^{+}\right]<\left[\mathrm{OH}^{-}\right]$. Ahora bien, el producto iónico del $\mathrm{H}_{2} \mathrm{O}\left(\left[\mathrm{H}^{+}\right]\left[\mathrm{OH}^{-}\right]=10^{-14}\right)$ es siempre constante en cualquier solución acuosa independiente de la presencia de los solutos disueltos. Si las sustancias disueltas alteran la concentración bien de los iones $\mathrm{H}^{+}$o de los iones $\mathrm{OH}^{-}$tiene que ocurrir un cambio concomitante de la misma magnitud en el otro ion para mantener constante el producto iónico del $\mathrm{H}_{2} \mathrm{O}$.

b. Iones débiles. Los iones débiles se producen a partir de sustratos que solo se disocian parcialmente cuando se disuelven en el agua. Estos se pueden clasificar en dos grupos.

A. Dióxido de carbono $\left(\mathrm{CO}_{2}\right)$ e iones asociados (volátiles).

B. Ácidos débiles (no volátiles) que son principalmente proteínas (albúmina y globulinas) y fosfato inorgánico.

c. Iones fuertes. Los iones fuertes son aquellos iones que están completamente disociados en soluciones biológicas (ej. $\mathrm{Na}^{+}, \mathrm{K}^{+}, \mathrm{Cl}^{-}$, lactato). 
3. Variables independientes y dependientes

Stewart concibió la disociación del $\mathrm{H}_{2} \mathrm{O}$ como el elemento único para explicar los cambios en la $\left[\mathrm{H}^{+}\right]$en los diferentes compartimentos líquidos del organismo. Así, la $\left[\mathrm{H}^{+}\right]$en cualquier solución acuosa depende del grado de disociación del $\mathrm{H}_{2} \mathrm{O}$ en $\mathrm{H}^{+}$e OH . Es decir, los cambios en la $\left[\mathrm{H}^{+}\right]$ ocurren no como resultado de añadir o extraer iones $\mathrm{H}^{+}$de la solución, sino como una consecuencia de la disociación de las moléculas de $\mathrm{H}_{2} \mathrm{O}$ en respuesta a cambios de tres variables independientes que se estudian a continuación. Las moléculas de $\mathrm{H}_{2} \mathrm{O}$ presentes en los líquidos biológicos son la fuente del ion $\mathrm{H}^{+}$. Para Stewart las modificaciones de la concentración de bicarbonato $\left(\mathrm{HCO}_{3}^{-}\right)$no son causa de los trastornos del equilibrio ácido base sino una consecuencia de los mismos, por lo que según Stewart el $\mathrm{HCO}_{3}^{-}$es una variable dependiente.

Según Stewart tres variables independientes influencian la disociación del $\mathrm{H}_{2} \mathrm{O}$, incluso en soluciones complejas como el plasma y la orina. Estas variables independientes entre sí son la $\mathrm{pCO}_{2}$, la "diferencia de iones fuertes" (SID) y la concentración total de ácidos débiles no volátiles ([Атот]).

La influencia de las variables independientes se puede predecir resolviendo seis ecuaciones de equilibrio simultáneas (que incorpora la ecuación de Henderson-Hasselbalch)

a. $\quad K w^{\prime}=\left[\mathrm{H}^{+}\right] \times\left[\mathrm{OH}^{-}\right]$: el producto iónico del agua deriva del equilibro de disociación de agua.

b. $\left[\mathrm{H}^{+}\right] \times\left[\mathrm{A}^{-}\right]=\mathrm{Kh} \times[\mathrm{HA}]$ : equilibrio de disociación de ácido débil no volátil.

c. $[\mathrm{HA}]+\left[\mathrm{A}^{-}\right]=[\mathrm{Aтот}]$ : conservación de masa para ácidos débiles no volátiles.

d. $\left[\mathrm{H}^{+}\right] \times\left[\mathrm{HCO}_{3}^{-}\right]=\mathrm{Kc}^{\circ} \times \mathrm{pCO}_{2}$ : equilibrio de disociación del ácido carbónico o equilibrio de formación del ion $\mathrm{HCO}_{3}^{-}$(relación de Henderson-Hasselbalch).

e. $\quad\left[\mathrm{H}^{+}\right] \times\left[\mathrm{CO}_{3}^{2-}\right]=\mathrm{Kc} \times\left[\mathrm{HCO}_{3}^{-}\right]$: equilibrio de disociación del ion $\mathrm{HCO}_{3}^{-}$.

f. $[\mathrm{SID}]+\left[\mathrm{H}^{+}\right]-\left[\mathrm{HCO}_{3}^{-}\right]-\left[\mathrm{CO}_{3}^{2-}\right]-\left[\mathrm{A}^{-}\right]-\left[\mathrm{OH}^{-}\right]=0$ : electroneutralidad.

Estudiamos a continuación las variables independientes según Stewart que influencian la disociación de $\mathrm{H}_{2} \mathrm{O}$ serían:

a. Presión parcial del dióxido de carbono $\left(\mathrm{pCO}_{2}\right)$. La modificación de la $\mathrm{pCO}_{2}$ a través de la ventilación alveolar causa cambios rápidos en la $\left[\mathrm{H}^{+}\right]$en soluciones acuosas debido a la disociación reversible del ácido carbónico. El pequeño tamaño y alta solubilidad del $\mathrm{CO}_{2}$ le permite pasar fácilmente entre distintos compartimentos y alterar la $\left[\mathrm{H}^{+}\right]$en todos los líquidos corporales.

b. Concentración total de ácido débil no volátil [Атот]. Los ácidos débiles no se disocian completamente en soluciones biológicas. Las proteínas (albúmina y globulinas) son los principales ácidos débiles en el plasma y su concentración está controlada en gran parte por el hígado. Los fosfatos inorgánicos también contribuyen a la [Атот] siendo particularmente significativo su efecto en condiciones de hipoalbuminemia. La hipoalbuminemia y la consecuente reducción de ácidos débiles totales, es génesis de alcalosis. De esta manera la pérdida de ácidos débiles del plasma induce a una alcalinización.

c. Diferencia de iones fuertes (SID). Los iones fuertes son los que están completamente disociados en soluciones acuosas. Los iones fuertes más importantes son el $\mathrm{Na}^{+}, \mathrm{el} \mathrm{K}$, $\mathrm{el} \mathrm{Mg}^{2+}$, el $\mathrm{Ca}^{2+}$, el $\mathrm{Cl}^{-}$y el lactato- A pH 7,4 el ácido láctico se disocia en más de un $99,9 \%$, por lo tanto es un ácido fuerte, de esta forma se asume que el lactato se encuentra en su forma aniónica. La diferencia de iones fuertes es la cantidad por la cual los cationes fuertes exceden a la de los aniones fuertes, medido en miliequivalentes por litro. Así, para el plasma, y se conoce como SID aparente (SIDa).

$$
\mathrm{SIDa}(\mathrm{mEq} / \mathrm{L})=\left(\left[\mathrm{Na}^{+}\right]+\left[\mathrm{K}^{+}\right]+\left[\mathrm{Ca}^{2+}\right]+\left[\mathrm{Mg}^{2+}\right]\right)-\left(\left[\mathrm{Cl}^{-}\right]+[\text {Lactato }]\right) .
$$

En el plasma hay normalmente un exceso de cationes con respecto a los aniones, dando al SID un valor positivo de 38 a $42 \mathrm{mEq} / \mathrm{L}$. La concentración en miliequivalentes representa la carga, así como la cantidad de iones presentes. Recordemos que las concentraciones de iones en ocasiones se expresan como equivalentes por litro y no en moles por litro. Un equivalente 
(Eq) es igual a la molaridad de un ion multiplicada por el número de cargas que porta el ion. Así, el ion de $\mathrm{Na}^{+}$con carga +1 , tiene un equivalente por mol. El ion de $\mathrm{Ca}^{2+}$, tiene dos equivalentes por mol. La misma regla es válida para los iones cargados negativamente. El ion $\mathrm{Cl}^{-}$tiene un equivalente por mol y el ion $\mathrm{HPO}_{4}^{2-}$ tiene dos equivalentes por mol. Un miliequivalente $(\mathrm{mEq})$ es $1 / 1000$ de un equivalente de un elemento químico, radical o compuesto. Los miliequivalentes son útiles para expresar la concentración de soluciones biológicas diluidas. Muchas mediciones clínicas, como la concentración de iones de $\mathrm{Na}^{+}$en sangre, se informan en miliequivalentes por litro (mEq/L). La SID es el desequilibrio de carga de los iones fuertes. Dado que los iones fuertes están siempre disociados, no participa en las reacciones químicas (iones no metabolizables).

La SID abreviada (SID):

$$
\begin{gathered}
\mathrm{SID}=\left[\mathrm{Na}^{+}\right]+\left[\mathrm{K}^{+}\right]-\left[\mathrm{Cl}^{-}\right]=140+4-102=34 \mathrm{mEq} / \mathrm{L} . \\
{\left[\mathrm{Na}^{+}\right]=140 ;\left[\mathrm{K}^{+}\right]=4 ;\left[\mathrm{Cl}^{-}\right]=102 \mathrm{mEq} / \mathrm{L}}
\end{gathered}
$$

Sólo los cambios en las variables independientes SID, [Атот] у $\mathrm{pCO}_{2}$ producen cambios en las variables dependientes: $\left[\mathrm{H}^{+}\right],\left[\mathrm{HCO}_{3}^{-}\right],\left[\mathrm{A}^{-}\right],[\mathrm{HA}],\left[\mathrm{CO}_{3}^{2-}\right]$ y la $\left[\mathrm{OH}^{-}\right]$. Por lo tanto, los trastornos del equilibrio ácido base solo pueden ocurrir por cambios en la SID, la [A тот] y la $\mathrm{pCO}_{2}$. Según Stewart la ganancia o pérdida de $\mathrm{HCO}_{3}^{-}$no es la causa de los trastornos del equilibrio ácido-base sino consecuencia de los mismos. Dado que la $\mathrm{pCO}_{2}$ está regulada por la respiración, los cambios en la $\mathrm{pCO}_{2}$ producen trastornos ácido-base respiratorios. Los trastornos ácido-base metabólicos resultan de cambios de la SID o de la [Атот].

Dado que la neutralidad eléctrica se debe mantener, la SID tiene una influencia poderosa sobre la disociación del agua y por lo tanto sobre la $\left[\mathrm{H}^{+}\right]$. Las concentraciones de iones fuertes en el organismo están determinadas por la absorción intestinal y la excreción renal.

La SIDa tiene que estar contrapesada por cargas negativas cuantitativamente iguales para preservar la electroneutralidad plasmática. Las cargas negativas que compensan la SIDa son principalmente las de la albúmina, el fosfato y el bicarbonato y la suma de todas ellas se ha llamado diferencia de iones fuertes efectiva (SIDe).

$$
\operatorname{SIDe}(\mathrm{mEq} / \mathrm{L})=[\text { Albumina- }]+[\text { Fosfato inorgánico }]+\left[\mathrm{HCO}_{3}^{-}\right]
$$

La diferencia entre la SIDa y la SIDe se conoce como hueco o brecha de iones fuertes (SIG).

$$
\mathrm{SIG}(\mathrm{mEq} / \mathrm{L})=\mathrm{SIDa}-\mathrm{SIDe}
$$

En el plasma humano normal la SIDa es igual a la SIDe y por lo tanto la SIG vale cero. Si la SIDa es mayor que la SIDe, hay presencia de aniones no medidos en el plasma. Esta diferencia o brecha se ha denominado diferencia de iones fuertes para distinguirla de la brecha aniónica (anión gap). La diferencia de iones fuertes es menor de $2 \mathrm{mEq}$ y se eleva en situaciones como la cetoacidosis diabética y la insuficiencia renal. Conforme disminuye la diferencia de iones fuertes aumenta la $\left[\mathrm{H}^{+}\right]$y disminuye por lo tanto el $\mathrm{pH}$.

Si bien en el momento actual no hay evidencia experimental de que la SID modifique la disociación del agua, si se puede predecir su efecto considerando la resolución de las seis ecuaciones de equilibrio simultáneas anteriormente citadas.

Hay que tener presente que la autoionización del $\mathrm{H}_{2} \mathrm{O}$ es un mecanismo clave para los cambios en la $\left[\mathrm{H}^{+}\right]$en soluciones acuosas. Se sabe que dos moléculas de agua se pueden disociar en agua líquida rindiendo un ion hidróxido $\left(\mathrm{H}_{3} \mathrm{O}^{+}\right)$y un ion hidroxilo $(\mathrm{OH}-)$ en un tiempo aproximado de 10 horas. Geissler y colegas estudiaron la autoionización del agua y demostraron que campos eléctricos de gran alcance impulsan la disociación del hidrógeno unido al oxígeno. 


\section{Origen y destino de los iones $\mathrm{H}+$ del plasma y de la orina}

\subsection{Disociación del $\mathrm{H}_{2} \mathrm{O}$ por la $\mathrm{pCO}_{2}$. Coincidencia de Henderson-Hasselbalch y Stewart}

\subsubsection{Amortiguación de iones $\mathrm{H}^{+}$: Capilar tisular}

$\mathrm{El} \mathrm{CO}_{2}$ se produce continuamente a lo largo de la vida en cantidades variables como un producto terminal del metabolismo celular (respiración celular). (Fig. 1). La pCO intracelular está alrededor de $46 \mathrm{mmHg}$ y en la sangre arterial es de $40 \mathrm{mmHg}$. En consecuencia, el $\mathrm{CO}_{2}$ difunde rápidamente desde las células al líquido intersticial, de aquí al plasma y del plasma a los eritrocitos, a medida que la sangre atraviesa los capilares sistémicos.

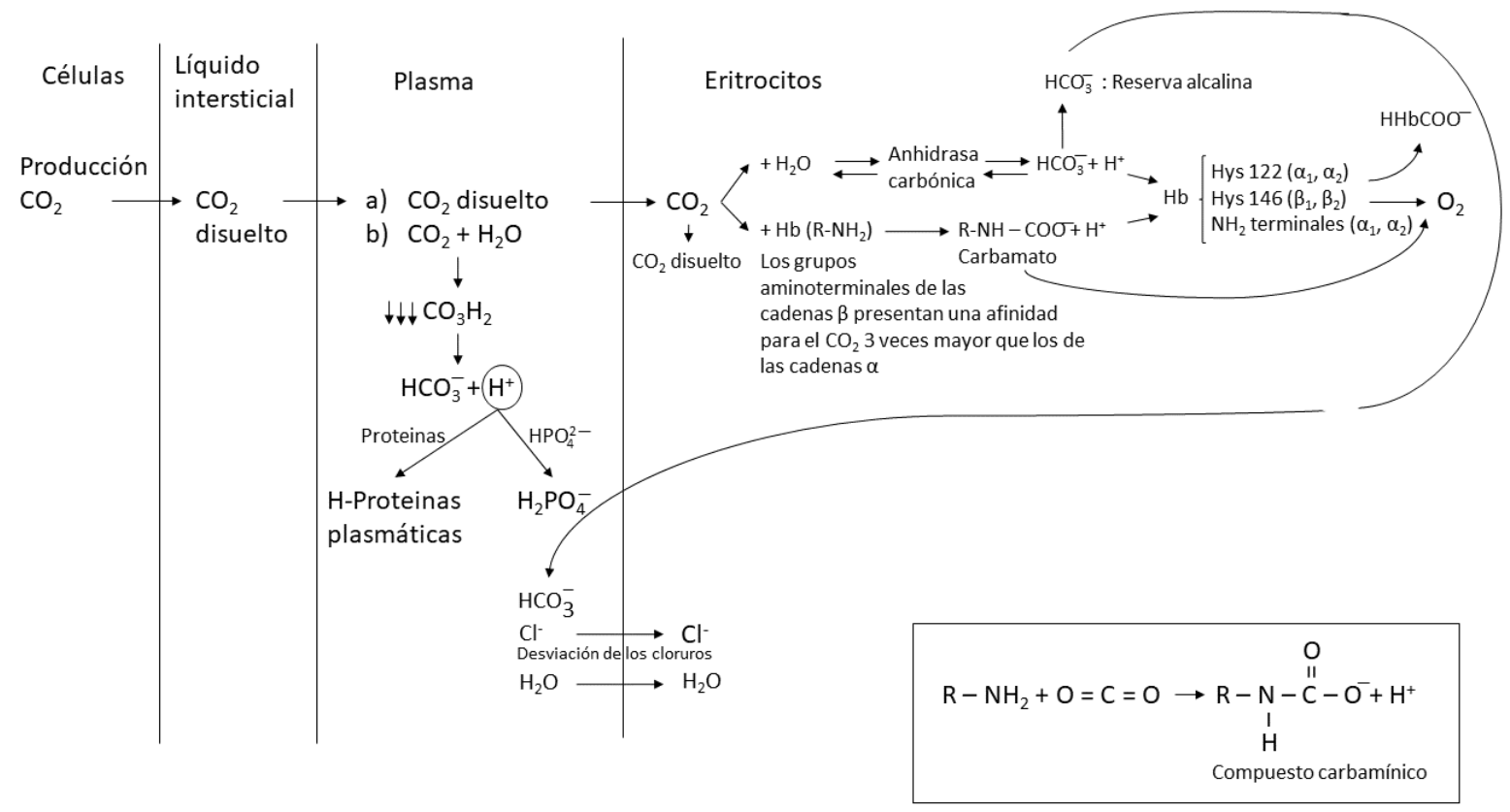

Figura 1 Resumen de los desplazamientos del $\mathrm{CO}_{2}$ a medida que la sangre fluye por los capilares pulmonares. Todos los movimientos a través de las membranas ocurren por difusión pasiva. Los fenómenos plasma-eritrocitos son simplemente la inversion de los que ocurren durante el flujo sanguíneo por los capilares de los tejidos, como se observa en la figura.

Una parte reducida del $\mathrm{CO}_{2}$ permanece físicamente disuelta en el plasma y otra parte, también reducida del $\mathrm{CO}_{2}$ reacciona con el $\mathrm{H}_{2} \mathrm{O}$ en el plasma.

$$
\mathrm{CO}_{2}+\mathrm{H}_{2} \mathrm{O}<->\mathrm{CO}_{3} \mathrm{H}_{2}<->\mathrm{HCO}_{3}^{-}+\mathrm{H}^{+}
$$

El ion $\mathrm{H}^{+}$resultante procede de la molécula de $\mathrm{H}_{2} \mathrm{O}$. La concentración de $\mathrm{CO}_{2}$ es unas mil veces mayor que la concentración de $\mathrm{HCO}_{3}^{-}$. Los iones $\mathrm{H}^{+}$son amortiguados intermediariamente por proteínas plasmáticas y fosfato $\left(\mathrm{HPO}_{4}^{2-}\right)$ inorgánico del plasma.

La reacción de hidratación del $\mathrm{CO}_{2}$, que no está catalizada por la anhidrasa carbónica en el plasma, es mucho menos rápida que la catalizada por dicha enzima en el eritrocito (hematíe o glóbulo rojo) y dado que la cantidad de proteína y fosfato que ha de reaccionar con los iones $\mathrm{H}^{+}$es relativamente pequeña, resulta que solo una pequeña cantidad del $\mathrm{CO}_{2}$ que entra en la sangre se convierte en $\mathrm{HCO}_{3}^{-}$en el plasma. $\mathrm{El} \mathrm{CO}$ antes de llegar al plasma difunde por el líquido intersticial. El líquido intersticial tiene menos capacidad (menos proteína y fosfato) para amortiguar el $\mathrm{CO}_{2}$ que el plasma.

La mayor parte (aproximadamente 95\%) del $\mathrm{CO}_{2}$ pasa al interior de los eritrocitos (hematíes o glóbulos rojos). Una parte reducida del $\mathrm{CO}_{2}$ permanece físicamente disuelta en los eritrocitos. La mayor parte de $\mathrm{CO}_{2}$ que pasa al eritrocito se convierte en ion $\mathrm{HCO}_{3}^{-}$y en ion $\mathrm{H}^{+}$. Esto ocurre porque los eritrocitos contienen grandes cantidades de la enzima anhidrasa carbónica, la cual no está presente en el plasma. El ion $\mathrm{H}^{+}$liberado procede de la molécula de agua como se indicó 
anteriormente. El remanente $(25 \%)$ del $\mathrm{CO}_{2}$ reacciona directamente con radicales amino de las moléculas de hemoglobina para formar el compuesto carbaminohemoglobina, lo cual favorece la liberación de $\mathrm{O}_{2}$ por parte de la hemoglobina y también se liberan iones $\mathrm{H}^{+}$.

El papel de la hemoglobina como amortiguador de los iones $\mathrm{H}^{+}$liberados por la anhidrasa carbónica al hidratar el $\mathrm{CO}_{2}$ y también por la formación de los compuestos carbamínicos, depende de una característica notable de su molécula pues la hemoglobina reducida tiene una afinidad mucho mayor por el ion $\mathrm{H}^{+}$que la que tiene la oxihemoglobina. Al fluir la sangre a través de los capilares de los tejidos dada la diferencia de $\mathrm{pO}_{2}$ entre el líquido intersticial adyacente a los capilares (aproximadamente $40 \%$ ) y la $\mathrm{pO}_{2}$ de los capilares (aproximadamente $95 \%$ ), el oxígeno difunde con mucha rapidez del capilar al líquido intersticial y de aquí las células (en primer lugar, el $\mathrm{O}_{2}$ disuelto en el plasma), con lo cual la oxihemoglobina comienza a perder parte de su oxígeno y se va transformando en hemoglobina reducida o desoxigenada. Por tener la hemoglobina reducida una gran afinidad por los iones $\mathrm{H}^{+}$, la mayor parte de este se une a la hemoglobina. A su vez, esta unión de los iones $\mathrm{H}^{+}$a la hemoglobina, facilita la liberación del oxígeno que queda todavía unido a la misma. Es decir, la unión de los iones $\mathrm{H}^{+}$a la molécula de hemoglobina induce en esta una menor afinidad por el oxígeno. De este modo, la molécula de hemoglobina libera una cantidad de oxígeno que no llegaría a tal nivel si el único factor implicado fuera la diferencia de la $\mathrm{pO}_{2}$ entre el líquido intersticial y el capilar.

A esta liberación adicional de $\mathrm{O}_{2}$ por la hemoglobina también participa el $\mathrm{CO}_{2}$ que se le ha unido, formándose los compuestos carbamínicos. La liberación de oxígeno de la hemoglobina en los capilares de los tejidos, que ocurre simultáneamente con el aumento de $\mathrm{CO}_{2}$, aumenta la capacidad amortiguadora de la hemoglobina.

El aumento de la concentración de $\mathrm{HCO}_{3}^{-}$que tiene lugar dentro de los hematíes cuando pasan

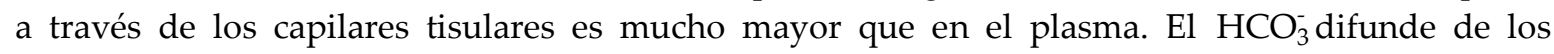
eritrocitos al plasma debido al gradiente de concentración producido a través de la membrana eritrocitaria. De esta manera un $70 \%$ del $\mathrm{HCO}_{3}^{-}$pasa al plasma después de haberse formado en los eritrocitos. La electroneutralidad se mantiene por la difusión de un ion cloruro $\left(\mathrm{Cl}^{-}\right)$al interior del eritrocito por cada $\mathrm{HCO}_{3}^{-}$que sale. Este fenómeno se conoce como desplazamiento de $\mathrm{Cl}^{-}$, o desplazamiento de $\mathrm{Cl}^{-}-\mathrm{HCO}_{3}^{-}$o desviación del $\mathrm{Cl}^{-}$o efecto de Hamburger. Este desplazamiento del $\mathrm{Cl}^{-}$está facilitado por un intercambiador $\mathrm{Cl}^{-}-\mathrm{HCO}_{3}^{-}$localizado en la membrana del eritrocito y, como consecuencia, el contenido de $\mathrm{Cl}^{-}$de los eritrocitos en sangre venosa es considerablemente mayor que en sangre arterial.

Según Stewart la entrada de $\mathrm{Cl}^{-}$a través de la membrana del eritrocito es quien defiende al plasma contra el aumento de la concentración de ion $\mathrm{H}^{+}$causada por le entrada de $\mathrm{CO}_{2}$ en el plasma procedente de la respiración celular de los tejidos. La entrada de $\mathrm{Cl}^{-}$al eritrocito procedente del plasma eleva la SID del plasma y por lo tanto ayuda a retornar la concentración de ion $\mathrm{H}^{+}$del plasma hacia la normalidad. Al aumentar el valor del SID disminuye el número de moléculas disociadas de $\mathrm{H}_{2} \mathrm{O}$ y así el número de $\mathrm{H}^{+}$libres (determinantes de $\mathrm{pH}$ ).

La formación de $\mathrm{HCO}_{3}^{-}$y la entrada de $\mathrm{Cl}^{-}$van acompañadas de un aumento de la osmolaridad de los eritrocitos que produce una presión osmótica que implica la entrada de $\mathrm{H}_{2} \mathrm{O}$ y por lo tanto un aumento de alrededor del $1 \%$ del volumen de los eritrocitos en los capilares sistémicos (de los tejidos).

\subsubsection{Eliminación pulmonar de $\mathrm{CO}_{2}$ : Capilar alveolar}

La sangre venosa llega a los capilares alveolares con una $\mathrm{pCO}_{2}$ de unos $45 \mathrm{mmHg}$ mientras que en el aire alveolar es de unos $40 \mathrm{mmHg}$, resultando un desnivel alveolocapilar de $5 \mathrm{mmHg}$, mucho menor que en el caso del $\mathrm{O}_{2}$. Sin embargo, este escaso desnivel queda de sobra compensado por la mayor difusión del $\mathrm{CO}_{2}$, veinte veces mayor que la del $\mathrm{O}_{2}$, hasta el punto de que se calcula que, en la primera décima parte del recorrido del capilar alveolar ocurre una difusión neta de $\mathrm{CO}_{2}$ de la sangre hacia el interior en los alveolos y es espirado, y el $\mathrm{O}_{2}$ difunde de los alveolos pulmonares a la sangre y se forma la oxihemoglobina (Fig. 2). 


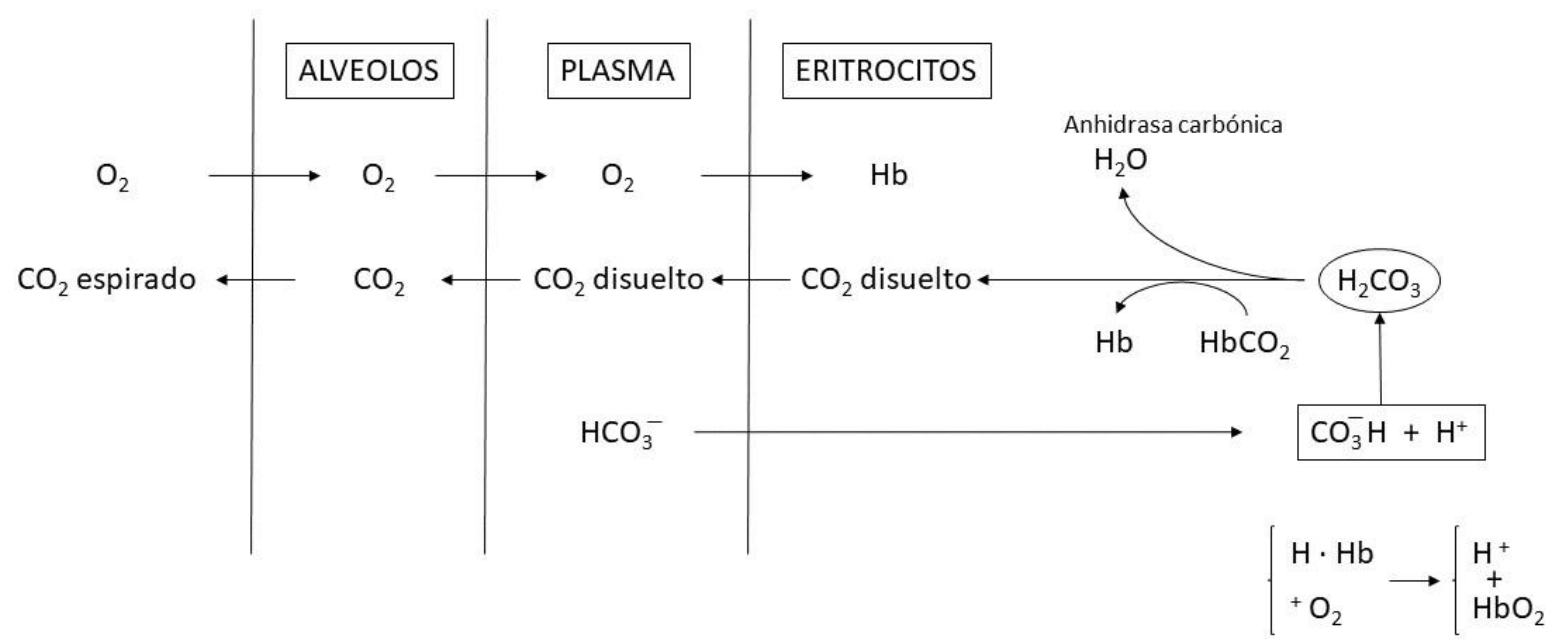

Figura 2 Resumen de los desplazamientos del $\mathrm{CO}_{2}$ y de las reacciones al fluir de la sangre por los capilares de los tejidos. Todos los desplazamientos a través de las membranas ocurren por difusión pasiva. Nótese que la mayor parte del $\mathrm{CO}_{2}$ se convierte finalmente en $\mathrm{HCO}_{3}^{-}$; esto sucede casi completamente en los eritrocitos (porqué allí está localizada la anhidrasa carbónica), pero luego la mayor parte del $\mathrm{HCO}_{3}^{-}$difunde de los eritrocitos hacia el plasma.

A medida que el $\mathrm{CO}_{2}$ de la sangre se exhala por vía respiratoria, la $\mathrm{pCO}_{2}$ baja en plasma y en los eritrocitos, y todas las reacciones químicas en eritrocitos y plasma se desplazan hacia la izquierda, con descomposición de $\mathrm{H}_{2} \mathrm{O}, \mathrm{HCO}_{3}^{-}$y carbaminohemoglobina. A medida que el $\mathrm{O}_{2}$ difunde en la sangre, la $\mathrm{pO}_{2}$ en plasma y eritrocitos aumenta e induce a la hemoglobina a liberar 2,3bifosfoglicerato, iones $\mathrm{H}^{+}$y CO . La pérdida de $\mathrm{CO}_{2}$ por la sangre y la oxigenación de la hemoglobina transcurren simultáneamente y cada uno de estos procesos facilita el otro. Normalmente, la rapidez con que el $\mathrm{CO}_{2}$ se genera a partir de $\mathrm{HCO}_{3}^{-}$e iones $\mathrm{H}^{+}$y a partir de $\mathrm{HbCO}_{2}$, es la misma con que se difunde hacia el interior de los alvéolos. Como resultado, todo el ion $\mathrm{H}^{+}$generado por el $\mathrm{H}_{2} \mathrm{CO}_{3}$ se reincorpora completamente a las moléculas de agua. Por lo tanto, a partir de esta fuente, no hay normalmente ganancia o pérdida neta alguna de ion $\mathrm{H}^{+}$en el organismo. Todo el $\mathrm{CO}_{2}$ presente en la sangre procedente de los tejidos difunde al interior de los alveolos, a partir de los cuales es espirado y eliminado del organismo. Por lo tanto, en la reconversión del $\mathrm{HCO}_{3}^{-}$en $\mathrm{CO}_{2}$ y su espiración por los pulmones, se consumen los iones $\mathrm{H}^{+}$amortiguados intermediariamente (por la hemoglobina, sobre todo), siendo así eliminados.

Por lo tanto, al pasar la sangre por los capilares alveolares, el $\mathrm{HCO}_{3}^{-}$se introduce en los eritrocitos nuevamente por intercambio con $\mathrm{Cl}^{-}$. En la saturación con $\mathrm{O}_{2}$, la hemoglobina devuelve los iones $\mathrm{H}^{+}$amortiguados (efecto Bohr). Estos reaccionan con el $\mathrm{HCO}_{3}^{-}$para dar $\mathrm{H}_{2} \mathrm{CO}_{3}$, que se

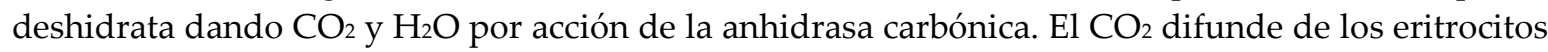
al plasma y de allí al espacio alveolar para su eliminación.

Las fuerzas que impulsan este proceso son, por una parte, la baja $\mathrm{pCO}_{2}$ de aire de los alveolos y, por otro el desprendimiento de iones $\mathrm{H}^{+}$de la hemoglobina condicionado por el $\mathrm{O}_{2}$. Ambos efectos desplazan el equilibrio $\mathrm{HCO}_{3}^{-} / \mathrm{CO}_{2}$ hacia el $\mathrm{CO}_{2}$.

Por lo tanto, en condiciones fisiológicas cuando únicamente se considera la variable independiente $\mathrm{PCO}_{2}$ :

1. $\quad \mathrm{El} \mathrm{CO}_{2}$ producido a nivel celular se exhala en la misma proporción con que se ha producido por los pulmones por lo tanto no cambia.

2. Al no cambiar la $\mathrm{pCO}_{2}$ no se afectan los centros respiratorios y por lo tanto no se modifica la ventilación pulmonar.

3. El $\mathrm{HCO}_{3}^{-}$no se gasta ni aumenta, y por lo tanto no cambia su concentración. 
4. El $\mathrm{pH}$ no cambia. Una pequeña cantidad de ion $\mathrm{H}+$ procedente de la disociación del $\mathrm{H}_{2} \mathrm{CO}_{3}$ es amortiguada en el plasma por proteínas plasmáticas y $\mathrm{HPO}_{4}^{2-}$. La mayor parte de los iones $\mathrm{H}^{+}$ son amortiguados por la hemoglobina.

5. Según el modelo de Stewart no se modifica el $\mathrm{pH}$ del plasma debido a la entrada de $\mathrm{Cl}^{-}$en el eritrocito al pasar este por el capilar tisular. Pues al disminuir la $\left[\mathrm{Cl}^{-}\right]$en el plasma aumentaría el SID y con ello disminuiría la disociación del agua provocada por la hidratación del $\mathrm{CO}_{2}$.

\subsection{Disociación del agua por la SID y por la [Атот].}

Según Stewart los iones $\mathrm{H}^{+}$proceden de la disociación del agua no sólo por la $\mathrm{pCO}_{2}$ sino también por una disminución de la SID y /o por aumento de la [ATOT].

\subsection{Amortiguación de iones $\mathrm{H}^{+}$por $\mathrm{HCO}_{3}^{-}$, hemoglobina, proteínas plasmáticas y proteínas intracelulares}

Según Stewart el $\mathrm{HCO}_{3}^{-}$no actúa como amortiguador, es una variable dependiente. Para Stewart es el $\mathrm{Na}^{+}$el que disminuye la disociación del agua. Para Henderson-Haselbalch el $\mathrm{HCO}_{3}^{-}$ presente en el plasma juega un papel fundamental en la amortiguación por dos razones. En primer lugar, la concentración de $\mathrm{HCO}_{3}^{-}$es la más alta de las concentraciones de cualquiera de los otros amortiguadores. En segundo lugar, el $\mathrm{HCO}_{3}^{-}$es particularmente eficaz para amortiguar los protones porque en el proceso se forma $\mathrm{H}_{2} \mathrm{CO}_{3}$, que se descompone en $\mathrm{CO}_{2}$ y $\mathrm{H}_{2} \mathrm{O}$ y el hecho de ser exhalado el $\mathrm{CO}_{2}$ hace que la reacción siguiente sea irreversible.

$$
\mathrm{HCO}_{3}^{-}+\mathrm{H}^{+}<->\mathrm{H}_{2} \mathrm{CO}_{3}<->\mathrm{CO}_{2} \text { (exhalado) }+\mathrm{H}_{2} \mathrm{O}
$$

La eficacia del $\mathrm{HCO}_{3}^{-}$para amortiguar el ion $\mathrm{H}^{+}$es tal, que puede gastarse hasta el $80 \%$ del $\mathrm{HCO}_{3}^{-}$de la sangre antes de que aparezcan síntomas de acidosis extrema, como el aumento de la respiración o hiperpnea y coma acidótico si es lo bastante grave.

Además del $\mathrm{HCO}_{3}^{-}$, contribuye en la amortiguación de los iones $\mathrm{H}+$ la hemoglobina (alrededor del $6 \%$ ) y las proteínas plasmáticas (1\%). Las proteínas intracelulares proporcionan la contribución mayor a la acción amortiguadora $(51 \%)$, intercambiándose los iones $\mathrm{H}^{+}$extracelulares con los iones intracelulares de $\mathrm{Na}^{+}(36 \%)$ y $\mathrm{K}^{+}(15 \%)$. Es probable que parte de los iones $\mathrm{Na}^{+}$intercambiados con iones $\mathrm{H}^{+}$procedieran del hueso, ya que los iones $\mathrm{Na}^{+}$se unen a los cristales óseos de apatita y son intercambiables. Esto puede ser particularmente importante en la acidosis crónica, donde puede haber reabsorción de hueso con liberación de iones calcio y fosfato como posteriormente se expone.

\subsection{Eliminación pulmonar de $\mathrm{CO}_{2}$ formado por la amortiguación de iones $\mathrm{H}^{+}$a partir del $\mathrm{HCO}_{3}^{-}$}

Los iones $\mathrm{H}^{+}$amortiguados por el $\mathrm{HCO}_{3}^{-}$plasmático dan origen al $\mathrm{H}_{2} \mathrm{CO}_{3}$ el cual se disocia en $\mathrm{CO}_{2}$ y $\mathrm{H}_{2} \mathrm{O}$. El $\mathrm{CO}_{2}$ se elimina por los pulmones y representa $1 / 500$ del total del $\mathrm{CO}_{2}$ que se elimina por vía respiratoria y por lo tanto no cambia la $\left[\mathrm{CO}_{2}\right]$. Al no cambiar la $\mathrm{pCO}_{2}$ no se afecta la actividad de los centros respiratorios y por ende no se modifica la ventilación pulmonar.

\subsection{Eliminación renal de iones $\mathrm{H}^{+}$. Generación de $\mathrm{HCO}_{3}^{-}$}

Los iones $\mathrm{H}^{+}$eliminados por el riñón, proceden de la disociación del agua inducida por la $\mathrm{pCO}_{2}$ intracelular renal, la cual a su vez deriva fundamentalmente de la $\mathrm{pCO}_{2}$ plasmática del capilar peritubular renal. Esta $\mathrm{pCO}_{2}$ plasmática es el resultado de la amortiguación de iones $\mathrm{H}^{+}$por el $\mathrm{HCO}_{3}^{-}$ plasmático. A su vez estos iones $\mathrm{H}^{+}$proceden según Stewart, de la disociación del agua inducida por una disminución del SID y /o un aumento de la [Атот]. El $\mathrm{HCO}_{3}^{-}$procede de la reacción del $\mathrm{CO}_{2}$ plasmático procedente de la respiración celular con el agua (Fig.3). 
Riñón

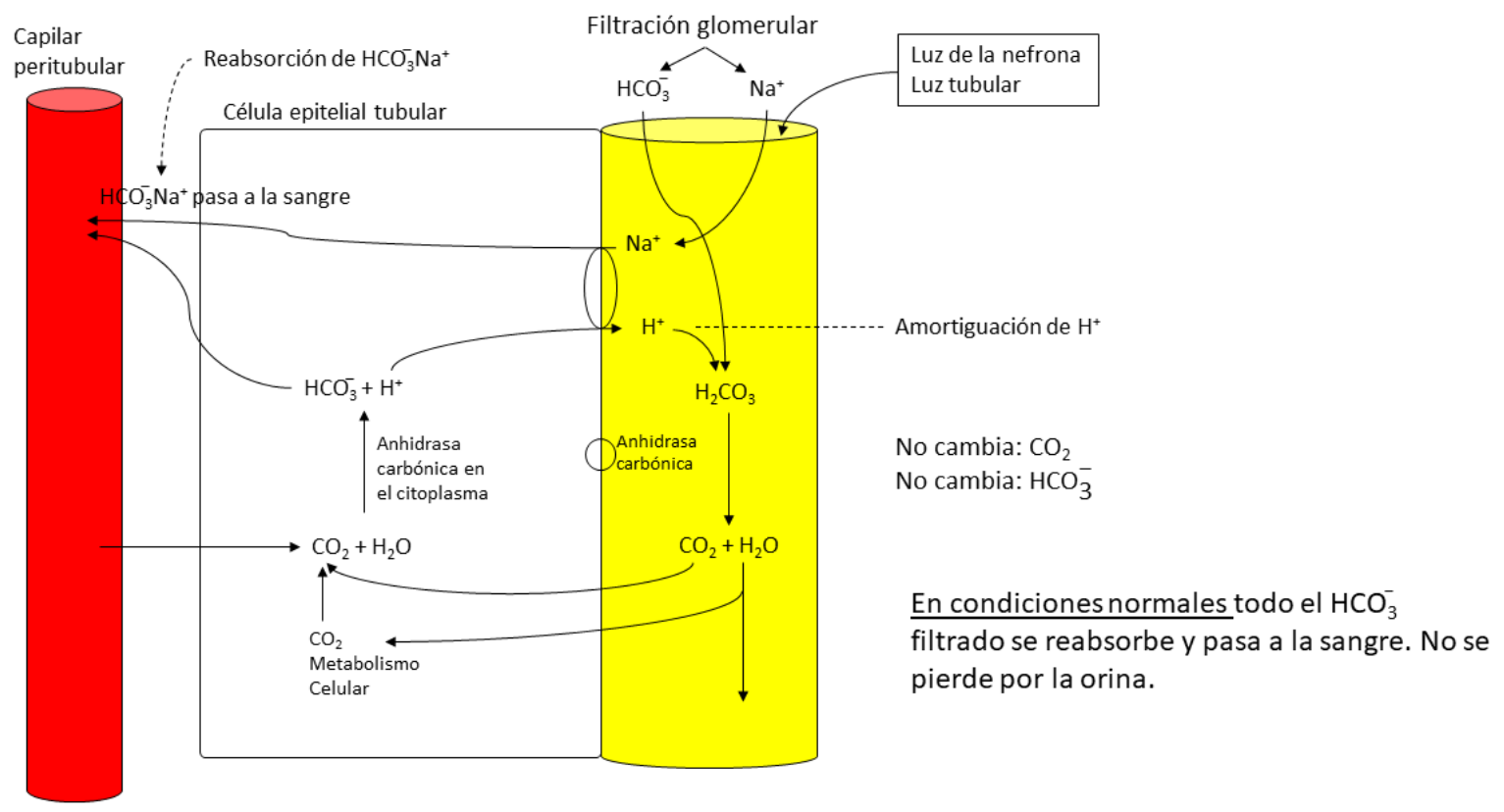

Figura $3 \mathrm{El} \mathrm{HCO}_{3}^{-}$filtrado se combina con $\mathrm{el} \mathrm{H}^{+}$segregado y se reabsorbe indirectamente. Las células epiteliales tubulares renales poseen anhidrasa carbónica que en el túbulo proximal se localiza en el borde en cepillo (borde luminal), además de en el citoplasma

1. Disponibilidad de iones $\mathrm{H}^{+}$por la célula epitelial tubular renal

El riñón secreta iones $\mathrm{H}^{+}$a nivel de la luz de los túbulos de la nefrona. La eliminación de iones $\mathrm{H}^{+}$por el riñón tiene lugar mediante tres mecanismos: reabsorción de $\mathrm{HCO}_{3}^{-}$, amortiguador fosfato (acidez titulable) y secreción de amoniaco.

Debido a la eliminación pulmonar de $\mathrm{CO}_{2}$ fisiológica, tanto del $\mathrm{CO}_{2}$ que corresponde al generado por la respiración celular como al que se ha formado por la amortiguación de los iones $\mathrm{H}^{+}$ procedentes de la disociación del $\mathrm{H}_{2} \mathrm{O}$ inducida por la disminución de la SID y/o el aumento de la [Атот], la $\mathrm{pCO}_{2}$ plasmática no se ha modificado. Por lo tanto, el número de moléculas de $\mathrm{CO}_{2}$ que difunden normalmente del capilar peritubular a la célula epitelial tubular renal en condiciones fisiológicas no cambia tras la amortiguación de iones $\mathrm{H}^{+}$en el plasma. Asimismo, no se modifica el $\mathrm{CO}_{2}$ que se ha generado en la propia célula epitelial tubular como consecuencia de la respiración celular. Por otra parte difunden moléculas de $\mathrm{CO}_{2}$ desde la luz tubular al interior de la célula epitelial tubular renal. La fuente primordial de $\mathrm{CO}_{2}$ para esta célula epitelial es la que procede del capilar peritubular que a su vez depende de la $\mathrm{pCO}_{2}$ de la circulación sistémica.

Dentro de la célula epitelial tubular la anhidrasa carbónica tipo II (CA II) facilita la generación del ion $\mathrm{H}^{+}$y del ion $\mathrm{HCO}_{3}^{-}$a partir de $\mathrm{CO}_{2}$ y $\mathrm{H}_{2} \mathrm{O}$. El ion $\mathrm{H}^{+}$es entonces secretado dentro del líquido tubular a través de la membrana apical, mientras que el $\mathrm{HCO}_{3}^{-}$sale de la célula a través de la membrana basolateral al capilar peritubular.

2. Carga filtrada de $\mathrm{HCO}_{3}^{-}$

$\mathrm{La}\left[\mathrm{HCO}_{3}^{-}\right]$en el plasma disminuye al amortiguar los iones $\mathrm{H}^{+}$procedentes de la disociación del $\mathrm{H}_{2} \mathrm{O}$. Por lo tanto esta disminuida la $\left[\mathrm{HCO}_{3}^{-}\right]$filtrada.

3. Reabsorción de $\mathrm{HCO}_{3}^{-}$filtrado en el glomérulo renal

La reabsorción de $\mathrm{HCO}_{3}^{-}$comporta la secreción de un mol de ion $\mathrm{H}^{+}$por cada mol de ion $\mathrm{Na}^{+}$ que se recupera (procedente del filtrado glomerular). Esto tiene lugar a nivel del túbulo proximal. Aquí el ion $\mathrm{H}^{+}$secretado es amortiguado totalmente por el $\mathrm{HCO}_{3}^{-}$. La reabsorción de $\mathrm{HCO}_{3}^{-}$es función lineal de la $\mathrm{pCO}_{2}$ sanguínea, pues gracias a la hidratación del $\mathrm{CO}_{2}$ en presencia de anhidrasa carbónica se libera un ion $\mathrm{H}^{+}$necesario para dicha reabsorción. El túbulo proximal reabsorbe al menos un $70 \%$ u $80 \%$ del $\mathrm{HCO}_{3}^{-}$filtrado, aproximadamente. Los mecanismos de 
esta reabsorción se muestran en la figura 3. La mayoría, probablemente más del $70 \%$ de esta reabsorción de $\mathrm{HCO}_{3}^{-}$ocurre por secreción de iones $\mathrm{H}^{+}$a través de la membrana apical de la célula epitelial tubular por un intercambiador $\mathrm{Na}^{+}-\mathrm{H}^{+}$(NHE3). Esta proteína intercambia un ion $\mathrm{Na}^{+}$por un ion $\mathrm{H}^{+}$, dirigido por un gradiente de $\mathrm{Na}^{+}$, aproximadamente $140 \mathrm{mEq} / \mathrm{L}$ de $\mathrm{Na}^{+}$en la luz tubular y 15-20 mEq/L de $\mathrm{Na}^{+}$en el interior celular. La baja concentración de $\mathrm{Na}^{+}$intracelular se mantiene por la $\mathrm{Na}^{+} / \mathrm{K}^{+}$ATPasa presente en la membrana basolateral. Una $\mathrm{H}^{+}$ATPasa de la membrana apical, justifica la secreción de $\mathrm{H}^{+}$remanente en el túbulo proximal y la reabsorción de $\mathrm{HCO}_{3}^{-}$. En el neonato, antes de la expresión de NHE3, NHE8 es la isoforma de NHE más importante.

En la luz del túbulo proximal, el ion $\mathrm{H}^{+}$secretado reacciona con el $\mathrm{HCO}_{3}^{-}$filtrado presente en la luz tubular y, tras la formación de ácido carbónico, se acaba generando $\mathrm{CO}_{2}$ y $\mathrm{H}_{2} \mathrm{O}$, a los cuales se les puede considerar permeables y se reabsorben en el túbulo proximal. $\mathrm{El}_{2} \mathrm{H}_{3}$ se convierte en $\mathrm{CO}_{2}$ y $\mathrm{H}_{2} \mathrm{O}$ mediante una reacción catalizada por la anhidrasa carbónica IV (CA IV) unida a la membrana apical y expuesta a la luz tubular. La membrana apical de las células epiteliales que recubren el túbulo contorneado proximal es permeable al $\mathrm{CO}_{2}$ y al $\mathrm{H}_{2} \mathrm{O}$ y penetran en la célula epitelial tubular con rapidez. El $\mathrm{CO}_{2}$ como molécula pequeña, no cargada, puede pasar a través de bicapas lipídicas de las membranas por difusión. Así el $\mathrm{CO}_{2}$ presente en el capilar peritubular puede acceder a la célula epitelial tubular. Por lo tanto, esta célula dispone de $\mathrm{CO}_{2}$ procedente de la sangre del capilar peritubular, que es su fuente principal.

En el interior de las células epiteliales tubulares, la anhidrasa carbónica, que está presente en el citoplasma, puede catalizar la formación de $\mathrm{H}_{2} \mathrm{CO}_{3}$ a partir del $\mathrm{CO}_{2}$ y $\mathrm{H}_{2} \mathrm{O}$. $\mathrm{El} \mathrm{H}_{2} \mathrm{CO}_{3}$ se disocia en iones $\mathrm{H}^{+}$y $\mathrm{HCO}_{3}^{-}$. Los iones $\mathrm{H}^{+}$se eliminan a través de la luz tubular, y el $\mathrm{HCO}_{3}^{-}$que se formó, difunde hacia el líquido intersticial y posteriormente al capilar peritubular. Así, por cada ion $\mathrm{H}^{+}$secretado penetran al líquido intersticial un ion $\mathrm{Na}^{+}$y un ion $\mathrm{HCO}_{3}^{-}$. En consecuencia, por cada ion $\mathrm{H}^{+}$secretado, ingresan en el capilar peritubular un ion $\mathrm{Na}^{+}$y un ion $\mathrm{HCO}_{3}^{-}$.

La salida de $\mathrm{HCO}_{3}^{-}$de las células a través de la membrana basolateral al capilar peritubular ocurre a través de un cotransportador $\mathrm{Na}^{+}-\mathrm{HCO}_{3}^{-}$electrogénico $\left(\mathrm{NBC}_{\mathrm{e} 1}\right)$. También hay evidencias que algo de $\mathrm{HCO}_{3}^{-}$sale de la célula en intercambio con $\mathrm{Cl}^{-}$.

Los mecanismos celulares por los cuales el $\mathrm{HCO}_{3}^{-}$se reabsorbe por las células de la parte gruesa ascendente del asa de Henle y el túbulo contorneado distal son esencialmente los mismos que los descritos para el túbulo proximal. Sin embargo, algunas de las isoformas de los transportadores son diferentes. Por ejemplo, la salida de $\mathrm{HCO}_{3}^{-}$por las células de la porción gruesa ascendente del asa de Henle ocurre por el cotransportador $\mathrm{Na}^{+}-\mathrm{HCO}_{3}^{-}$electroneutro $\left(\mathrm{NBC}_{\mathrm{n} 1}\right)$. Además, algo de $\mathrm{HCO}_{3}^{-}$sale de estas células en intercambio con el $\mathrm{Cl}^{-}$a través del intercambiador aniónico 2 (AE-2) y algo por un cotransportador $\mathrm{K}^{+}-\mathrm{HCO}_{3}^{-}$. Finalmente el antiportador $\mathrm{Na}^{+} / \mathrm{H}^{+}$de la membrana apical en el túbulo contorneado distal puede ser la isoforma NHE2. Por lo tanto, las células epiteliales de la nefrona secretan iones $\mathrm{H}^{+}$en el líquido tubular y así se reabsorbe la carga filtrada de $\mathrm{HCO}_{3}^{-}$. A una concentración de $\mathrm{HCO}_{3}^{-}$plasmático de $24 \mathrm{mEq} / \mathrm{L}$ y una tasa de filtración glomerular de $180 \mathrm{~L} /$ día, la carga filtrada de $\mathrm{HCO}_{3}^{-}$es > $4.300 \mathrm{mEq} /$ día. Aproximadamente el $80 \%$ de esta carga filtrada de $\mathrm{HCO}_{3}^{-}$se reabsorbe en el túbulo proximal. Un $16 \%$ adicional se reabsorbe por el asa ascendente gruesa de Henle y el túbulo contorneado distal y el $4 \%$ restante se reabsorbe en el túbulo colector. Se ha estimado que dos tercios de la reabsorción de $\mathrm{HCO}_{3}^{-}$proximal ocurre vía secreción de $\mathrm{H}^{+}$por $\mathrm{NHE}_{3}$. Una $\mathrm{H}^{+}-$ ATPasa vacuolar proporciona otro mecanismo para la secreción de $\mathrm{H}^{+}$apical y es responsable de aproximadamente un tercio de la reabsorción de $\mathrm{HCO}_{3}^{-}$. En este mecanismo la secreción del ion $\mathrm{H}^{+}$es independiente del $\mathrm{Na}^{+}$en la luz tubular.

4. $\quad$ Acidez titulable

Como hay más iones $\mathrm{H}^{+}$que moléculas de $\mathrm{HCO}_{3}^{-}$en la luz tubular, en condiciones fisiológicas, los iones $\mathrm{H}^{+}$que ya no pueden ser amortiguados por $\mathrm{HCO}_{3}^{-}$filtrado porque se ha gastado y como no pueden estar libres en la luz tubular porque dañarían el riñón, se amortiguan en la luz tubular con fosfato $\left(\mathrm{HPO}_{4}^{2-}\right)$, creatinina y $\mathrm{NH}_{3}$ secretado a la luz tubular. Debido a la reabsorción de $\mathrm{HCO}_{3}^{-}$por el túbulo proximal y el asa de Henle (que luego estudiaremos), el líquido que 
alcanza los túbulos distal y colector suele contener poco $\mathrm{HCO}_{3}^{-}$. Así cuando se segregan iones $\mathrm{H}^{+}$a la luz tubular a este nivel de la nefrona, se combinan con tampones no- $\mathrm{HCO}_{3}^{-}$, principalmente con el $\mathrm{HPO}_{4}^{2-}(\mathrm{Pi})$ y se excreta como ácido titulable. El amortiguador $\mathrm{HPO}_{4}^{2-}$ es un amortiguador muy importante en la orina, gracias al cual el riñón puede fabricar una orina 800 veces más ácida que el plasma sin que su pH baje de 4,5. (Figs 4 y 5).

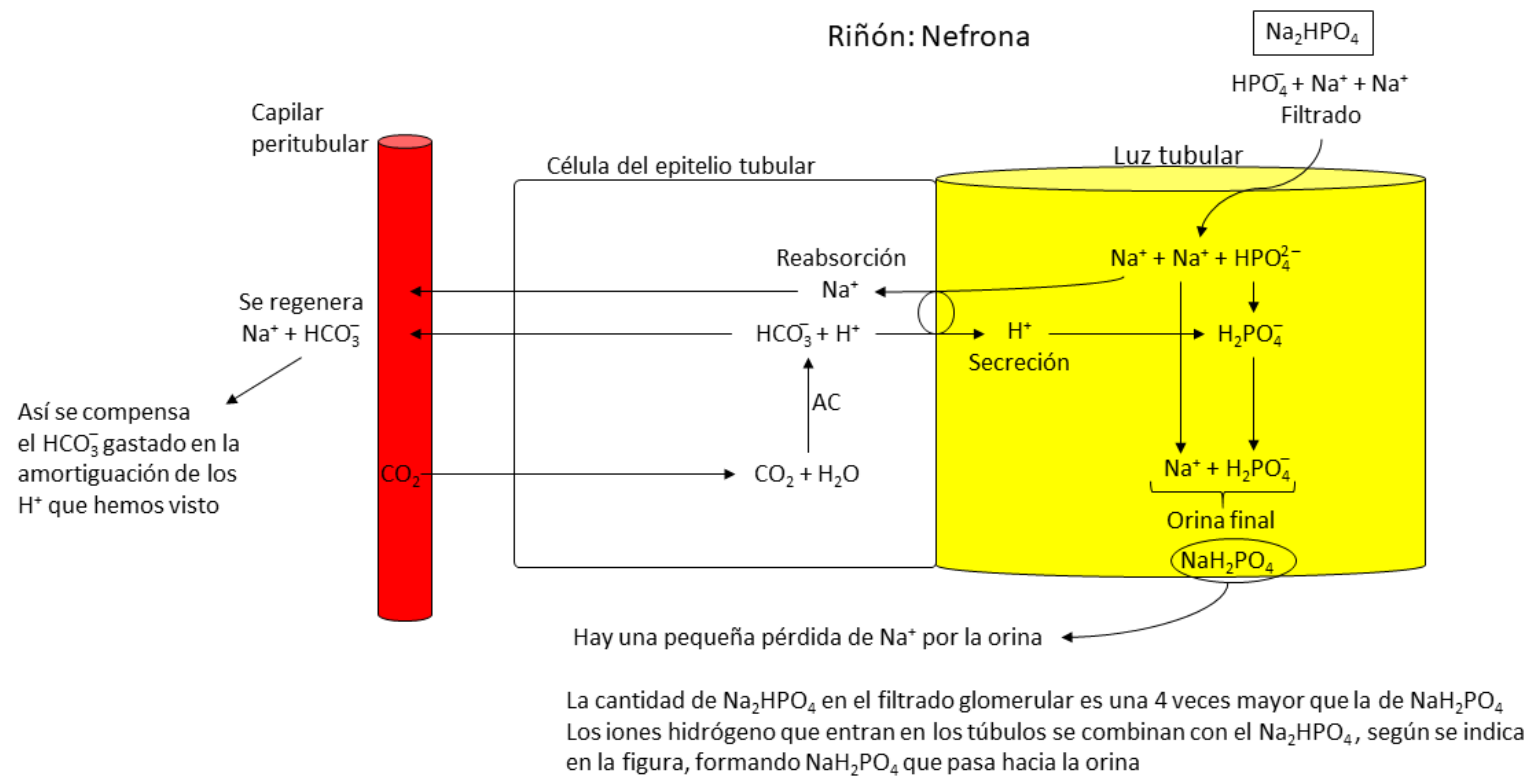

Figura 4 El ácido titulable (como el $\mathrm{PO}_{4}^{2-} \mathrm{H}_{2}$ ) se forma por secreción de $\mathrm{H}^{+}$en la orina. Por cada $1 \mathrm{mEq}$ de ácido titulable excretado, se añade $1 \mathrm{mEq}$ de nuevo $\mathrm{HCO}_{3}^{-}$(generado) a la sangre en los capilares peritubulares.

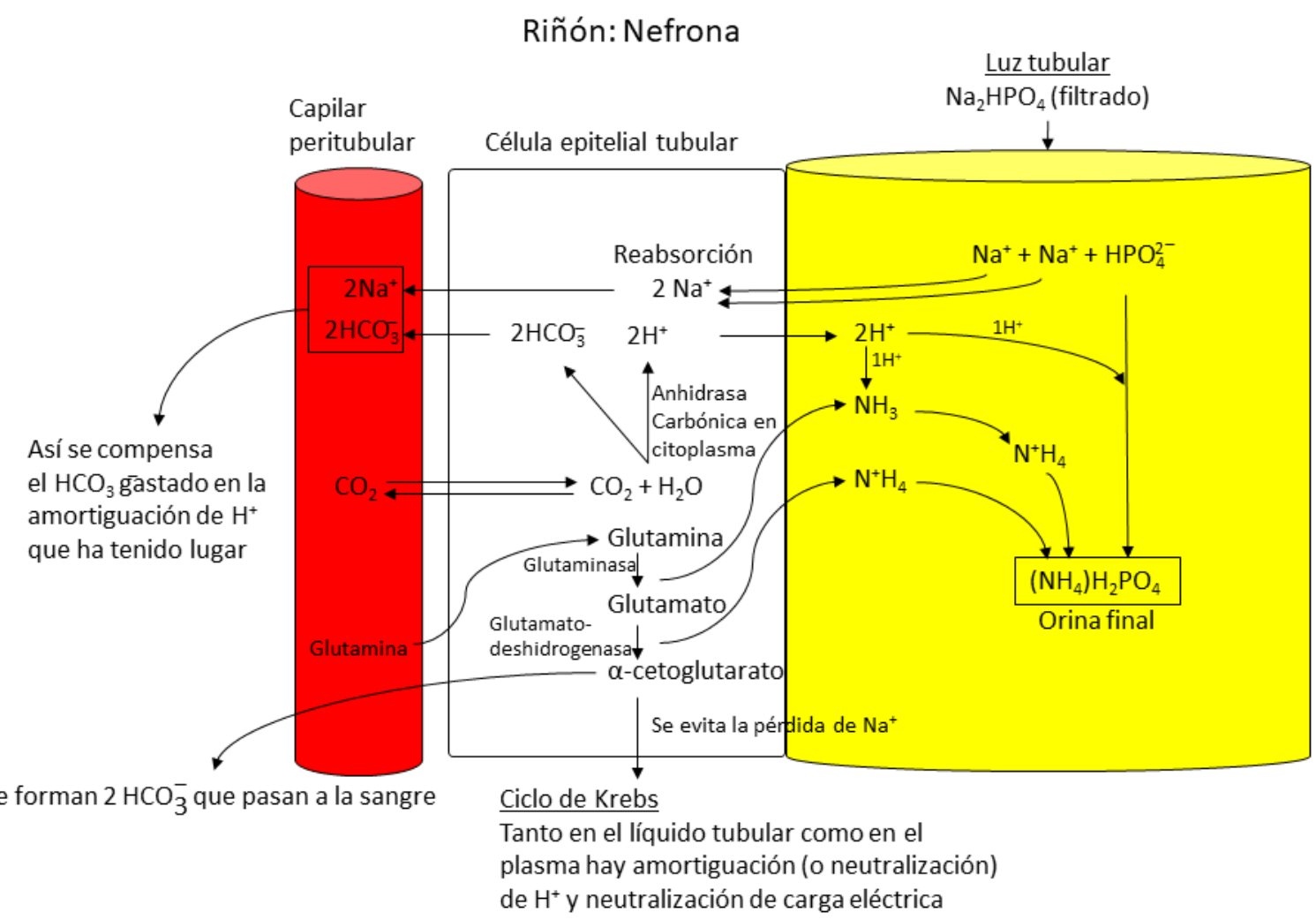

Figura 5 Los iones amonio se forman en las células epiteliales tubulares a partir de la glutamina y se segregan en la orina tubular. $\mathrm{Los} \mathrm{H}^{+}$procedentes del $\mathrm{CO}_{3} \mathrm{H}_{2}$ se consumen cuando el a-cetoglutarato se convierte en glucosa o en $\mathrm{CO}_{2}$ y agua. Se adicionan (generan) nuevos iones $\mathrm{HCO}_{3}^{-}$a la sangre de los capilares peritubulares ( $1 \mathrm{mEq}$ de $\mathrm{HCO}_{3}^{-}$por cada $1 \mathrm{mEq}$ de $\mathrm{N}^{+} \mathrm{H}_{4}$ excretado en la orina). 
Los iones $\mathrm{H}^{+}$derivados de la hidratación del $\mathrm{CO}_{2}$ por la anhidrasa carbónica citosólica presente en la célula epitelial tubular, se secretan en la luz tubular y se combinan con varios aniones que son posteriormente excretados en la orina como el $\mathrm{HPO}_{4}^{2-}$. Aproximadamente un $75 \%$ de la acidez titulable se atribuye a la formación de $\mathrm{H}_{2} \mathrm{PO}_{4}^{-}$al reaccionar el ion $\mathrm{H}^{+}$con el $\mathrm{HPO}_{4}^{2-}$ en la luz tubular y el remanente está compuesto de creatinina protonada y otros aniones orgánicos protonados. Aunque en un principio se consideró como una función del túbulo colector, está ahora demostrado que la mayoría de la generación del $\mathrm{HCO}_{3}^{-}$asociado con la formación de $\mathrm{H}_{2} \mathrm{PO}_{4}^{-}$, ocurre en el túbulo proximal, ya que el $\mathrm{pH}$ luminal al final de este segmento de la nefrona es aproximadamente de 6,7. Posteriormente se explica esta generación de $\mathrm{HCO}_{3}^{-}$. En cambio, la generación de $\mathrm{HCO}_{3}^{-}$asociado con la protonación de otros aniones orgánicos urinarios ocurre fundamentalmente en el túbulo colector dado el bajo $\mathrm{pK}$ de estas sustancias ( $\mathrm{pK}$ alrededor de $4,4)$.

El $\mathrm{HCO}_{3}^{-}$producido es transportado preferentemente a través de la membrana plasmática basolateral, pasa a los capilares peritubulares y de ahí a la circulación sistémica.

5. Eliminación de $\mathrm{NH}_{4}^{+}$y de $\mathrm{Cl}$. Metabolismo de la glutamina y del $\mathrm{NH}_{4}^{+}$

Es probable que sea el músculo esquelético la fuente principal de glutamina en el hombre. Recordemos que la glutamina se sintetiza a partir de glutamato y amoniaco mediante la enzima glutamina sintetasa. Durante el equilibrio ácido-base normal, el intestino delgado y el hígado son los sitios principales de utilización de glutamina y los riñones extraen y metabolizan muy poca glutamina. La glutamina entra en la célula epitelial tubular renal tanto desde el capilar peritubular $(80 \%)$ como desde la luz tubular procedente del filtrado glomerular $(20 \%)$. Así, la captación de glutamina por el riñón implica procesos de transporte tanto desde la membrana apical, en contacto con la luz del túbulo renal, y por tanto, de la glutamina filtrada en el glomérulo, como de la membrana basolateral próxima al capilar peritubular.

En condiciones basales, muy poco de la glutamina absorbida en el túbulo proximal se metaboliza en la célula epitelial tubular y en cambio se transporta a través de la membrana basolateral al espacio peritubular, y de aquí al capilar peritubular, resultando una reabsorción neta de la glutamina. El catabolismo de la glutamina en el riñón sólo es significativo durante la acidosis metabólica, es decir su transporte a la matriz mitocondrial donde se hidroliza a ácido glutámico por acción de la glutaminasa y entonces es desaminada oxidativamente por la glutamato deshidrogenasa. La glutamina mitocondrial se metaboliza a través de la glutaminasa dependiente de fosfato (PDG) presente en la membrana mitocondrial interna y cataliza la reacción:

$$
\text { Glutamina }+\mathrm{H}_{2} \mathrm{O} \rightarrow \text { Ácido glutámico }+\mathrm{NH}_{4}^{+}
$$

La glutamina se desamina por la glutaminasa. El glutamato se convierte en $\alpha$-cetoglutarato a través de la enzima mitocondrial glutamato deshidrogenasa (GDH)

$$
\text { Glutamato }+\mathrm{NAD}^{+} \rightarrow \alpha \text {-cetoglutarato }+\mathrm{NH}_{4}^{+}+\mathrm{NADH}+\mathrm{H}^{+}
$$

Resultando la liberación de una molécula de $\mathrm{NH}_{4}^{+}$y la generación de $\alpha$-cetoglutarato. Ya se explicó anteriormente el mecanismo propuesto para la generación de dos moléculas de $\mathrm{HCO}_{3}^{-}$. El $\alpha$-cetoglutarato es entonces metabolizado a través de una serie de reacciones enzimáticas formando malato. El malato es entonces transportado fuera de la mitocondria a través de una vía de intercambio malato-fosfato. El malato en el citoplasma se metaboliza por las acciones combinadas de la malato deshidrogenasa y fosfoenol-piruvato carboxiquinasa, formando fosfoenol piruvato. El fosfoenol piruvato se metaboliza por una piruvato quinasa para formar piruvato, el cual puede entrar en la mitocondria y el ciclo de los ácidos tricarboxílicos, donde se metaboliza a $\mathrm{CO}_{2}$. Alternativamente el fosfoenolpiruvato se puede metabolizar a fructosa 1,6bifosfato, la cual se convierte en fructosa-6-fosfato por la fructosa 1,6 bifosfatasa. La fructosa-6fosfato se convierte a glucosa-6-fosfato, la cual se convierte en glucosa por la glucosa-6-fosfatasa. Entonces la glucosa sale a través de la membrana plasmática basolateral a través de GLUT2 o GLUT1. 


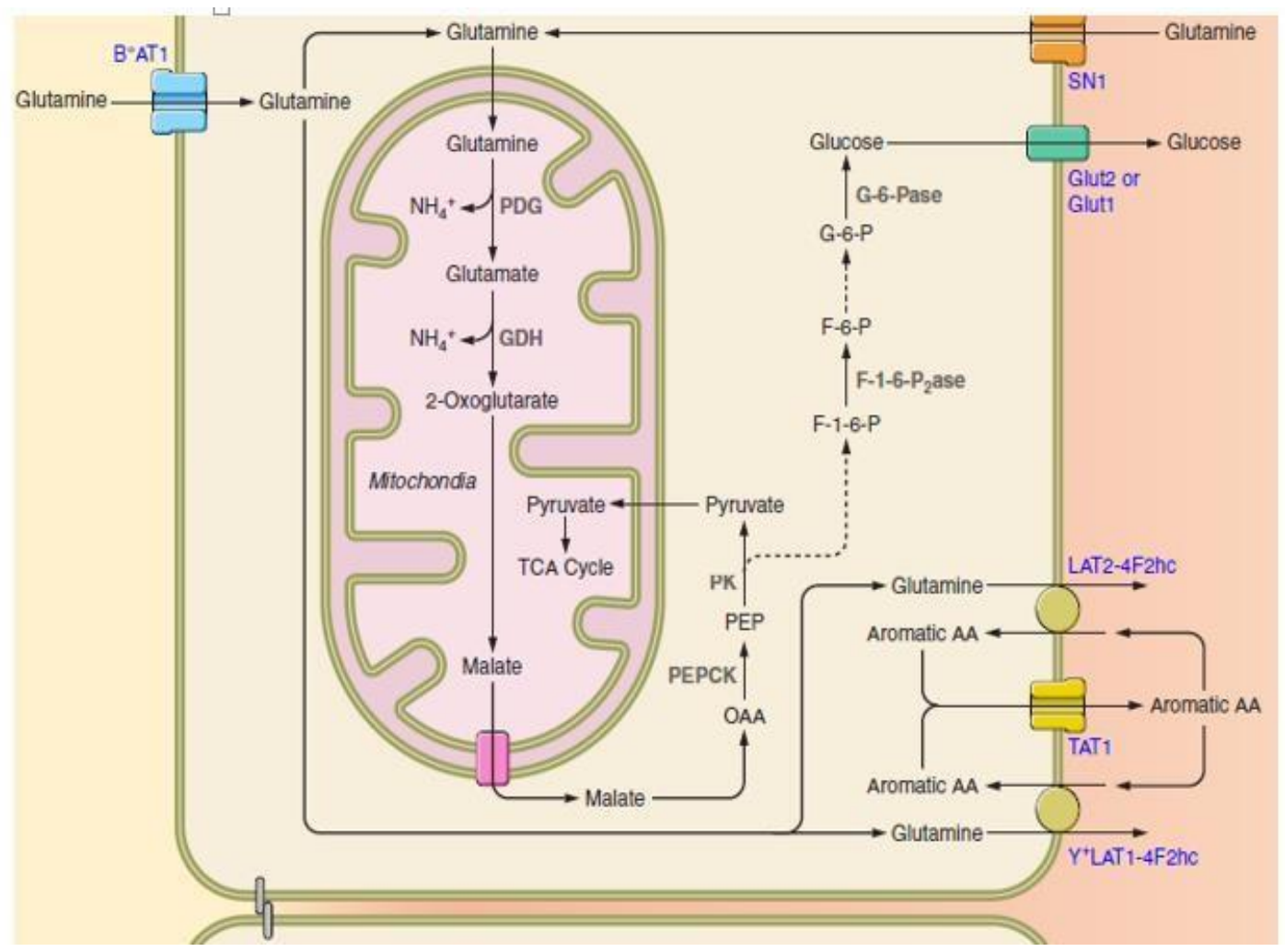

Figura 6 Resumen del metabolismo de la glutamina. BoN1: Cotransportador de aminoácido dependiente de $\mathrm{Na}^{+}$; SN1: Transportador de glutamina; Glut1 y Glut2: Transportadores de glucosa; LAT2-4F2hc y Y+LAT1-4F2hc: Intercambiadores de aminoácidos neutros heterodiméricos [22]

Durante el equilibrio ácido-base normal la actividad del transportador mitocondrial de glutamina y la glutaminasa deben de estar en gran parte inactivadas, lo cual justifica la reabsorción efectiva de la glutamina. Durante el equilibrio ácido-base normal, aproximadamente dos tercios de los iones $\mathrm{NH}_{4}^{+}$producidos a partir de la glutamina pasan a la luz tubular y se excretan con ion $\mathrm{Cl}^{-}$en una orina ligeramente acidificada. Según Stewart el importante papel de la glutamina en el riñón es producir amonio para permitir la eliminación de una cantidad suficiente de $\mathrm{Cl}^{-}$en forma de $\mathrm{ClNH}_{4}$, aumentando así el valor positivo de la SID y proteger al organismo frente a la acidosis. Cuanto mayor es el grado de acidosis más alta es la velocidad de producción renal de amonio. $\mathrm{Al}$ aumentar el valor positivo de la SID, disminuye la disociación del $\mathrm{H}_{2} \mathrm{O}$ y los iones $\mathrm{H}^{+}$reaccionan con $\mathrm{OH}^{-}$formándose moléculas de $\mathrm{H}_{2} \mathrm{O}$, disminuyendo así la concentración de iones $\mathrm{H}^{+} \mathrm{y}$ aumentando por lo tanto el $\mathrm{pH}$.

En condiciones basales, casi absolutamente nada del $\mathrm{NH}_{4}^{+}$urinario deriva de la filtración glomerular. El túbulo proximal genera el ion $\mathrm{NH}_{4}^{+}$que aproximadamente en un $50 \%$ se elimina por la orina pasando el 50\% restante a la sangre. La glutamina sirve como sustrato metabólico primario para la amoniogénesis. La captación de glutamina en el túbulo proximal implica su transporte a través de la membrana plasmática apical a través de un cotransportador de aminoácido dependiente de $\mathrm{Na}^{+}$, BoAT-1 (SLC6A19) y a través de la membrana plasmática basolateral por el transportador SN1 (SLC38A3) de aminoácidos neutros acoplado a $\mathrm{Na}^{+}$. El metabolismo completo de cada molécula de glutamina produce la generación mitocondrial de dos $\mathrm{NH}_{4}^{+}$y dos $\mathrm{HCO}_{3}^{-}$. Al menos un componente del amonio mitocondrial parece ser transportado de la mitocondria al citosol a través del transportador AQP8. 


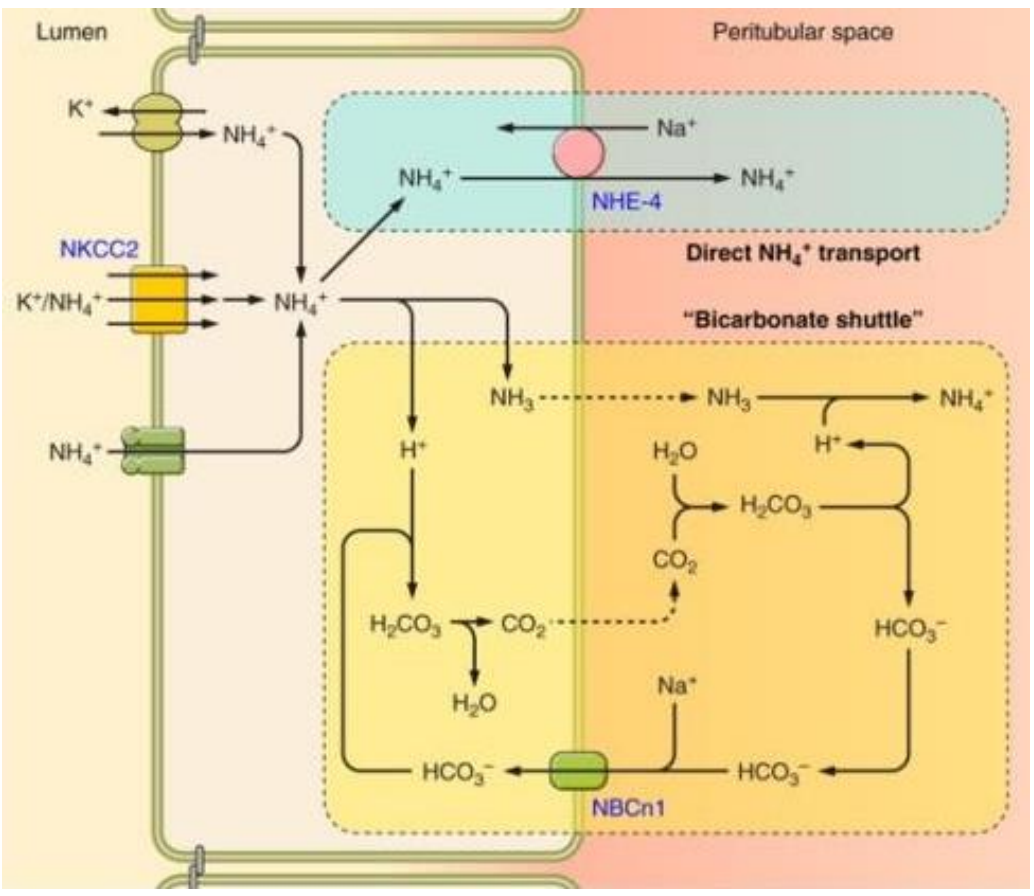

Figura 7 NKCC2: Cotransportador especifico renal de $\mathrm{Na}_{-}^{+} \mathrm{K}_{-}^{+} 2 \mathrm{Cl}^{-}$. $\mathrm{K}^{+}$y N $\mathrm{N}^{+} \mathrm{H}_{4}$ parecen competir por el mismo sitio de union. El transporte acoplado con iones $\mathrm{Na}^{+} \mathrm{y} \mathrm{Cl}^{-}$produce una reabsorción activa secundaria de $\mathrm{N}^{+} \mathrm{H}_{4}$ [22]

NHE-4: Isoforma 4 del intercambiador $\mathrm{Na}^{+} / \mathrm{H}^{+}$

$\mathrm{NBC}_{n} 1$ : Cotransportador $\mathrm{Na}^{+} / \mathrm{HCO}_{3}^{-}$electroneutro

En la Fig.8 se muestra un resumen del transporte de amonio por el epitelio tubular renal en condiciones basales.

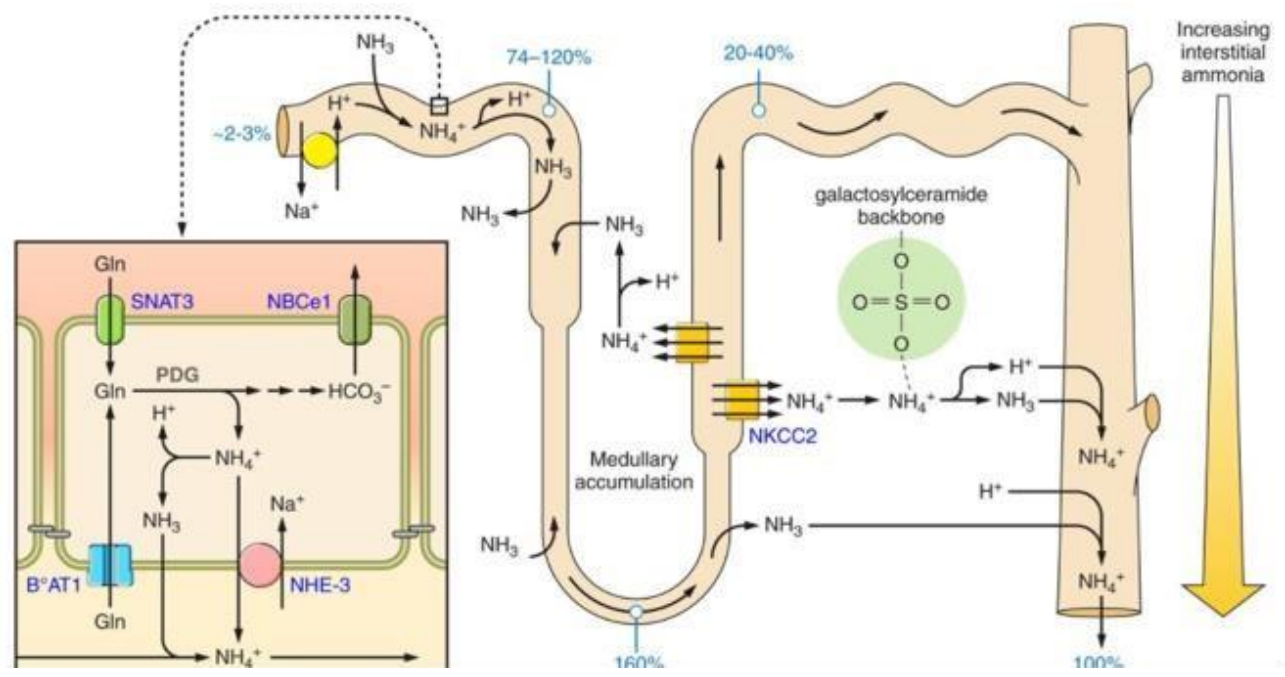

Figura 8 SNAT3: Transportador de glutamine [22]

Bo-AT1: Cotransportadopr de aminoácido dependiente de $\mathrm{Na}^{+}$

NHE-3: Intercambiador $\mathrm{Na}^{+} / \mathrm{H}^{+}$; $\mathrm{NBCe} 1$ : Cotransportador de $\mathrm{Na}+/ \mathrm{HCO}_{3}^{-}$electroneutro

NKCC2: Cotransportador específico renal de $\mathrm{Na}_{-}^{+} \mathrm{K}_{-}^{+} 2 \mathrm{Cl}^{-}$ 

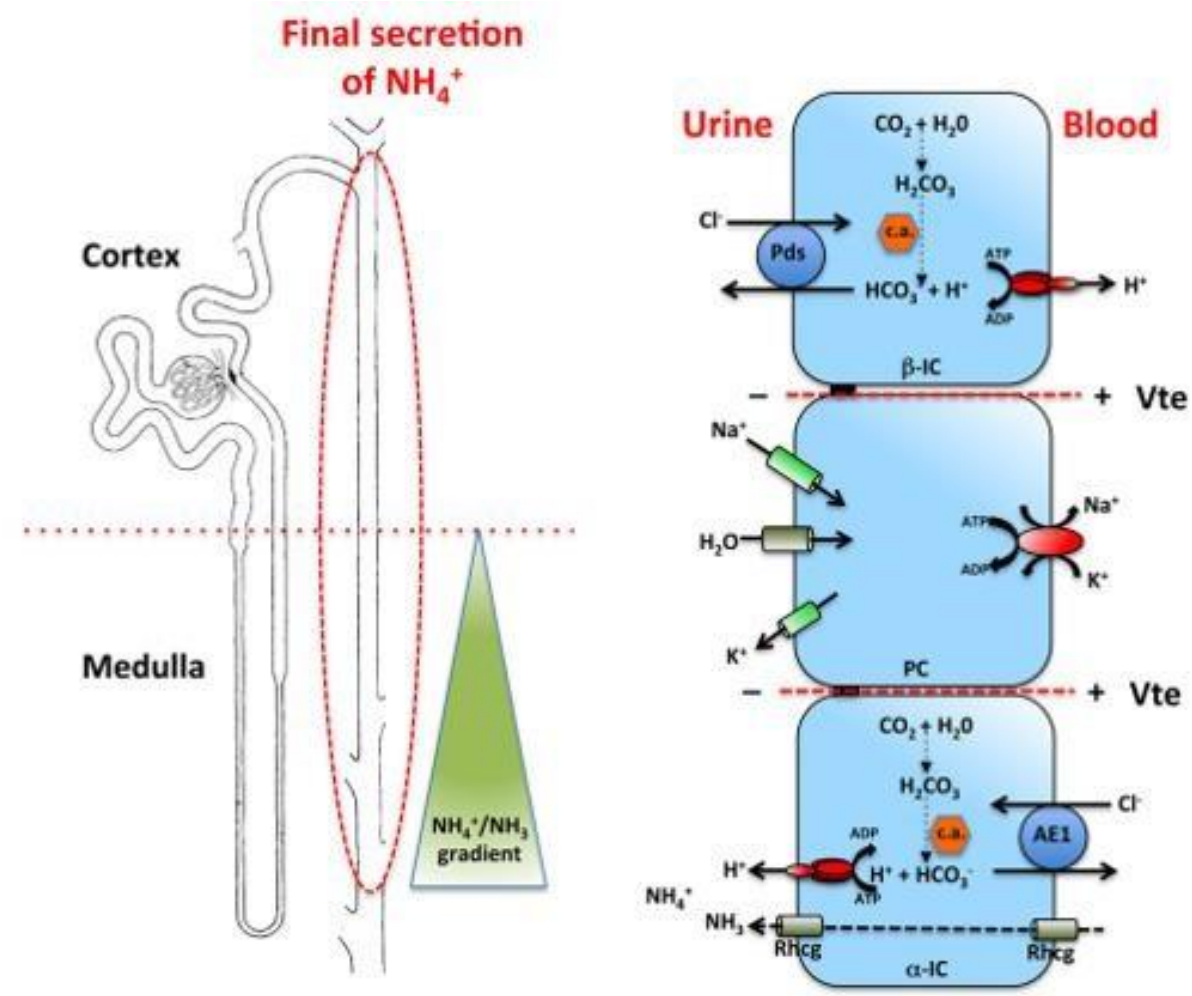

Figura 9 Mecanismos moleculares de acidificación de la orina y secreción de amonio en el túbulo conector [23]:

$\beta$-1c: Células intercaladas $\beta ; \alpha$-1c: Células intercaladas $\alpha$

Pds: Pendrina; CA: Anhidrasa carbónica; PC: Célula prineipal.

Recientemente se han encontrado glicoproteinas asociadas al $\mathrm{RH}$ eritrocitario que median el transporte de $\mathrm{NH}_{3} / \mathrm{N}^{+} \mathrm{H}_{4}$. Homólogos no eritroideos $\mathrm{RHlog}$ y $\mathrm{RHcg}$ se expresan en riñón de mamíferos.

Tradicionalmente, la eliminación de $\mathrm{NH}_{4}^{+}$se ha considerado como la eliminación de iones $\mathrm{H}^{+}$en conjunción con el amortiguador amoniaco $\left(\mathrm{NH}_{3}\right)$ :

$$
\mathrm{NH}_{3}+\mathrm{H}^{+}<->\mathrm{NH}_{4}^{+}
$$

Sin embargo, $\mathrm{NH}_{3} / \mathrm{NH}_{4}^{+}$no es un amortiguador fisiológico porque su pK es demasiado alto (aproximadamente 9,2) y la mayoría de este amortiguador a $\mathrm{pH}$ fisiológico es $\mathrm{NH}_{4}^{+}$sobre la base del pKa. Además, el $\mathrm{NH}_{4}^{+}$,y no el $\mathrm{NH}_{3}$, se produce dentro del riñón. En cambio, la eliminación de amonio total en la orina representa la eliminación de ácido mediante la producción de nuevo $\mathrm{HCO}_{3}^{-}$, cuando se considera en conjunción con el metabolismo de la glutamina. La glutamina es el precursor predominante de $\mathrm{NH}_{3}$ en el riñón.

Existen otras vías de producción de $\mathrm{NH}_{3}$ pero se cree que son menos importantes. Además del túbulo proximal, otros segmentos de la nefrona pueden producir $\mathrm{NH}_{3}$ pero no en la misma cantidad e incluso no tienen la misma capacidad adaptativa de aumentar significativamente la amoniogénesis en acidosis mantenidas como el túbulo proximal. Una variedad de condiciones afectan la producción de $\mathrm{NH}_{3}$, pero el más importante es el estado de acidosis. La acidosis metabólica crónica puede aumentar la producción de $\mathrm{NH}_{3}$ varias veces en el riñón. Los niveles de $\mathrm{K}^{+}$también alteran la producción de $\mathrm{NH}_{3}$, de tal modo que la hipercaliemia suprime la formación de $\mathrm{NH}_{3}$ (y su transporte tanto en el túbulo proximal como en la porción gruesa del asa de Henle) y la hipocaliemia aumenta la producción de $\mathrm{NH}_{3}$ en el riñón.

Recordemos que para Stewart la eliminación de $\mathrm{Cl}^{-}$por la orina, que tiene lugar en forma de $\mathrm{ClNH}_{4}$, aumentaría el valor de la SID y de este modo influiría en el pH del plasma. 
6. Generación de $\mathrm{HCO}_{3}^{-}$en el riñón y eliminación de $\mathrm{Cl}^{-}$por la orina

La reabsorción de $\mathrm{HCO}_{3}^{-}$por sí misma no recupera la pérdida de $\mathrm{HCO}_{3}^{-}$que se ha gastado en la amortiguación de los iones $\mathrm{H}^{+}$procedentes de la disociación del $\mathrm{H}_{2} \mathrm{O}$ por la disminución de la [SID] y/o el aumento de la [Атот] y en la síntesis de urea, sino que solo mantiene el $\mathrm{HCO}_{3}^{-}$ existente. Para mantener el equilibrio ácido-base, los riñones reemplazan este $\mathrm{HCO}_{3}^{-}$perdido mediante la generación de nuevo $\mathrm{HCO}_{3}^{-}$, para lo cual se requiere $\mathrm{CO}_{2}, \mathrm{H}_{2} \mathrm{O}$, anhidrasa carbónica citoplasmática y amortiguadores en la orina que amortigüen los iones $\mathrm{H}^{+}$secretados a la luz tubular de la nefrona. El hígado también participa en los niveles de $\mathrm{HCO}_{3}^{-}$plasmático a través de la neutralización de aniones orgánicos metabolizables, como veremos posteriormente. La generación de $\mathrm{HCO}_{3}^{-}$es una función esencial del riñón, asegurando que el contenido de $\mathrm{HCO}_{3}^{-}$ corporal total permanezca relativamente constante a pesar de la pérdida de $\mathrm{HCO}_{3}^{-}$citada anteriormente. El riñón genera $\mathrm{HCO}_{3}^{-}$cuando tiene lugar la formación de ácido titulable, la secreción de $\mathrm{NH}_{4}^{+}$y neutralización de aniones orgánicos metabolizables.

- Formación de ácido titulable en la orina y generación de $\mathrm{HCO}_{3}^{-}$en el epitelio tubular renal.

Con respecto a la formación de ácido titulable hay que tener en cuenta que el $\mathrm{CO}_{2}$ presente en la sangre del capilar peritubular difunde a la célula epitelial tubular y es hidratado en presencia de anhidrasa carbónica citosólica rindiendo iones $\mathrm{H}^{+}$y $\mathrm{HCO}_{3}^{-}$. El ion $\mathrm{H}^{+}$es secretado a la luz tubular y allí es amortiguado por el $\mathrm{HPO}_{4}^{2-}$ filtrado en el glomérulo renal y el $\mathrm{HCO}_{3}^{-}$generado pasa al capilar peritubular junto con el $\mathrm{Na}^{+}$, mientras que el $\mathrm{H}_{2} \mathrm{PO}_{4}^{-}$se elimina por orina (acidez titulable).

- Formación de $\mathrm{NH}_{4}^{+}$en la orina y generación de $\mathrm{HCO}_{3}^{-}$en el epitelio tubular renal. La formación $\mathrm{NH}_{4}^{+}$a partir de $\mathrm{NH}_{3}$ y $\mathrm{H}^{+}$secretados a la luz de los túbulos colectores genera $\mathrm{HCO}_{3}^{-}$en la célula epitelial tubular renal del mismo modo que en la formación de ácido titulable. Se está formando $\mathrm{HCO}_{3}^{-}$casi al mismo tiempo que la célula epitelial tubular va disponiendo de $\mathrm{NH} 3$ a partir del metabolismo de la glutamina.

Por otra parte, recordemos que al catabolizarse la glutamina en glutamato y posteriormente dicho glutamato en $\alpha$-cetoglutarato, se liberan dos moléculas de NH3 y se genera una molécula, de $\alpha$-cetoglutarato, anión orgánico metabolizable, que posee dos grupos carboxilos disociados. En la neutralización de la carga negativa de cada grupo carboxilo disociado de esta molécula, se consumen dos iones $\mathrm{H}^{+}$originados a partir de la hidratación de $\mathrm{CO}_{2}$ y catalizado por la anhidrasa carbónica de la célula epitelial tubular. $\mathrm{Al}$ mismo tiempo se han generado dos moléculas $\mathrm{HCO}_{3}^{-}$a partir de la hidratación del $\mathrm{CO}_{2}$.

- Neutralización de aniones orgánicos metabolizables en el riñón y generación de $\mathrm{HCO}_{3}^{-}$ en el mismo.

El riñón también genera nuevo $\mathrm{HCO}_{3}^{-}$a partir de la neutralización de aniones orgánicos metabolizables, como el citrato, el lactato, ácidos grasos y el $\beta$ - hidroxibutirato que poseen grupos carboxilo disociados (Fig.10 y Tabla I).

Tabla I Generación de $\mathrm{HCO}_{3}^{-}$en el riñón

\begin{tabular}{|c|c|}
\hline \multirow[b]{2}{*}{$\begin{array}{l}\text { 1) Cuando se amortiguan } \\
\mathrm{H}^{+} \text {en la luz tubular con: }\end{array}$} & $\mathrm{HPO}_{4}$.Filtrado \\
\hline & $\begin{array}{l}\mathrm{NH}_{3} \text { (Glutamina filtrada y difundida desde el } \\
\text { capilar peritubular) }\end{array}$ \\
\hline \multirow{4}{*}{$\begin{array}{l}\text { 2) Cuando se protonan } \\
\text { aniones orgánicos } \\
\text { metabolizables: }\end{array}$} & $\alpha$-actoglutarico \\
\hline & Citrato \\
\hline & Lactato \\
\hline & $\beta$ - hidroxibutirato \\
\hline
\end{tabular}




\section{Riñón}

Célula tubular

Luz tubular

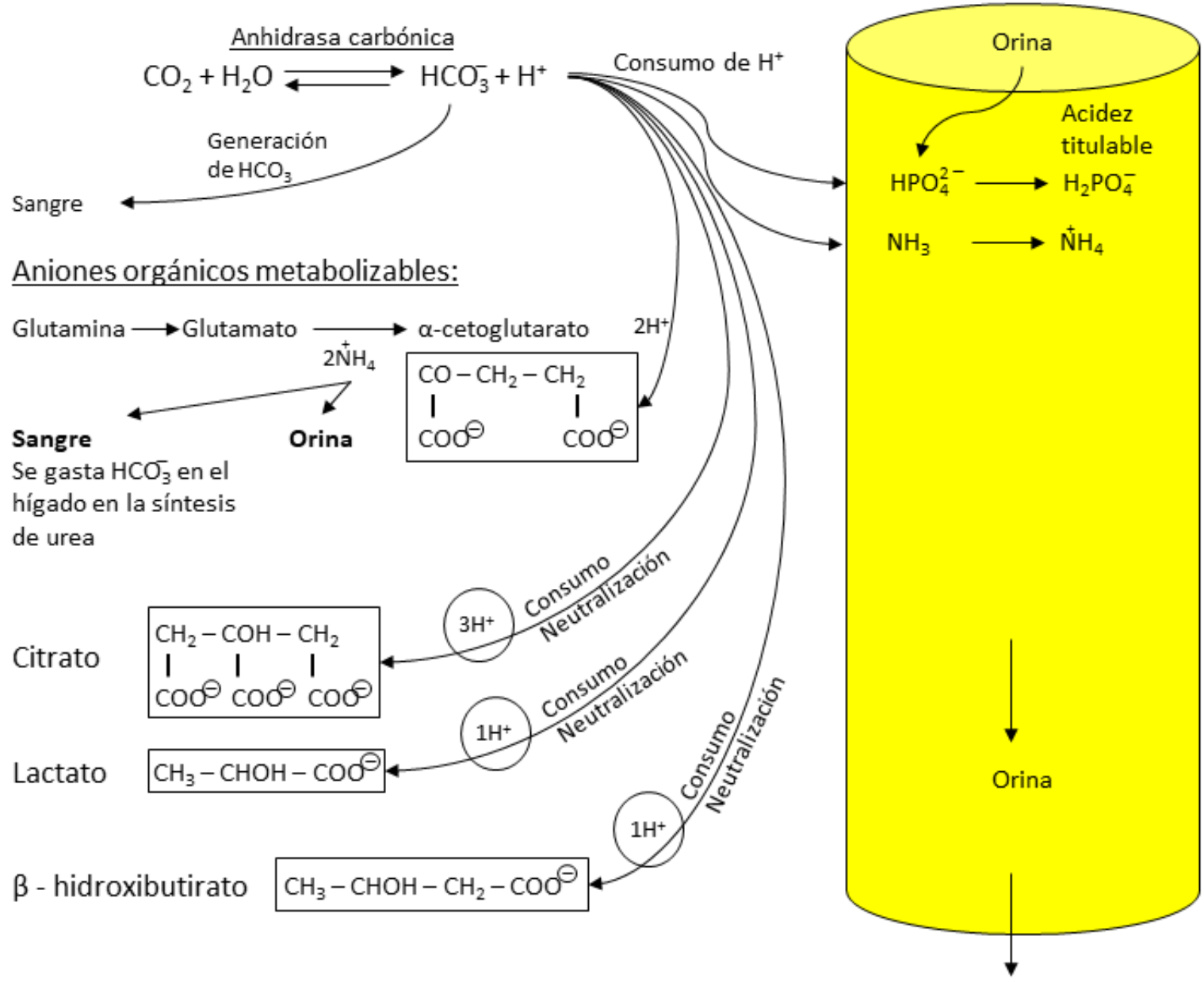

Figura 10 Generación de $\mathrm{HCO}_{3}^{-}$en el riñón. Se neutralizan tantos $\mathrm{H}^{+}$como grupos - COO-

Estas moléculas son aceptoras de iones $\mathrm{H}^{+}$y por lo tanto, son bases de Brönsted- Lowry y por lo tanto consumen iones $\mathrm{H}^{+}$. Los iones $\mathrm{H}^{+}$que neutralizan dichos grupos carboxilos disociados, derivan de la disociación del $\mathrm{H}_{2} \mathrm{O}$ al reaccionar esta con el $\mathrm{CO}_{2}$ procedente en su casi totalidad del capilar peritubular y catalizada por la anhidrasa carbónica, generándose $\mathrm{HCO}_{3}^{-}$. Estos procesos bioquímicos tienen lugar principalmente en el túbulo proximal y en menor extensión en otros segmentos de la nefrona. Por lo tanto, los aniones orgánicos metabolizables son bases fisiológicas potentes. Así, el citrato que tiene tres grupos carboxilos disociados, consumirá tres iones $\mathrm{H}^{+}$en su neutralización y se generarán tres iones $\mathrm{HCO}_{3}^{-}$. El lactato tiene un grupo carboxilo disociado, luego consumirá un ion $\mathrm{H}^{+}$en su neutralización y se generará un ion $\mathrm{HCO}_{3}^{-}$. La importancia clínica del potencial formador de $\mathrm{HCO}_{3}^{-}$que tiene los aniones orgánicos metabolizables ha sido reconocida en el uso del acetato o del citrato en el tratamiento de la acidosis metabólica. Asimismo, un aumento de la excreción urinaria de aniones orgánicos metabolizables es equivalente a la pérdida de $\mathrm{HCO}_{3}^{-}$.

- Utilización del $\mathrm{HCO}_{3}^{-}$generado en el riñón.

No todo el $\mathrm{HCO}_{3}^{-}$generado en el riñón se emplea en compensar el $\mathrm{HCO}_{3}^{-}$consumido por los iones $\mathrm{H}^{+}$producidos a partir de la disociación del agua inducida por la disminución de la [SID] y/o el aumento de la [Атот]. El $\mathrm{NH}_{4}^{+}$generado en el riñón fundamentalmente a partir del catabolismo de la glutamina se vierte a la orina (50 \% aproximadamente del producido en este órgano) a través de los uréteres o pasa a la 
circulación sistémica a través de las venas renales (50\% restante). Dado que el $\mathrm{NH}_{4}^{+}$y el $\mathrm{HCO}_{3}^{-}$se consumen en la síntesis de urea en el hígado, la liberación de $\mathrm{NH}_{4}^{+}$por el riñón a la circulación sistémica a través de las venas renales, reduce en cantidades iguales la cantidad de $\mathrm{HCO}_{3}^{-}$que retorna a la circulación sistémica. Si bien el término de bicarbonato efectivo se acuña dentro del modelo de Henderson-Hasselbalch, creo que se podría emplear también para designar la fracción de $\mathrm{HCO}_{3}^{-}$generado por el riñón, que está disponible para compensar el $\mathrm{HCO}_{3}^{-}$consumido por la carga de iones $\mathrm{H}^{+}$ procedentes de la disociación del agua inducida por una disminución de [SID] y/o un aumento de [Атот]. Por lo tanto, en condiciones fisiológicas el ciclo de la urea, un proceso que consume $\mathrm{HCO}_{3}^{-}$, compite con los iones $\mathrm{H}^{+}$que acabamos de citar, en el consumo de $\mathrm{HCO}_{3}^{-}$generado por el riñón y liberado a través de las venas renales a circulación sistémica. La sangre venosa renal contiene tanto el nuevo $\mathrm{HCO}_{3}^{-}$generado como el $\mathrm{HCO}_{3}^{-}$reabsorbido por los túbulos renales. Hay que resaltar que el $\mathrm{HCO}_{3}^{-}$ presente en la sangre venosa renal no se refiere al $\mathrm{HCO}_{3}^{-}$formado por hidratación del $\mathrm{CO}_{2}$ metabólico (respiración celular) dado que este último $\mathrm{HCO}_{3}^{-}$se excreta por los pulmones como $\mathrm{CO}_{2}$. Si bien todas las moléculas de $\mathrm{HCO}_{3}^{-}$son iguales, independientemente de su origen, resulta didácticamente muy útil hacer esta distinción como se hace en el modelo de Henderson-Hasselbalch.

La generación de $\mathrm{NH}_{4}^{+}$a partir de $\mathrm{NH}_{3}$ y $\mathrm{H}^{+}$secretados a la luz de los túbulos colectores no genera $\mathrm{HCO}_{3}^{-}$dado que los iones $\mathrm{H}^{+}$secretados derivan del $\mathrm{NH}_{4}^{+}$producido en el túbulo proximal (de la glutamina) y no del $\mathrm{CO}_{2}$ hidratado.

7. Intercambio de $\mathrm{Na}^{+}$en el túbulo distal con iones $\mathrm{H}^{+} \mathrm{O}$ iones $\mathrm{K}^{+}$

En el túbulo distal tiene lugar la reabsorción de $\mathrm{Na}^{+}$que no ha sido reabsorbido en el túbulo proximal, y representa aproximadamente el $9 \%$ del $\mathrm{Na}^{+}$filtrado. La reabsorción es de tipo activa, mediada por la acción de la bomba $\mathrm{Na}^{+}-\mathrm{K}^{+}$ATPasa. La secreción de $\mathrm{H}^{+}$en el túbulo distal es activa, condicionada por la presencia de una bomba en la membrana celular, la eliminación de $\mathrm{H}^{+}$está potenciada por la aldosterona. Referente a la secreción del $\mathrm{K}^{+}$es de tipo pasivo y se halla regulada por el elevado contenido intracelular de $\mathrm{K}^{+}$.

\subsection{Consumo metabólico de iones $\mathrm{H}^{+}$y generación y consumo de $\mathrm{HCO}_{3}^{-}$en el hígado: Papel del hígado en el} equilibrio ácido-base

Consideramos a continuación los iones $\mathrm{H}+$ procedentes de la disociación del agua inducida por la $\mathrm{pCO}_{2}$ intracelular hepática y su consumo mediante la protonación de aniones orgánicos metabolizables así como la generación de $\mathrm{HCO}_{3}^{-}$y su consumo en el propio hepatocito (Fig. $11 \mathrm{y}$ Tabla II).

Tabla II Hígado

\begin{tabular}{ll}
\hline 1) Generación de $\mathrm{HCO}_{3}^{-}$ & Acetato \\
\cline { 2 - 2 } $\begin{array}{l}\text { ediante la protonación de } \\
\text { aniones orgánicos } \\
\text { metabolizables: }\end{array}$ & Citrato \\
\cline { 2 - 2 } & Lactato \\
\hline 2) Consumo de $\mathrm{HCO}_{3:}^{-}$ & Enato la síntesis de Urea \\
\hline
\end{tabular}




\section{Hígado}

Anhidrasa carbónica

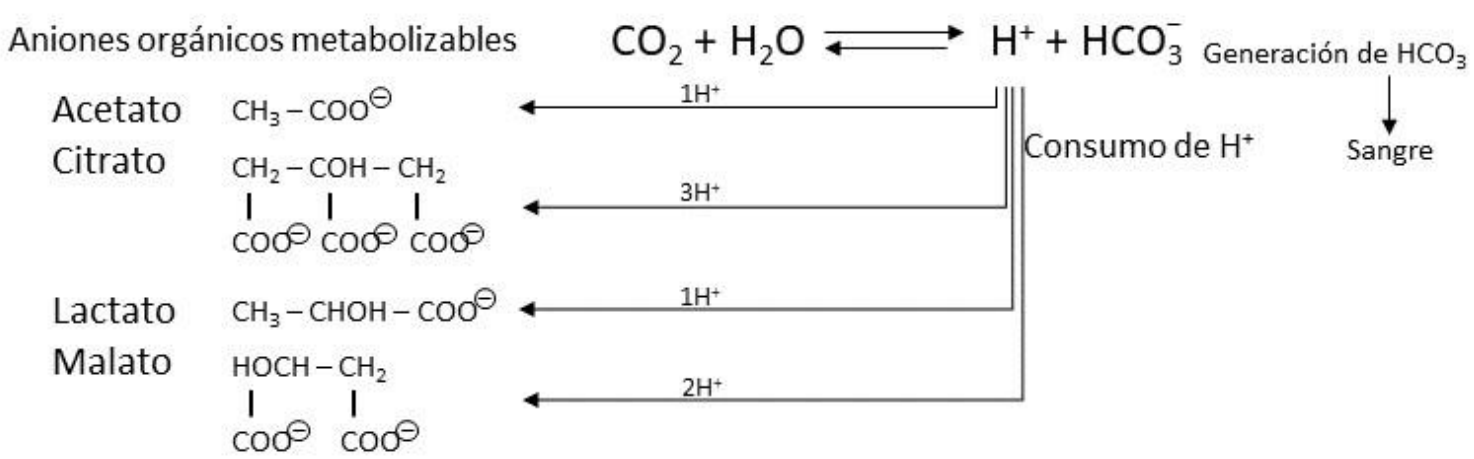

Figura 11 Consumo metabólico de iones $\mathrm{H}+$ y generación y consumo de $\mathrm{HCO}_{3}^{-}$en el hígado

En el hígado los aniones acetato, citrato, lactato y malato consumen iones $\mathrm{H}^{+}$procedentes de la hidratación del $\mathrm{CO}_{2}$ catalizada por la anhidrasa carbónica, en su conversión en productos electroneutros dando lugar al mismo tiempo a la generación de $\mathrm{HCO}_{3}^{-}$intracelular en dicha reacción. Recordemos que el consumo de iones $\mathrm{H}^{+}$, lo cual supone retirarlos del entorno, pues dejan de estar libres, aumenta la actividad de la anhidrasa carbónica y por lo tanto por cada ion $\mathrm{H}^{+}$consumido se forma una molécula de $\mathrm{HCO}_{3}^{-}$a partir de una molécula de $\mathrm{CO}_{2}$ hidratado. Por lo tanto, la protonación de una molécula de acetato (que tiene un grupo carboxilato) genera una molécula de $\mathrm{HCO}_{3}^{-}$, la de una molécula de citrato (que tiene tres grupos carboxilato) genera tres moléculas de $\mathrm{HCO}_{3}^{-}$, la de lactato (que tiene dos grupos carboxilato) una molécula de $\mathrm{HCO}_{3}^{-}$y la de malato (que tiene un grupo carboxilato), dos moléculas de $\mathrm{HCO}_{3}^{-}$. Obsérvese el número de grupos carboxilato por moléculas citadas y su relación con los iones $\mathrm{H}^{+}$consumidos en su neutralización. Dado que el $\mathrm{HCO}_{3}^{-}$ está cargado, es incapaz de difundir a través de bicapas lipídicas, requiriendo proteínas integrales de membrana para su transporte. Como el $\mathrm{HCO}_{3}^{-}$es una base, su transporte a través de las membranas afecta al $\mathrm{pH}$.

3.6.1. Consumo metabólico de iones $\mathrm{H}^{+}$y generación de $\mathrm{HCO}_{3}^{-}$en el hígado mediante protonación de aniones orgánicos metabolizables

1. Fuentes de acetato

Recordemos que el hígado produce acetato libre, mediante la hidrólisis directa de la acetil-CoA. La formación de acetato es una consecuencia de la existencia de una acetil-CoA hidrolasa mitocondrial. Otra fuente de acetato hepático es el alcohol, la mayoría del alcohol absorbido llega al hígado y se oxida a acetaldehído. La oxidación posterior del acetaldehído a acetato la cataliza la aldehído deshidrogenasa. La flora bacteriana del colon produce por fermentación de componentes de la dieta no absorbidos ácidos grasos de cadena corta como el acetato y otros más. Las células del colon (colonocitos) utilizan estos ácidos grasos para obtener la mayor energía posible procedente de la dieta. Si se producen en exceso respecto a las necesidades del colon, los ácidos grasos de cadena corta pasan a la sangre portal para su utilización por el hígado.

2. Fuentes de citrato

Los niveles plasmáticos de citrato parecen ser bastante independientes de la dieta porque una vez que se absorbe el citrato procedente de los alimentos, se metaboliza rápidamente a nivel hepático. El citrato se utiliza principalmente en el hígado y en el riñón. Las fuentes principales de citrato plasmático son el hueso y el metabolismo intermediario hepático y muscular.

3. Fuentes de lactato.

Un individuo con actividad física normal produce diariamente alrededor de $120 \mathrm{~g}$ de lactato. Los tejidos virtualmente anaerobios y su metabolismo (eritrocito, médula renal y retina, por ejemplo), producen del orden de $40 \mathrm{~g}$. La contribución de los demás tejidos (intestino delgado, cerebro, cerebro, piel y músculos) varía según su actividad y dependiendo de la situación, por 
lo que es difícil determinar la importancia de cada uno. La contribución del músculo es particularmente variable, pudiendo el ejercicio vigoroso aumentar la producción diaria de lactato por encima de los $120 \mathrm{~g}$. Aunque el hígado es el tejido principal para la utilización de lactato (oxidación y gluconeogénesis), otros tejidos como el músculo cardiaco y el músculo estriado pueden captar lactato de la sangre y oxidarlo para producir energía.

4. Fuentes de malato.

El malato presente en la sangre en concentraciones micromolares es captado por los hepatocitos perivenosos. El músculo libera malato, intermediario del ciclo de Krebs, en sangre venosa procedente fundamentalmente del metabolismo de los aminoácidos.

\subsubsection{Consumo de $\mathrm{HCO}_{3}^{-}$en la síntesis de urea}

La síntesis de urea consume $\mathrm{HCO}_{3}^{-}$y por lo tanto agrava potencialmente la acidosis, causando una depleción adicional del contenido de $\mathrm{HCO}_{3}^{-}$ya disminuido por la carga ácida. El hallazgo de que la tasa de la síntesis de urea disminuye cuando el contenido de $\mathrm{HCO}_{3}^{-}$plasmático aumenta, como sucede en la inducción de alcalosis metabólica y en la recuperación de la acidosis metabólica, proporciona evidencias adicionales contra el papel de la génesis de urea en la regulación de la eliminación de $\mathrm{HCO}_{3}^{-}$y, por lo tanto, en la prevención y atenuación de la alcalosis metabólica que presenta una elevación primaria del contenido de $\mathrm{HCO}_{3}^{-}$.

Sólo 6 de 51 niños con defectos en el ciclo de la urea mostraron alcalosis metabólica, luego parece improbable que la síntesis de urea sea un proceso crucial en la regulación del equilibrio ácido-base. Los resultados favorecen la idea de que la síntesis de urea sirve principalmente para la eliminación de nitrógeno.

En la Fig. 12 se muestra un esquema del metabolismo del ion hidrógeno.

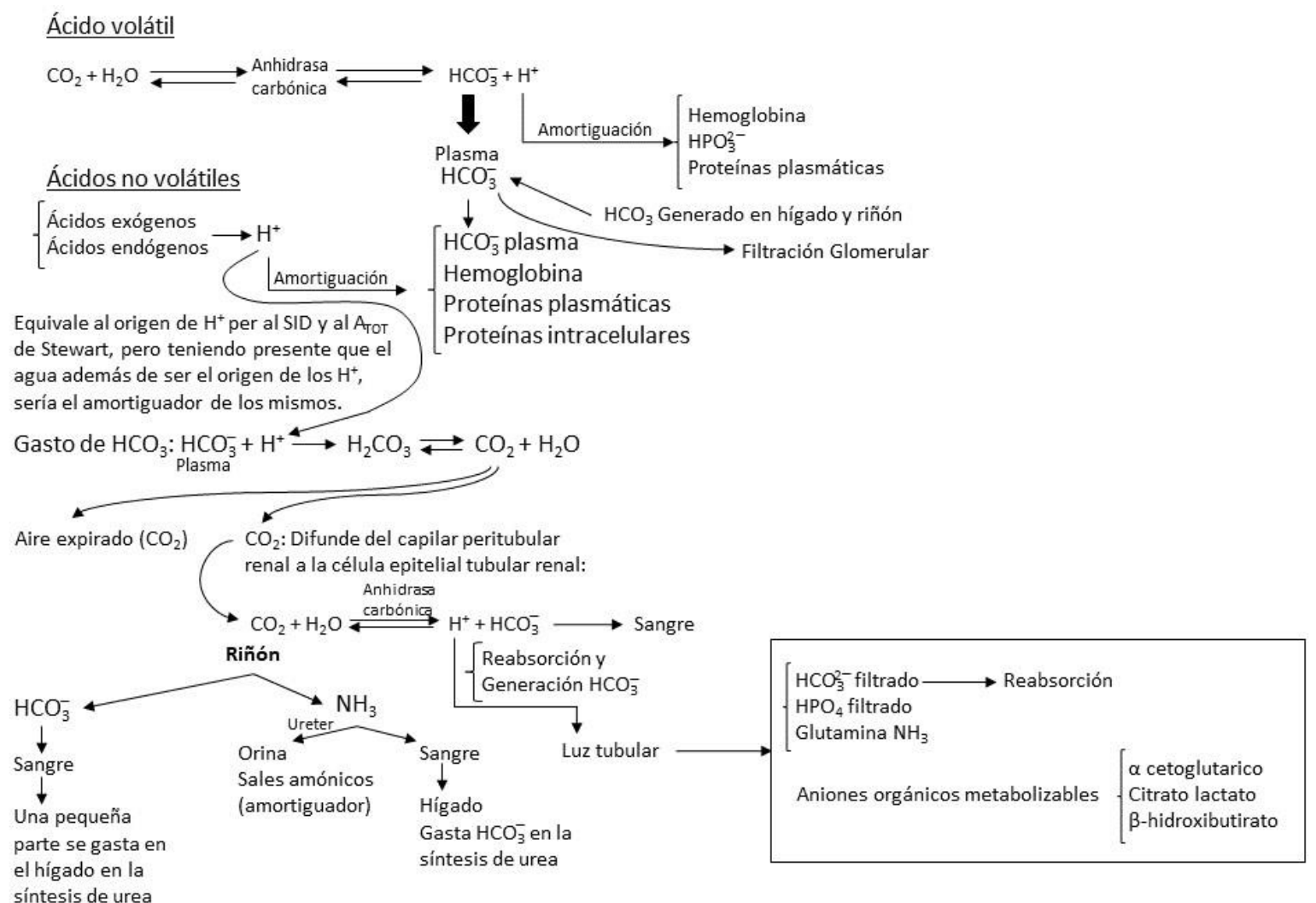

Figura 12 Metabolismo del ion hidrógeno 


\section{Efecto de la digestión sobre el equilibrio ácido-base: Bases moleculares de la marea alcalina} según el modelo de Henderson-Hasselbalch y el modelo de Stewart

Debido a la cantidad masiva de ácido y base que fluye cada día por la mucosa duodenal, el duodeno es uno de los principales órganos que interviene en el equilibrio ácido-base. $[9,10]$ (Fig. 13).

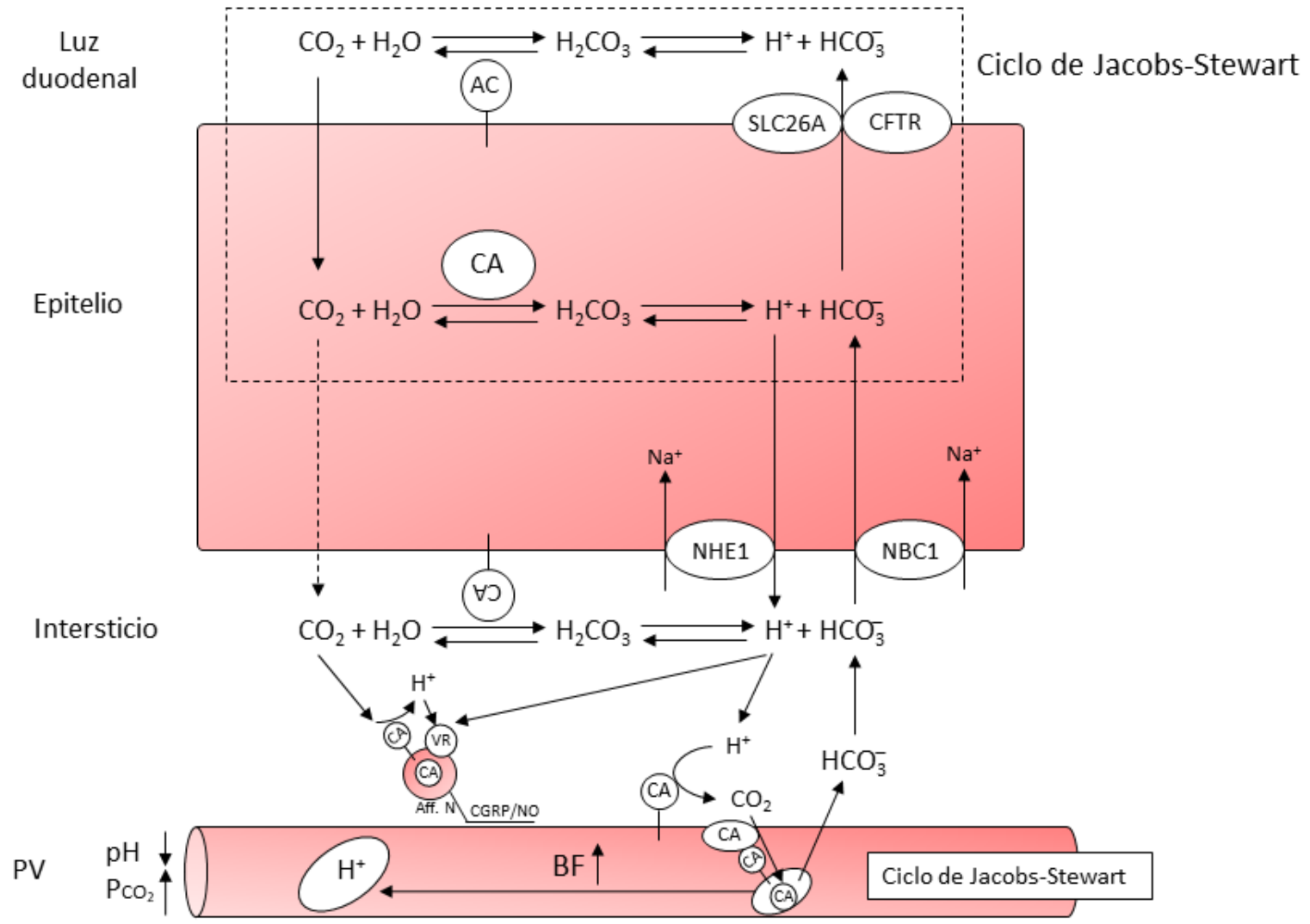

Figura 13 Modelo de movimiento y detección duodenal transmucosa de $\mathrm{CO}_{2}$ y $\mathrm{H}^{+}$[24]

CA: Anhidrasa carbónica; NHE: Intercambiador $\mathrm{Na}^{+}-\mathrm{H}^{+}$; $\mathrm{NBC}$ : cotransportador $\mathrm{Na}^{+}-\mathrm{HCO}_{3}^{-}$

SLC26A: Familia 26Ax transportadora de solutos; CFTR: Regulador de la conductancia transmembrana de fibrosis quística;

PV: Vena porta; VR: Receptor vaniloide; CGRP: Péptido relacionado con el gen de la calcitonina;

NO: Óxido nítrico; BF: Flujo sanguíneo.

Las células parietales gástricas son responsables de la secreción de $\mathrm{HCl}$ en la luz del estómago. La formación de $\mathrm{HCl}$ transcurre del siguiente modo:

La aceleración del tránsito intestinal (diarrea aguda) impide la absorción distal del $\mathrm{HCO}_{3}^{-}$ excedente y produce acidosis metabólica por pérdida de $\mathrm{HCO}_{3}^{-}$. Cuando se impide el paso del contenido gástrico hacia el duodeno (vómitos, drenaje nasogástrico) la secreción bilio dudodeno pancreática no se neutraliza, y el exceso de $\mathrm{HCO}_{3}^{-}$se reabsorbe, creando una alcalosis metabólica por exceso diario de $\mathrm{HCO}_{3}^{-}$próximo a $150 \mathrm{mEq} /$ día.

El $\mathrm{CO}_{2}$ de la circulación sistémica entra en las células parietales gástricas, donde es hidratado por la enzima anhidrasa carbónica, dando lugar a un ion $\mathrm{H}^{+}$que es secretado por la $\mathrm{H}^{+} \mathrm{K}^{+}$ATPasa de la membrana apical a la luz gástrica, y un $\mathrm{HCO}_{3}^{-}$que es secretado a la circulación a través de un intercambiador de aniones de la membrana basolateral, muy probablemente el AE2. El ácido secretado entra en la luz gástrica donde la peristalsis antral lo transporta a la luz duodenal. $\mathrm{El} \mathrm{HCO}_{3}^{-}$ alcaliniza la circulación creando la marea alcalina. Por la peristalsis antral el contenido de ácido gástrico entra en el duodeno, donde se combina con $\mathrm{HCO}_{3}^{-}$secretado por el duodeno, a través de las glándulas de Brunner, el páncreas exocrino, a través del conducto de Wirsung y el hígado a través del colédoco. Con la reacción del $\mathrm{HCl}$ gástrico y el $\mathrm{HCO}_{3}^{-}$secretado en la luz duodenal se genera $\mathrm{CO}_{2}$ en cantidades equimoleculares. Kaunitz y Akiba postulan que este $\mathrm{CO}_{2}$ generado es trasportado 
desde la luz duodenal a la circulación subepitelial, circula a través de la circulación pulmonar y sistémica donde es entonces captado por las células parietales para completar el ciclo.

Kaunitz y Akiba han emitido la hipótesis de que los iones $\mathrm{H}^{+}$secretados por el estómago son neutralizados por el $\mathrm{HCO}_{3}^{-}$secretado en el duodeno, generando $\mathrm{CO}_{2}$ y $\mathrm{H}_{2} \mathrm{O}$. $\mathrm{El} \mathrm{CO}_{2}$ atraviesa la membrana apical de la célula epitelial pasando al citosol, donde por una anhidrasa carbónica de la célula se convierte en un ion $\mathrm{H}^{+}$y un ion $\mathrm{HCO}_{3}^{-}$. El ion $\mathrm{H}^{+}$acidifica la célula y sale de la misma a través de NHE1 presente en la membrana basolateral al intersticio subepitelial. El ion $\mathrm{H}^{+}$estimula unos sensores de ácido tales como el receptor vaniloide, ahora conocido como TRPV1, sirviendo como un sensor de ácido primario. Este receptor está presente en la submucosa y en el núcleo de la vellosidad del epitelio duodenal. La activación del receptor TRPV1 en las terminaciones nerviosas aferentes produce una respuesta efectora, tal como la generación de óxido nítrico (NO) y la liberación del péptido vasoactivo, conocido como péptido relacionado con el gen de la calcitonina (CGRP) o de prostaglandinas, lo cual se traduce en un aumento del flujo sanguíneo, hiperemia y secreción de $\mathrm{HCO}_{3}^{-}$y moco. Además es probable que la activación del receptor TRPV1 produzca sensación de ardor de estómago.

El ion $\mathrm{H}^{+}$también se convierte a $\mathrm{CO}_{2}$ por la anhidrasa carbónica subepitelial, incluyendo la anhidrasa carbónica basolateral (CAIX) o vascular (CAIV). El $\mathrm{CO}_{2}$ entra en la sangre de la vena porta y es trasportado por los eritrocitos, acidificando la sangre de la vena porta y aumentando la $\mathrm{pCO}_{2}$ a

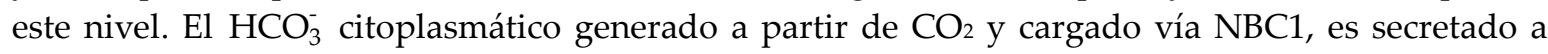
través de un intercambiador aniónico SLC26Ax apical, o CFTR a la luz duodenal. El $\mathrm{HCO}_{3}^{-}$luminal se convierte a $\mathrm{CO}_{2}$ por una anhidrasa carbónica extracelular. Así el movimiento neto de $\mathrm{CO}_{2}$ es de la luz duodenal a la mucosa, mientras que el movimiento neto de $\mathrm{HCO}_{3}^{-}$es de la mucosa a la luz duodenal. Estos movimientos simultáneos producen una absorción neta de ion $\mathrm{H}^{+} \mathrm{y}$ una secreción neta de $\mathrm{HCO}_{3}^{-}$.

$\mathrm{El} \mathrm{CO}_{2}$ difunde a través de la membrana apical de las células duodenales a su citoplasma. $\mathrm{El} \mathrm{CO}_{2}$ por una anhidrasa carbónica citosólica se convierte en $\mathrm{HCO}_{3}^{-}$y un ion $\mathrm{H}^{+}$. El ion $\mathrm{H}^{+}$acidifica la célula y es expulsado al intersticio subepitelial a través del intercambiador $\mathrm{Na}^{+} / \mathrm{H}^{+}(\mathrm{NHE} 1)$. Los iones $\mathrm{H}^{+}$ estimulan sensores ácidos tales como el receptor vaniloide (VR1), ahora llamado receptor del potencial vaniloide transitorio 1 (TRPV1), seguido de la liberación del péptido relacionado con el gen de la calcitonina (CGRP) y de óxido nítrico (NO), los cuales producen un aumento de flujo sanguíneo. El duodeno permite que se complete el ciclo del carbono que comienza con la captación de $\mathrm{CO}_{2}$ de la

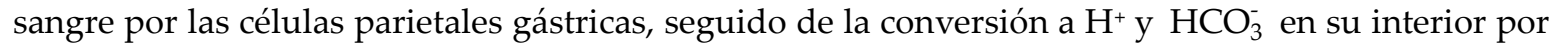
la anhidrasa carbónica, secreción de $\mathrm{H}^{+}$en la luz gástrica, con secreción de $\mathrm{HCO}_{3}^{-}$en la circulación venosa gástrica (marea alcalina), mezcla duodenal de $\mathrm{H}^{+}$gástrico y de $\mathrm{HCO}_{3}^{-}$secretado en la luz duodenal, liberación de $\mathrm{CO}_{2}$, absorción de $\mathrm{CO}_{2}$ y trasporte de $\mathrm{CO}_{2}$ a la célula parietal gástrica. La anhidrasa carbónica epitelial citosólica y extracelular facilita cooperativamente la absorción de $\mathrm{CO}_{2}$, resultando en la absorción neta de $\mathrm{H}^{+}$por el duodeno.

En resumen las células parietales gástricas secretan $\mathrm{Cl}^{-}$y $\mathrm{H}^{+}$en la luz gástrica. Este ion $\mathrm{H}^{+}$deriva

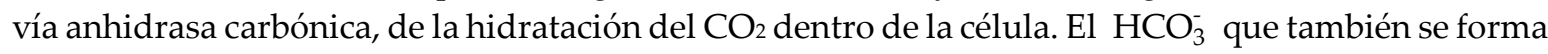
en este proceso, pasa a la sangre y causaría lo que se conoce como marea alcalina postprandial. La secreción del páncreas exocrino de un líquido rico en $\mathrm{HCO}_{3}^{-}$con un movimiento neto del $\mathrm{HCO}_{3}^{-}$ desde el plasma al interior de las células pancreáticas exocrinas y de aquí a la luz duodenal, corrige esta marea alcalina y sería la interpretación según el modelo de Hendersson-Hasselbalch.

Según el modelo de Stewart la comprensión de la marea alcalina postprandial implica a nivel gástrico un movimiento neto de iones $\mathrm{Cl}^{-}$desde el plasma a la célula parietal de la mucosa gástrica y desde ellas son secretados a la luz del estómago. Este proceso está aumentado después de las comidas y provoca la reducción del valor positivo de la SID en el jugo gástrico aumentando la disociación del $\mathrm{H}_{2} \mathrm{O}$ y por lo tanto aumentando la $\left[\mathrm{H}^{+}\right]$en el jugo gástrico. En cambio a nivel plasmático la disminución de $\mathrm{Cl}^{-}$aumentará el valor positivo de la SID con lo que disminuirá la disociación de $\mathrm{H}_{2} \mathrm{O}$ y los iones $\mathrm{H}^{+}$reaccionarán con $\mathrm{OH}^{-}$aumentando la formación de moléculas de $\mathrm{H}_{2} \mathrm{O}$ y aumentando el $\mathrm{pH}$, lo que se conoce como marea alcalina postprandial. Normalmente esto se corrige por el movimiento de $\mathrm{Cl}^{-}$en sentido opuesto en el duodeno. Si hay una pérdida de jugo 
gástrico del cuerpo se desarrolla alcalosis porque el $\mathrm{Cl}^{-}$es eliminado del plasma en una cantidad mucho mayor que la que retorna al mismo, con lo cual aumentaría la SID plasmática.

El páncreas secreta un jugo con baja $\left[\mathrm{Cl}^{-}\right]$y por lo tanto tiene un alto valor de la SID. El plasma del cual procede ese $\mathrm{Cl}^{-}$tiene, a pesar de todo, una concentración del mismo alta, dado que muy poco ha pasado a la célula pancreática exocrina y por lo tanto tiene un valor bajo de la SID y también corrige la marea alcalina.

\section{Efecto de algunos componentes de la dieta sobre la absorción de bicarbonato en el intestino delgado}

El intestino delgado participa en la reabsorción del $\mathrm{HCO}_{3}^{-}$presente en la secreción pancreática exocrina, dependiendo de la composición de la dieta. El intestino modula de este modo el nivel de $\mathrm{HCO}_{3}^{-}$en sangre. Esto es lo que se llama "generación de la carga ácida y alcalina por el intestino" en el modelo de Hendersson-Hasselbalch.

El jugo pancreático posee un elevado contenido de $\mathrm{HCO}_{3}^{-}$de sodio (aproximadamente 113 $\mathrm{mEq} / \mathrm{L}$ ) en comparación con 20-24 mEq en el plasma. Cada día se secretan alrededor de $1500 \mathrm{~mL}$ de jugo pancreático, el cual neutraliza el quimo ácido que llega al duodeno desde el estómago con el doble efecto de proteger la mucosa duodenal del daño por ácido y por pepsina y de llevar el $\mathrm{pH}$ del contenido luminal a los valores óptimos requeridos para la actividad de las enzimas pancreáticas. El $\mathrm{HCO}_{3}^{-}$se forma en un $80 \%$ del $\mathrm{CO}_{2}$ procedente de la actividad metabólica en las células de los conductos y las células centroacinares, a pesar de representar solo el 5\% de la población celular del páncreas, y en un $20 \%$ del $\mathrm{CO}_{2}$ procedente de la sangre. El páncreas contiene anhidrasa carbónica que cataliza la conversión intracelular de $\mathrm{CO}_{2}$ en $\mathrm{HCO}_{3}^{-}$. El jugo pancreático tiene la concentración de $\mathrm{HCO}_{3}^{-}$más alta (alrededor de $140 \mathrm{nM}$ ) que cualquier otro líquido corporal. Pese a ello estas células se cargan con $\mathrm{HCO}_{3}^{-}$mediante un cotransportador de $\mathrm{Na}^{+}$y $\mathrm{HCO}_{3}^{-}\left(\mathrm{NBC}_{\mathrm{e} 1}\right)$ y difusión de $\mathrm{CO}_{2}$ procedente de la sangre, seguido de la catalización mediada por anhidrasa carbónica la cual hidrata el $\mathrm{CO}_{2}$ y produce un ion $\mathrm{H}^{+}$y un $\mathrm{HCO}_{3}^{-}$. El intercambiador de $\mathrm{Na}^{+} / \mathrm{H}^{+}(\mathrm{NHE} 1)$ extrae $\mathrm{H}^{+}$y carga la célula con $\mathrm{Na}^{+}$adicional. El transportador CFTR media la secreción de $\mathrm{HCO}_{3}^{-}$pancreático a la luz ductal.

El intestino por sí mismo no genera específicamente equivalentes ácidos y básicos, sino que dependiendo de la composición de la dieta aumenta o disminuye la cantidad de $\mathrm{HCO}_{3}^{-}$(a partir de la secreción pancreática) que se reabsorbe continuamente de un modo fisiológico, modulando así el nivel de $\mathrm{HCO}_{3}^{-}$en sangre. La razón de esto es la tasa de absorción específica de cada electrolito. Además, el intestino delgado determina las cantidades absorbidas de aminoácidos que contienen azufre y de sales alcalinas de ácidos orgánicos metabolizables, los cuales entonces dispone el hígado $\mathrm{u}$ otros tejidos metabólicamente activos. Componentes de la dieta como el carbonato de calcio, cloruro de calcio, cloruro de magnesio y sulfato de magnesio influyen en la reabsorción de $\mathrm{HCO}_{3}^{-}$a nivel intestinal, como se expone a continuación:

1. Carbonato de calcio

El carbonato de calcio $\left(\mathrm{CaCO}_{3}\right)$ se emplea en productos de panadería, pastelería, bollería industrial, bebidas con calcio, cereales para el desayuno y frutas enlatadas. También se utiliza como aditivo coadyuvante en la obtención de aceite de oliva.

Una sustancia insoluble como el $\mathrm{CaCO}_{3}$ tiene que reaccionar con ácido gástrico o ácido de los alimentos para llegar a ser soluble y absorbible. La absorción del $\mathrm{CO}_{3}$ parece estar facilitada cuando el $\mathrm{CaCO}_{3}$ reacciona con $\mathrm{HCl}$ en el estómago y ácido de los alimentos. La reacción en el estómago es la siguiente:

$$
\mathrm{CaCO}_{3}+2 \mathrm{HCl} \rightarrow \mathrm{CaCl}_{2}+\mathrm{H}_{2} \mathrm{CO}_{3}
$$

Algo de este $\mathrm{CaCl}_{2}$ se absorbe como tal pero la mayoría después de reaccionar con $\mathrm{NaHCO}_{3}$ en el duodeno, se vuelve a convertir en $\mathrm{CaCO}_{3}$ y se excreta en heces y algo se excreta como $\mathrm{CaHPO}_{4}$ después de reaccionar con fosfato sódico. La absorción del $\mathrm{CaCO}_{3}$ directamente o como $\mathrm{CaCl}_{2}$ representa una ganancia $\mathrm{HCO}_{3}^{-}$. El intercambio de $\mathrm{CO}_{3}$ por fosfato también representa una 
ganancia de $\mathrm{HCO}_{3}^{-}$, mientras la pérdida de $\mathrm{CaCO}_{3}$ en heces, no tiene efecto sobre el equilibrio ácido-base.

2. Cloruro de calcio

El cloruro de calcio es un estabilizante sintético potenciador del sabor que se emplea en patatas fritas, alimentos procesados, productos precocinados, verduras en conserva, frutas enlatadas, bebidas alcohólicas y en panadería como levadura para harinas. El cloruro de calcio $\left(\mathrm{CaCl}_{2}\right)$ administrado por vía endovenosa es neutro, pero por vía oral es un agente acidificante.

Si la absorción de $\mathrm{Ca}^{2+}$ se asume que es de un $25 \%$ y el del $\mathrm{Cl}^{-}$de un $95 \%$, y el calcio se ingiere en la forma de su sal de cloro $\left(\mathrm{CaCl}_{2}\right)$, un exceso de cloro con respecto al calcio entra en las células intestinales y en la sangre. La porción de calcio no absorbida reacciona con el $\mathrm{HCO}_{3}^{-}$secretado por el páncreas exocrino y es excretado en heces. Dado que el sodio de la secreción pancreática se reabsorbe como $\mathrm{NaCl}$ (el cual no es ácido ni base) y no como $\mathrm{NaHCO}_{3}$ (el cual es una base), ocurre una pérdida neta de equivalentes de base. Así el $\mathrm{CaCl}_{2}$ es un agente acidificante cuando se ingiere por vía oral. Según el modelo de Stewart este efecto acidificante se explicaría por el aumento de la $\left[\mathrm{Cl}^{-}\right]$plasmático, lo cual disminuiría la [SID], lo cual provocaría la disociación del agua aumentando la $\left[\mathrm{H}^{+}\right]$

3. Cloruro de magnesio

El cloruro de magnesio se emplea como cuajo para preparar tofu a partir de leche de soja. Por ejemplo, si se ingiere $\mathrm{MgCl}_{2}$, de una cantidad dada de $\mathrm{Mg}^{2+}$ solo se absorbe alrededor de un tercio, mientras que el $\mathrm{Cl}^{-}$se absorbe en un $95 \%$. Si se ingiere $\mathrm{MgCl}_{2}$, un exceso de cloro $\left(\mathrm{Cl}^{-}\right)$ con respecto al de $\mathrm{Mg}^{2+}$ entra en la sangre. Debido al principio de electroneutralidad está claro que otros cationes necesitan compensarlo. El catión primario que está disponible abundantemente para ser absorbido junto con un exceso de aniones (tales como el $\mathrm{Cl}^{-}$) es el $\mathrm{Na}^{+}$ procedente de la secreción pancreática que contiene grandes cantidades de bicarbonato sódico. El anión $\mathrm{HCO}_{3}^{-}$forma sales de carbonato con la parte de $\mathrm{Mg}^{2+}$ no absorbida. Como resultado, el fondo de $\mathrm{HCO}_{3}^{-}$circulante o disponible en la circulación no es repuesto convenientemente. Esta ausencia de $\mathrm{HCO}_{3}^{-}$sódico en sangre, representa una pérdida de capacidad amortiguadora, y se puede llamar carga ácida. Las consecuencias comparables para la reabsorción de $\mathrm{HCO}_{3}^{-}$ intestinal se ven cuando se ingieren sales de calcio de ácidos no metabolizables. $\mathrm{El} \mathrm{Na}^{+}$se reabsorbe junto con el $\mathrm{Cl}^{-}$que ya existía en el organismo, por lo tanto la modificación en este caso es la absorción de $\mathrm{Cl}^{-}$y la pérdida de $\mathrm{HCO}_{3}^{-}$por heces. El aumento de la $\left[\mathrm{Cl}^{-}\right]$plasmático disminuirá el [SID] con lo cual aumentará la disociación de $\mathrm{H}_{2} \mathrm{O}$ y con ello la $\left[\mathrm{H}^{+}\right]$.

4. Sulfato de magnesio

El sulfato de magnesio es un estabilizante natural o sintético y corrector de la acidez. Se emplea en verduras en conserva, frutas enlatadas, helados, patés, harinas, panadería, cerveza, vinos y licores.

El efecto global del MgSO4 sobre el equilibrio ácido-base es similar al de la ingestión de $\mathrm{CaCl}$, ya que el SO4 es más fácilmente absorbible que el $\mathrm{Mg}$. Sin embargo, aunque el magnesio se absorbe mejor que el calcio, es menos efectivo en la unión de fosfato que el calcio. 


\section{Clasificación de los trastornos primarios del equilibrio ácido-base según el modelo de Stewart}

Según el método de Stewart la clasificación de los trastornos ácido-base se basa en los cambios de las tres "variables independientes". [4-7]. (Tabla IV).

Tabla IV Cambios en los niveles o en la respuesta a hormonas y a la vitamina D en la acidosis metabólica

\begin{tabular}{ll}
\hline Glucocorticoides & $\begin{array}{l}\text { Aumenta la producción de } \\
\text { glucocorticoides. }\end{array}$ \\
\hline \multirow{2}{*}{ GH } & $\begin{array}{l}\text { Disminuye la secreción de GH. } \\
\text { Disminuye la secreción de IGF-1 } \\
\text { mediada por GH. }\end{array}$ \\
\hline \multirow{2}{*}{ IGF-1 } & $\begin{array}{l}\text { Aumenta en plasma, en hígado y } \\
\text { en riñón (pero no en músculo). }\end{array}$ \\
\hline \multirow{2}{*}{ Insulina } & $\begin{array}{l}\text { Supresión del metabolismo de la } \\
\text { glucosa mediada por insulina. }\end{array}$ \\
\hline \multirow{2}{*}{ PTH } & $\begin{array}{l}\text { Disminuye la sensibilidad de } \\
\text { secreción de PTH a cambios en el } \\
\text { Ca }{ }^{2+} \text { plasmático. }\end{array}$ \\
\hline & $\begin{array}{l}\text { Disminuye los niveles de T3 y de T4 } \\
\text { en plasma. } \\
\text { T3 y T4 }\end{array}$ \\
\hline Vitamina D & $\begin{array}{l}\text { Se suprime la activación a 1,25 } \\
(\text { OH) } 2 \text { colecalciferol posiblemente. }\end{array}$ \\
\hline
\end{tabular}

Los trastornos respiratorios, al igual que en la aproximación tradicional de Henderson-Hasselb

alch, son debidas a cambios en la $\mathrm{pCO}_{2}$, dado que la $\mathrm{pCO}_{2}$ está regulada por la respiración, mientras que los trastornos metabólicos son debidos a alteraciones bien en la SID o en la [А тот]. La SID está disminuida en la acidosis metabólica y aumentada en la alcalosis metabólica. Por el cálculo del SIG se puede aumentar la clasificación de la acidosis metabólica pero está fuera del objetivo de este tema. En la acidosis metabólica hiperclorémica, tanto la SID efectiva como la aparente disminuyen igualmente, pues el aumento $\mathrm{de}^{\mathrm{Cl}^{-}}$es equilibrado por una disminución igual en la concentración de $\mathrm{HCO}_{3}^{-}$. Por lo tanto SIG permanece en cero o cerca del cero. En la acidosis metabólica con aumento del AG, el SID aparente no cambia (la concentración de $\mathrm{Cl}^{-}$no cambia), pero la SID efectiva disminuye (como resultado de una disminución de la concentración de $\mathrm{HCO}_{3}^{-}$) y la SIG por lo tanto se hace positivo. Una novedad principal del método tradicional es la clasificación de los trastornos ácido-base como resultado de la alteración de la [Атот]. [Атот] representa la concentración de proteínas séricas principalmente la albúmina y el fosfato inorgánico. Así un aumento en las proteínas séricas produce una acidosis metabólica y una disminución, una alcalosis metabólica. 


\section{Clasificación}

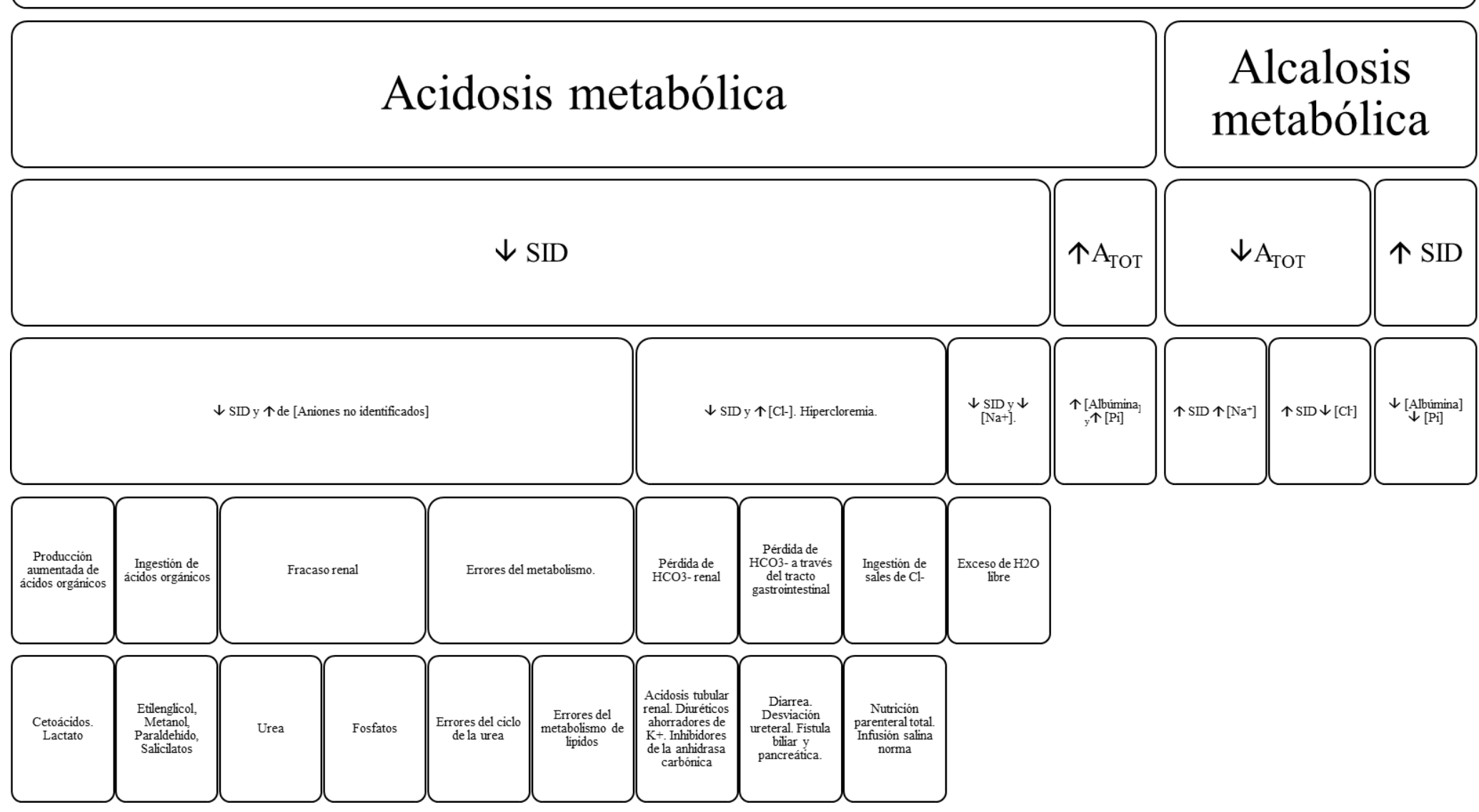




\section{Bases moleculares de las respuestas de compensación en los trastornos primarios del equilibrio ácido-base según el modelo de Stewart}

Cuando aparece un trastorno ácido-base el organismo emplea una serie de mecanismos para defenderse de las alteraciones del pH del LEC y del LIC. Estos mecanismos de defensa no corrigen el trastorno acido-base, sino que reducen la magnitud del cambio de $\mathrm{pH}$ ocasionado por el trastorno. Para que se normalice el $\mathrm{pH}$ sanguíneo se deben corregir los procesos de fondo que originaron el trastorno del equilibrio ácido-base. [11-18].

\subsection{Acidosis respiratoria}

1. Etiología

La acidosis respiratoria se debe a hipoventilación y reduce el $\mathrm{pH}$ al elevar la $\mathrm{pCO}_{2}$ como se explica a continuación. La acidosis respiratoria aguda aparece siempre que hay una insuficiencia brusca de la ventilación. Son causas frecuentes, la depresión del centro respiratorio por enfermedad cerebral o por fármacos, los trastornos neuromusculares y el paro cardiopulmonar. La acidosis respiratoria crónica aparece en enfermedades pulmonares, como el enfisema y la bronquitis crónica, en las que la ventilación alveolar eficaz está disminuida. También puede aparecer hipercapnia crónica como consecuencia de una hipoventilación alveolar primaria o por una hipoventilación alveolar en relación con la obesidad mórbida extrema (síndrome de Pickwick).

2. Amortiguación de los iones $\mathrm{H}^{+}$

$\mathrm{El} \mathrm{CO}_{2}$ retenido en la acidosis respiratoria aguda desplaza la ecuación del sistema amortiguador carbónico/bicarbonato hacia la derecha, aumentando la concentración en la sangre de $\mathrm{H}^{+} \mathrm{y}$ de $\mathrm{HCO}_{3}^{-}$.

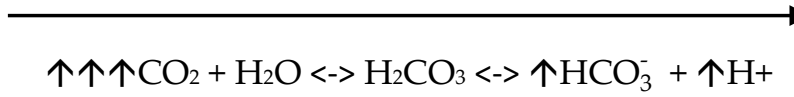

Los amortiguadores celulares proporcionan más del 95\% de la respuesta compensadora a la acidosis respiratoria aguda. El ion $\mathrm{H}^{+}$producido penetra en las células, intercambiándose por $\mathrm{Na}^{+}$y K+ $\mathrm{K}^{+}$se amortigua por las proteínas intracelulares. $\mathrm{El} \mathrm{HCO}_{3}^{-}$que queda en el líquido eleva el $\mathrm{HCO}_{3}^{-}$sanguíneo y representa una parte de la respuesta compensadora. Además, el $\mathrm{CO}_{2}$ difunde rápidamente a los eritrocitos donde la alta concentración intracelular de anhidrasa carbónica da lugar al ion $\mathrm{H}^{+}$, que es amortiguado por la hemoglobina, y al $\mathrm{HCO}_{3}^{-}$, que abandona el eritrocito y se intercambia por cloruro plasmático. Dado que el aumento compensador del $\mathrm{HCO}_{3}^{-}$sérico en la acidosis respiratoria aguda es pequeño, existe escasa protección contra la acidemia. También es pequeño el riesgo de alcalosis posterior a la hipercapnia. La hipoxemia que acompaña a la hipercapnia aguda puede producir también acidosis láctica.

3. Compensación renal

Si la hipercapnia se prolonga, se pone en marcha la capacidad del riñón de secretar ion $\mathrm{H}^{+}$y de producir y retener mayores cantidades de $\mathrm{HCO}_{3}^{-}$. Por ello, en la acidosis respiratoria crónica la compensación renal produce un aumento mucho mayor de $\mathrm{HCO}_{3}^{-}$sérico del observado en la acidosis respiratoria aguda. $\mathrm{Al}$ aumentar la $\mathrm{pCO}_{2}$ sanguínea, se eleva también la $\mathrm{pCO}_{2}$ en el interior de las células tubulares pues difunde desde el capilar peritubular, y ello permite que la anhidrasa carbónica aumente la concentración intracelular de $\mathrm{HCO}_{3}^{-}$y de ion $\mathrm{H}^{+}$. Dado que la disponibilidad de iones $\mathrm{H}^{+}$por la célula epitelial del túbulo renal es superior a la carga filtrada

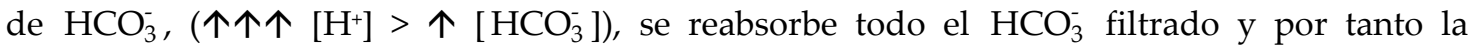
reabsorción de $\mathrm{HCO}_{3}^{-}$está aumentada. Cuando ya no hay $\mathrm{HCO}_{3}^{-}$disponible para amortiguar dichos iones $\mathrm{H}^{+}$, estos se amortiguan por el fosfato (acidez titulable) y por el amoniaco secretado. Esto equivale a la llamada excreción de ácido. Como se explicó anteriormente en condiciones fisiológicas, el hecho de que aumente la acidez titulable y el aumento de eliminación de $\mathrm{NH}_{4}{ }^{+}$ 
supone que aumente la generación de $\mathrm{HCO}_{3}^{-}$renal y que este pase a través de la membrana basolateral al capilar peritubular y de este modo a la circulación sistémica.

Así, aunque el $\mathrm{HCO}_{3}^{-}$plasmático está elevado, tanto la generación como la reabsorción del mismo elevan más el $\mathrm{HCO}_{3}^{-}$plasmático. $\mathrm{El} \mathrm{Cl}^{-}$sérico desciende ya que se intercambian $\mathrm{Cl}^{-}$por $\mathrm{HCO}_{3}^{-}$, por lo cual la excreción de $\mathrm{Cl}^{-}$está aumentada.

Con respecto al intercambio de $\mathrm{Na}^{+}$con ion $\mathrm{H}^{+} \mathrm{O}$ con $\mathrm{K}^{+}$en el túbulo distal, como está elevada la $\left[\mathrm{H}^{+}\right]$, estos se intercambian con el $\mathrm{Na}^{+}$presente en la luz tubular. Salen iones $\mathrm{H}^{+}$de las células epiteliales del túbulo distal a su luz y entra $\mathrm{Na}^{+}$del líquido tubular a la célula epitelial. Al estar disminuido el intercambio de $\mathrm{Na}^{+}$por $\mathrm{K}^{+}$en estas circunstancias la cifra de $\mathrm{K}^{+}$en plasma puede aumentar.

En la compensación de la acidosis respiratoria la eliminación de ion $\mathrm{H}^{+}$en la orina no es en sí misma importante puesto que el agua es fuente inagotable de $\mathrm{H}^{+}$según Stewart. En cambio, la eliminación de $\mathrm{Cl}^{-}$en la orina aumenta el valor de la SID en el plasma y así ayuda a retornar la concentración de ion $\mathrm{H}^{+}$(y por lo tanto del $\mathrm{pH}$ ) hacia valores normales pues reaccionaría el ion $\mathrm{H}^{+}$con el $\mathrm{OH}^{-}$formándose moléculas de $\mathrm{H}_{2} \mathrm{O}$. La importancia del $\mathrm{NH}_{4}^{+}$según el modelo de Stewart es que el $\mathrm{NH}_{4}^{+}$, catión débil, permite la excreción urinaria del anión $\mathrm{Cl}^{-}$sin pérdida de ningún catión fuerte y no por la eliminación de iones $\mathrm{H}^{+}$.

\subsection{Alcalosis respiratoria}

1. Etiología

La alcalosis respiratoria se debe a una hiperventilación alveolar aguda o crónica, que reduce la $\mathrm{pCO}_{2}$ de la sangre arterial, al aumentar la eliminación de $\mathrm{CO}_{2}$ en el aire espirado, por lo cual esta reacción se desplaza hacia la izquierda.

$\downarrow \downarrow \downarrow \mathrm{CO}_{2}+\mathrm{H}_{2} \mathrm{O}<->\mathrm{H}_{2} \mathrm{CO}_{3}<->\downarrow \mathrm{HCO}_{3}^{-}+\downarrow \mathrm{H}^{+}$

La hiperventilación se debe a la estimulación del centro respiratorio, directa (ej. intoxicación por salicilato) o indirectamente (vía refleja. ej. ataque de ansiedad e hipoxia), o bien a una ventilación mecánica excesiva.

2. Amortiguación de los iones $\mathrm{H}^{+}$.

El descenso de la concentración de iones $\mathrm{H}^{+}$de los líquidos corporales se amortigua, en parte, por los iones $\mathrm{H}^{+}$derivados de los sistemas amortiguadores de los compartimentos extracelular e intracelular (hemoglobina, proteínas y fosfato). El desplazamiento de iones $\mathrm{H}^{+}$hacia el exterior de la célula, se acompaña de un movimiento de $\mathrm{Na}^{+}$y $\mathrm{K}^{+}$hacia el interior. Este desplazamiento repentino de $\mathrm{K}^{+}$, aunque cuantitativamente pequeño, puede originar una disminución aguda de la concentración plasmática de $\mathrm{K}^{+}$, con los efectos cardiovasculares de la hipopotasemia. Mediante los iones $\mathrm{H}^{+}$que provienen de los amortiguadores, el $\mathrm{HCO}_{3}^{-}$se transforma en ácido carbónico, disminuyendo su concentración.

La hipocapnia induce una mayor afinidad de la hemoglobina por el oxígeno, con la consiguiente hipoxia tisular. Dicha hipoxia se ve favorecida por la vasoconstricción inducida por la propia hipocapnia. Dado que el oxígeno molecular es el aceptor de electrones de la cadena respiratoria, su menor disponibilidad tisular induce una disminución del flujo de electrones a través de la misma, lo cual condiciona una disminución de la concentración de ATP y un aumento de AMP. Los cambios de las concentraciones de estos nucleótidos activan la enzima glucolítica fosfofructoquinasa, aumentando la velocidad de la glucolisis. El enlentecimiento de la cadena respiratoria hace que se eleve la proporción de $\mathrm{NADH}$ frente $\mathrm{NAD}^{+}$, lo que facilita la conversión de ácido pirúvico en láctico. El aumento de ácido láctico disminuye el valor de la SID y por lo tanto aumenta la disociación del agua y aumenta la concentración de iones $\mathrm{H}^{+}$con lo cual disminuye el pH. C. Compensación renal.

Si la hipocapnia persiste, la caída del $\mathrm{HCO}_{3}^{-}$plasmático aumenta a causa de la puesta en marcha de la compensación renal. 
a. Disponibilidad de iones $\mathrm{H}^{+}$por la célula epitelial tubular renal. La caída de la $\mathrm{pCO}_{2}$ sanguínea, disminuye la difusión de $\mathrm{CO}_{2}$ desde la sangre de los capilares peritubulares a las células de los túbulos renales. Por tanto, se generan menos iones $\mathrm{H}^{+}$en la célula tubular y disminuye su secreción para intercambiar con el $\mathrm{Na}^{+}$.

b. Carga filtrada de $\mathrm{HCO}_{3}^{-}$. La carga filtrada de $\mathrm{HCO}_{3}^{-}$está disminuida puesto que han disminuido sus niveles plasmáticos al desplazarse la reacción hacia la izquierda.

c. Reabsorción de $\mathrm{HCO}_{3}^{-}$filtrado. A pesar de que la carga filtrada de $\mathrm{HCO}_{3}^{-}$está disminuida, todo el $\mathrm{HCO}_{3}^{-}$filtrado no se reabsorbe, puesto que hay menos iones $\mathrm{H}^{+}$disponibles para reaccionar con el $\mathrm{HCO}_{3}^{-}$en la luz tubular que moléculas de $\mathrm{HCO}_{3}^{-}$filtradas.

$$
\downarrow \downarrow \downarrow\left[\mathrm{H}^{+}\right]<\downarrow\left[\mathrm{HCO}_{3}^{-}\right]
$$

Por ello, disminuye la reabsorción de $\mathrm{HCO}_{3}^{-}$y aumenta la eliminación del mismo en la orina, por lo cual no tiene lugar la eliminación de $\mathrm{Cl}^{-}$, aumentando por tanto su concentración en sangre. Este aumento de la $\left[\mathrm{Cl}^{-}\right]$disminuye la SID, lo cual estimula la disociación del $\mathrm{H}_{2} \mathrm{O}$ y así aumenta la $\left[\mathrm{H}^{+}\right]$. La excreción $\mathrm{HCO}_{3}^{-}$arrastra $\mathrm{Na}^{+}$acompañante.

d. Eliminación de iones $\mathrm{H}^{+}$. Dado que los pocos iones $\mathrm{H}^{+}$secretados en la luz tubular se amortiguan por el $\mathrm{HCO}_{3}^{-}$filtrado, no quedan iones $\mathrm{H}^{+}$para eliminarse en la orina en forma de acidez titulable y sales amónicas. Ello condiciona que no haya generación de $\mathrm{HCO}_{3}^{-}$.

e. Intercambio de $\mathrm{Na}^{+}$en el túbulo distal con $\mathrm{H}^{+} \mathrm{o} \mathrm{K}^{+}$. El intercambio de $\mathrm{Na}^{+}$en el túbulo distal se hará con el $\mathrm{K}^{+}$, ya que no se dispone de iones $\mathrm{H}^{+}$, lo que condiciona un aumento de la excreción de $\mathrm{K}^{+}$con un moderado descenso del $\mathrm{K}^{+}$sérico.

\subsection{Acidosis metabólica}

1. Etiología

En el plasma hay normalmente un exceso de cationes fuertes sobre los aniones fuertes, lo cual da a la SID un valor de carga positiva de $38-42 \mathrm{mEq} / \mathrm{L}$. Recordemos que la carga eléctrica crea un campo eléctrico y este tiene la capacidad de inducir la disociación del hidrógeno unido a un átomo oxígeno y de este modo influir en la disociación del $\mathrm{H}_{2} \mathrm{O}$. La acidosis metabólica se produce por una disminución de la SID y/o un aumento en la [Aтот]. La acidosis metabólica se presenta en las siguientes situaciones:

a. Disminución de la SID:

- Exceso de agua libre. Si se añade suficiente agua libre para diluir la concentración de iones fuertes a la mitad, la SID también disminuirá a la mitad. Para entender mejor este concepto, consideremos un paciente con las concentraciones $(\mathrm{mEq} / \mathrm{L}) \mathrm{de} \mathrm{Na}^{+}, \mathrm{K}^{+}, \mathrm{Ca}^{2+}$, $\mathrm{Mg}^{2+}$ y Cl- de 140, 4, 6, 2 y 104 respectivamente.

La SID de este paciente es de $50 \mathrm{mEq} / \mathrm{L}(140+4+6+2-102)$. Al añadir suficiente $\mathrm{H} 2 \mathrm{O}$ libre disminuyen estas concentraciones a la mitad, y la SID valdrá $25 \mathrm{mEq} / \mathrm{L}(70+2+3+1-51)$. Así, el exceso de $\mathrm{H}_{2} \mathrm{O}$ libre desciende el valor de la SID y por lo tanto modifica el campo eléctrico. La disminución de la carga positiva y por lo tanto del campo eléctrico aumenta la disociación del hidrógeno unido al oxígeno de la molécula de $\mathrm{H}_{2} \mathrm{O}$ y se produce acidosis metabólica.

- Los cambios absolutos en los iones fuertes también alteran la SID. Los cambios en la concentración de $\mathrm{Na}^{+}$resultan principalmente un reflejo de los cambios en agua libre como acabo de indicar. Los cationes fuertes remanente de los cuales son $\mathrm{K}^{+}, \mathrm{Ca}^{2+}, \mathrm{Mg}^{2+}$ no varían significativamente para causar alteraciones en el equilibrio ácido-base. Sin embargo, los cambios en las concentraciones de aniones fuertes son significativos en el equilibrio ácidobase. Así un aumento de aniones fuertes como cetoácidos, lactato, salicilato y sulfato causan una disminución en la SID, lo cual produce una acidosis metabólica.

- La infusión de grandes volúmenes de "salino normal" causa acidosis metabólica. La hipercloremia se desarrolla debido a la relativamente alta concentración de $\mathrm{Cl}$ - del salino 
(150 mmol/L) comparado con la concentración de Cl- del plasma normal (100 mmol/L). La reducción resultante en la SID aumenta la disociación del $\mathrm{H}_{2} \mathrm{O}$ y por lo tanto la $\left[\mathrm{H}^{+}\right]$.

b. Aumento de la [ATOT]:

De acuerdo con el modelo de Stewart, la [Атот] es la segunda variable independiente que afecta el equilibrio ácido-base. Recordemos que la [Атот] se define como la concentración total de especies de ácido débil no volátil en su forma disociada y no disociada. En el organismo los principales ácidos débiles (iones débiles) son la albúmina y el fosfato inorgánico. Ambos contribuyen a través de su carga a satisfacer el principio de electroneutralidad. Las proteínas (albúmina y globulinas) son los principales ácidos débiles en el plasma, y sus concentraciones están en su mayor parte controladas por el hígado. Los fosfatos también contribuyen a la [Атот], siendo particularmente significativos para producir tal efecto durante la hipoalbuminemia. Un aumento en la concentración de proteínas plasmáticas aumenta la [Атот] induciendo un aumento en la [A-]. Los efectos son comparables a una reducción de la SID de tamaño equimolar, una acidosis metabólica.

2. Amortiguación de los iones $\mathrm{H}^{+}$.

Cuando hay un exceso iones $\mathrm{H}^{+}$de acuerdo con la ley de acción de masas, tiene lugar una desviación hacia la izquierda, de la siguiente reacción:

$$
\mathrm{CO}_{2}+\mathrm{H}_{2} \mathrm{O}<->\mathrm{H}_{2} \mathrm{CO}_{3}<->\mathrm{H}^{+}+\mathrm{HCO}_{3}^{-}
$$

disminuyendo por tanto el anión $\mathrm{HCO}_{3}^{-}$. Este aumento de la $\left[\mathrm{H}^{+}\right]$no aumenta la $\left[\mathrm{CO}_{2}\right]$ como se podría esperar porque los iones $\mathrm{H}^{+}$estimulan el centro respiratorio (como se expone a continuación), aumenta la ventilación pulmonar y por lo tanto disminuye la $\mathrm{pCO}_{2}$ por su mayor eliminación por vía respiratoria. Esto a su vez desplaza todavía más la reacción por la ley de acción de masas hacia la izquierda y por lo tanto disminuye más la $\left[\mathrm{HCO}_{3}^{-}\right]$. El exceso de iones $\mathrm{H}^{+}$también se amortigua parcialmente, entrando parte de los iones $\mathrm{H}^{+}$en el interior de las células, donde tiene lugar la acción de los amortiguadores intracelulares. Entonces, para mantener el equilibrio eléctrico, tienen que salir otros cationes $\left(\mathrm{K}^{+}\right)$al líquido extracelular, con lo que su concentración aumenta.

El esqueleto contiene una reserva masiva de bases que está disponible para amortiguar iones $\mathrm{H}^{+}$ si el riñón y los pulmones no son capaces de mantener el equilibrio ácido-base dentro de unos límites fisiológicos estrechos. El esqueleto actuaría en la amortiguación aguda de iones $\mathrm{H}+$ durante la acidosis metabólica.

El material inorgánico del hueso está formado por hidroxiapatita: Ca10 $\left(\mathrm{PO}_{4}\right)_{6}(\mathrm{OH})_{2}$, brucita: $\mathrm{CaHPO}_{4}^{-}$y carbonato cálcico: $\mathrm{CaCO}_{3}$. La mayoría del hueso consiste en complejos de fosfato cálcico y carbonato cálcico. Los iones $\mathrm{H}^{+}$reaccionarán con la hidroxiapatita según la siguiente reacción:

$$
\mathrm{Ca} 10\left(\mathrm{PO}_{4}\right)_{6}(\mathrm{OH})_{2}+8 \mathrm{H}^{+} \rightarrow 10 \mathrm{Ca}^{2+}+6 \mathrm{HPO}_{4}^{2-}+2 \mathrm{H}_{2} \mathrm{O} .
$$

Asimismo, los iones $\mathrm{H}^{+}$reaccionarían con la brucita:

$$
\mathrm{CaHPO}_{4}+\mathrm{H}^{+} \rightarrow \mathrm{Ca}^{2+}+\mathrm{H}_{2} \mathrm{PO}_{4}^{-}
$$

El $\mathrm{H}_{2} \mathrm{PO}_{4}^{-}$puede liberar un $\mathrm{H}^{+}$en medio alcalino. Cada $\mathrm{PO}_{4}$ liberado podría aceptar un ion $\mathrm{H}^{+}$. El $\mathrm{CO}_{3}^{2-}$ podría combinarse con un $\mathrm{H}^{+}$para formar $\mathrm{HCO}_{3}^{-}$y entonces con un $\mathrm{H}^{+}$adicional formar $\mathrm{H}_{2} \mathrm{CO}_{3}$ el cual rápidamente se disociaría a $\mathrm{CO}_{2}$ y $\mathrm{H}_{2} \mathrm{O}$. La utilización del carbonato óseo para tamponar $\mathrm{H}^{+}$tiene lugar del siguiente modo:

$$
\begin{aligned}
& \mathrm{CaCO}_{3}+2 \mathrm{H}^{+} \rightarrow \mathrm{HCO}_{3}^{-}+\mathrm{H}^{+}+\mathrm{Ca}^{2+} \\
& \mathrm{HCO}_{3}^{-}+\mathrm{H}^{+}+\mathrm{Ca}^{2+} \rightarrow \mathrm{H}_{2} \mathrm{CO}_{3}+\mathrm{Ca}^{2+} \\
& \mathrm{H}_{2} \mathrm{CO}_{3}+\mathrm{Ca}^{2+}<->\mathrm{CO}_{2}+\mathrm{H}_{2} \mathrm{O}+\mathrm{Ca}^{2+}
\end{aligned}
$$


El carbonato cálcico $\left(\mathrm{CaCO}_{3}\right)$ se disuelve fácilmente en soluciones ácidas con desprendimiento de $\mathrm{CO}_{2}$. En primer lugar, el carbonato del hueso se acaba perdiendo en forma de $\mathrm{CO}_{2}$ respiratorio. En segundo lugar, la utilización de carbonato deja libre el calcio del carbonato cálcico óseo. El calcio libre es filtrado y eliminado por el riñón. Como consecuencia, la acidosis crónica persistente interfiere con el normal desarrollo óseo y causa además una hipercalciuria capaz de provocar nefrocalcinosis y nefritis intersticial crónica.

In vitro, la salida de $\mathrm{Ca}^{2+}$ del hueso inducida por el ion $\mathrm{H}^{+}$se debe a la disolución del carbonato cálcico óseo. Se sugiere, que el carbonato cálcico puede ser el material inorgánico del hueso solubilizado por la secreción de ion $\mathrm{H}^{+}$celular. Durante la acidosis metabólica tiene lugar una pérdida del carbonato óseo. La reabsorción ósea mediada por células que ocurre durante la acidosis metabólica crónica produce la liberación de fosfato mineral. La acidosis induce la liberación de $\mathrm{Ca}^{2+}$ y carbonato del hueso. La liberación de $\mathrm{Ca}^{2+}$ observado en la acidosis metabólica parece ser el resultado de una combinación de la inhibición de los osteblastos con una estimulación de la actividad de los osteoclastos (reabsorción ósea mediada por células) y el efecto fisicoquímico de la liberación directa del mineral óseo (disolución fisicoquímica del mineral óseo a corto plazo).

3. Compensación respiratoria.

Aunque los iones $\mathrm{H}^{+}$no cruzan la barrera hematoencefálica con facilidad, el $\mathrm{CO}_{2}$ la cruza sin dificultad y en el proceso se combina con el agua para formar ácido carbónico que se disocia en $\mathrm{H}^{+}$y $\mathrm{HCO}_{3}^{-}$. Los iones $\mathrm{H}^{+}$son los que estimulan el centro respiratorio y producen el incremento de la ventilación alveolar.

El centro respiratorio, entendiendo por ello todas las áreas respiratorias del tronco encefálico, es intensamente estimulado por un aumento patológico de concentración de $\mathrm{CO}_{2}$ o de iones $\mathrm{H}^{+}$en los líquidos que lo bañan. El solo hecho de aumentar la $\left[\mathrm{CO}_{2}\right]$ en sangre, aun sin variar el ritmo de la respiración ni su profundidad en cada una de aquellas, se elimina proporcionalmente más $\mathrm{CO}_{2}$. Además, el aumento de la presión parcial de $\mathrm{CO}_{2}$ en condiciones patológicas junto con la desviación del $\mathrm{pH}$ hacia el lado menos alcalino, incrementa el número de respiraciones haciendo que la cantidad de $\mathrm{CO}_{2}$ eliminada se haga mucho mayor. El ajuste respiratorio es bastante rápido y de gran eficacia, pero solo una solución parcial y temporal.

Aparte de la sensibilidad directa del propio centro respiratorio para factores humorales, receptores químicos especiales (también sensibles a los iones $\mathrm{H}^{+}$) localizados fuera del sistema nervioso central (SNC), denominados quimiorreceptores, transmiten señales al centro respiratorio para ayudar a regular la actividad respiratoria. Estos quimiorreceptores están localizados primariamente en las grandes arterias de tórax y cuello. La mayor parte se hallan en los cuerpos carotídeos y aórtico, y presentan conexiones nerviosas aferentes para el centro respiratorio. Los cuerpos carotídeos se hallan localizados en las bifurcaciones de las arterias carótidas primitivas; sus fibras nerviosas aferentes siguen por el nervio de Hering y de allí, por el glosofaríngeo, hasta el bulbo. Los cuerpos aórticos se hallan localizados a lo largo del arco de la aorta y sus fibras nerviosas aferentes llegan al bulbo raquídeo siguiendo los nervios vagos. Cada uno de estos cuerpos recibe su riego sanguíneo especial por una pequeña arteria directamente desde el tronco arterial vecino respectivo. Un aumento en la concentración de dióxido de carbono $\left(\mathrm{CO}_{2}\right)$ o de $\mathrm{H}^{+}$, excita los quimiorreceptores, y de esta forma aumenta indirectamente la actividad respiratoria. Los efectos directos de ambos factores sobre el propio centro respiratorio son mucho más poderosos que el efecto transmitido por los quimiorreceptores.

El aumento de la ventilación alveolar favorece la eliminación de $\mathrm{CO}_{2}$, con lo cual desciende la $\mathrm{pCO}_{2}$ sanguínea. Una manifestación clínica cardinal de la acidosis metabólica es una hiperventilación, la cual, cuando es grave, se manifiesta como respiración de Kussmaul. La disminución de la $\mathrm{pCO}_{2}$ sanguínea tras la compensación respiratoria hace que la reacción

$$
\mathrm{CO}_{2}+\mathrm{H}_{2} \mathrm{O} \leftarrow \mathrm{HCO}_{3}^{-}+\mathrm{H}^{+}
$$


se desplace hacia la izquierda, disminuyendo la concentración de $\mathrm{HCO}_{3}^{-}$, ya previamente disminuida.

4. Compensación renal.

Consideramos los siguientes pasos:

a. Disponibilidad de iones $\mathrm{H}^{+}$por la célula epitelial tubular renal. Debido a que el aumento de la concentración de protones ha aumentado la ventilación pulmonar disminuye la $\mathrm{pCO}_{2}$ en la sangre. A causa de la disminución de la $\mathrm{pCO}_{2}$ sanguínea, difunde menos $\mathrm{CO}_{2}$ de la sangre de los capilares peritubulares a las células epiteliales tubulares renales, generándose menos bicarbonato $\mathrm{y} \mathrm{H}^{+}$en dichas células. Por lo tanto, la secreción de $\mathrm{H}^{+}$por el túbulo renal es menor que la normal $\left(\downarrow\left[\mathrm{H}^{+}\right]\right)$

b. Carga filtrada de $\mathrm{HCO}_{3}^{-}$. La concentración de $\mathrm{HCO}_{3}^{-}$en el plasma y la carga filtrada de $\mathrm{HCO}_{3}^{-}$en el glomérulo renal se reducen aún en grado mayor que la $\left[\mathrm{H}^{+}\right]$.

$$
\downarrow\left[\mathrm{H}^{+}\right]>\downarrow \downarrow\left[\mathrm{HCO}_{3}^{-}\right]
$$

c. Reabsorción del $\mathrm{HCO}_{3}^{-}$filtrado. Dado que hay más iones $\mathrm{H}^{+}$disponibles en la luz tubular que moléculas de $\mathrm{HCO}_{3}^{-}$filtradas, todas las moléculas de $\mathrm{HCO}_{3}^{-}$reaccionan con los iones $\mathrm{H}^{+}$, formándose ácido carbónico. Este ácido carbónico, por efecto de la anhidrasa carbónica presente en la cara luminal de la membrana apical de la célula epitelial tubular, se descompone en $\mathrm{CO}_{2}$ y $\mathrm{H}_{2} \mathrm{O}$. El $\mathrm{CO}_{2}$ y la mayoría del $\mathrm{H}_{2} \mathrm{O}$ difunden a la célula tubular. Por tanto, se reabsorbe todo el $\mathrm{HCO}_{3}^{-}$filtrado. Sin embargo, como la carga de $\mathrm{HCO}_{3}^{-}$filtrado es inferior a la normal, está disminuida la reabsorción de $\mathrm{HCO}_{3}^{-}$en relación con el individuo.

d. Eliminación de iones $\mathrm{H}^{+}$. Los iones $\mathrm{H}^{+}$excedentes que no se han amortiguado con el $\mathrm{HCO}_{3}^{-}$ filtrado, porque este ya se ha consumido, se amortiguan con el fosfato filtrado ( $\left.\mathrm{HPO}_{4}^{2-}\right)$ (acidez titulable) y el amoniaco y constituyen la eliminación del ion $\mathrm{H}^{+}$. Al mismo tiempo se genera $\mathrm{HCO}_{3}^{-}$que pasa a la sangre, tanto a partir del $\mathrm{CO}_{2}$ de la sangre que difunde desde el capilar peritubular a la célula epitelial tubular renal, como el que se forma a partir del metabolismo de la glutamina en el riñón, cuyo aporte al mismo está aumentado. Recordemos también que en el caso de la formación de $\mathrm{NH}_{4}^{+}$, este tiene lugar a partir del metabolismo de la glutamina en la célula epitelial tubular.

Según el modelo de Henderson Hasselbalch el papel de los riñones en la regulación del pH plasmático tiene lugar a través de la generación de $\mathrm{HCO}_{3}^{-}$junto con el efecto neto de excreción de ion $\mathrm{H}^{+}$. La generación de $\mathrm{HCO}_{3}^{-}$permite la recuperación de los niveles plasmáticos del mismo gastados en la amortiguación de los $\mathrm{H}^{+}$y la síntesis de urea. Sin embargo, según el modelo de Stewart el movimiento de iones $\mathrm{H}^{+}$entre compartimentos no cambia realmente el $\mathrm{pH}$ porque no altera ninguna de las variables independientes. Para Stewart la $\left[\mathrm{H}^{+}\right]$se mantiene por un cambio en la disociación de $\mathrm{H}_{2} \mathrm{O}$ que revierte cualquier fluctuación en la concentración de iones $\mathrm{H}^{+}$. Así la disociación del $\mathrm{H}_{2} \mathrm{O}$ es capaz de proporcionar una fuente inagotable de iones $\mathrm{H}^{+}$si aumenta o un sumidero de los mismos si disminuye, aumentando en este caso el número de moléculas de $\mathrm{H}_{2} \mathrm{O}$ al unirse el ion $\mathrm{H}^{+}$con el $\mathrm{OH}$. Por lo tanto, Stewart propone que el verdadero mecanismo por el cual los riñones regulan el pH plasmático es cambiando el flujo de iones fuertes a través de los túbulos renales, así los riñones alteran la SID. Una cuestión clave es saber cuál es el ion fuerte implicado. La [Na+] está estrechamente controlada para mantener la osmolaridad y el control del volumen plasmático y la $\left[\mathrm{K}^{+}\right]$necesita estar estrechamente controlada para asegurar una función cardiaca y neuromuscular apropiada. Por lo tanto, parece ser que es el $\mathrm{Cl}$ - el ion fuerte que los riñones usan para regular el equilibrio ácido-base sin interferir con otros procesos fisiológicos importantes. Así, los riñones juegan dos papeles importantes, la reabsorción del $\mathrm{HCO}_{3}^{-}$filtrado y la generación del mismo, así como la excreción de $\mathrm{Cl}^{-}$en la orina, lo cual aumenta la SID. Dado que se intercambia $\mathrm{Cl}^{-}$por $\mathrm{HCO}_{3}^{-}$al aumentar la reabsorción de $\mathrm{HCO}_{3}^{-}$ aumenta la excreción de $\mathrm{Cl}$ - por la orina y disminuye su concentración en suero, con lo cual 
aumenta la SID y disminuye la disociación del agua, por lo cual es una respuesta de compensación.

e. Intercambio de $\mathrm{Na}^{+}$con $\mathrm{H}^{+} \mathrm{o} \mathrm{K}$. Como hay excreción de $\mathrm{H}^{+}$se intercambian estos con el $\mathrm{Na}^{+}$ presente en la luz tubular, lo cual disminuye el intercambio del $\mathrm{Na}^{+}$presente en la luz tubular con el $\mathrm{K}^{+}$secretado por la célula tubular a la luz y por ello puede aumentar la concentración de $\mathrm{K}^{+}$plasmático. Además, hay que tener presente el $\mathrm{K}^{+}$que ha salido de las células intercambiándose con $\mathrm{H}^{+}$.

5. Características de la acidosis metabólica en el ser humano.

En el hombre en una etapa temprana ( 24 horas) de la acidosis metabólica (inducida experimentalmente) no solo aumenta la excreción urinaria de amonio sino que también aumenta la producción de amonio renal total como sería de esperar. Así la acidosis metabólica induce una adaptación precoz de la amoniogénesis renal y consecuentemente están disponibles una mayor cantidad de amortiguadores dado la mayor necesidad de excretar $\mathrm{Cl}^{-}$. En el hombre al comienzo de la acidosis metabólica, la extracción renal de glutamina no difiere de la medida en condiciones normales. En cambio, aumenta la extracción renal de glicina y ornitina de la sangre arterial, lo cual explica la mayor formación de $\mathrm{NH}_{4}^{+}$. En la rata la acidificación aguda no estimula la actividad glutaminasa dependiente de fosfato ni la de glutamato deshidrogenasa intramitocondrial. Entre el tercero y sexto día de la acidosis metabólica en humanos, aumenta la captación de glutamina renal y aumentan los niveles de $\alpha$ cetoglutarato. Asimismo, aumenta la producción de $\mathrm{NH}_{4}^{+}$en el túbulo proximal y la generación de $\mathrm{HCO}_{3}^{-}$a partir de la glutamina. A pesar del aumento de producción de $\mathrm{NH}_{4}^{+}$liberado a las venas renales en humanos, sus valores en plasma son aproximadamente igual al de los valores controles (cuando no hay acidosis). Aumenta la $\left[\mathrm{NH}_{4}^{+}\right]$intersticial fuera del túbulo colector de la médula interna renal, así como la secreción neta de iones $\mathrm{H}^{+}$en el túbulo colector. Estos cambios favorecen la difusión pasiva de $\mathrm{NH}_{4}^{+}$dentro de la luz del túbulo colector. Los mecanismos por el cual aumenta la concentración de $\mathrm{NH}_{4}^{+}$intersticial se desconoce, pero es posiblemente debida a la absorción de $\mathrm{NH}_{4}^{+}$en el asa de Henle.

En la acidosis metabólica crónica en humanos inducida experimentalmente mediante la administración de $\mathrm{HCl}, \mathrm{CaCl}_{2}$, o NH $\mathrm{NH}_{4} \mathrm{Cl}$, el riñón capta cantidades superiores de glutamina y glicina de la sangre arterial, la cual aporta sustrato para la amoniogénesis y suprime la degradación de proteínas en el riñón. Este último efecto, es potencialmente responsable de la hipertrofia tubular que se ha observado en la acidosis metabólica crónica experimental. En la acidosis experimental en humanos aumenta la producción de urea (como se citó anteriormente) pero no cambian sus niveles, tampoco cambian los niveles plasmáticos de glutamina y glutamato. En orina disminuyen los niveles de glutamina y glutamato y aumenta la eliminación de $\mathrm{NH}_{4}^{+}$. También se ha observado una liberación neta de glucosa en las venas renales y de este modo a la circulación sistémica, lo cual está de acuerdo con una estimulación de la gluconeogénesis a partir de aminoácidos observado en células tubulares. En cultivos de células epiteliales renales sometidas a condiciones de acidosis se ha observado la inducción de fosfoenolpiruvato quinasa y glutaminasa. Estos datos apoyan el concepto de que la gluconeogénesis renal está acoplada con la amoniogénesis y el mantenimiento del equilibrio ácido base. 
6. Alteraciones en la liberación y función de varias hormonas en la acidosis metabólica. (Tabla V).

Tabla V

\begin{tabular}{|c|c|c|c|c|c|}
\hline & \multirow[b]{3}{*}{$\begin{array}{l}\mathrm{HCO}_{3}^{-} \text {en } \\
\text { plasma }\end{array}$} & \multirow[b]{3}{*}[\mathrm{H}^{+}]{} & \multirow[b]{3}{*}{$\begin{array}{l}\mathrm{pH} \\
\text { plasmático }\end{array}$} & \multirow{2}{*}{\multicolumn{2}{|c|}{ Mecanismos de defensa }} \\
\hline & & & & & \\
\hline & & & & $\begin{array}{l}\text { Respuesta } \\
\text { compensatoria }\end{array}$ & $\begin{array}{l}\text { Compensación } \\
\text { esperada en orina }\end{array}$ \\
\hline $\begin{array}{l}\text { Acidosis } \\
\text { metabólica }\end{array}$ & $\downarrow \downarrow \downarrow \mathrm{HCO}_{3}^{-}$ & $\uparrow$ & $\downarrow$ & $\begin{array}{l}\downarrow \downarrow \mathrm{pCO}_{2} \\
\text { (hiperventilar) }\end{array}$ & $\begin{array}{l}\uparrow \text { Acidez titulable } \\
\uparrow \mathrm{N}^{+} \mathrm{H}_{4}\end{array}$ \\
\hline \multirow{3}{*}{$\begin{array}{l}\text { Alcalosis } \\
\text { metabóilica }\end{array}$} & \multirow{3}{*}{$\uparrow \uparrow \uparrow \mathrm{HCO}_{3}^{-}$} & \multirow{3}{*}{$\downarrow$} & \multirow{3}{*}{$\uparrow$} & \multirow{3}{*}{$\begin{array}{l}\uparrow \uparrow \mathrm{pCO}_{2} \\
\text { (hiperventilar) }\end{array}$} & $\downarrow$ Acidez titulable \\
\hline & & & & & $\downarrow \mathrm{N}^{+} \mathrm{H}_{4}$ \\
\hline & & & & & $\uparrow \mathrm{HCO}_{3}^{-}$ \\
\hline \multirow{2}{*}{$\begin{array}{l}\text { Acidosis no } \\
\text { respiratoria }\end{array}$} & \multirow{2}{*}{$\uparrow \uparrow \uparrow \mathrm{pCO}_{2}$} & \multirow{2}{*}{$\uparrow$} & \multirow{2}{*}{$\downarrow$} & \multirow{2}{*}{$\uparrow \uparrow \mathrm{HCO}_{3}^{-}$} & $\uparrow$ Acidez titulable \\
\hline & & & & & $\uparrow \mathrm{N}^{+} \mathrm{H}_{4}$ \\
\hline \multirow{3}{*}{$\begin{array}{l}\text { Alealosis } \\
\text { respiratoria }\end{array}$} & \multirow{3}{*}{$\downarrow \downarrow \downarrow \mathrm{pCO}_{2}$} & \multirow{3}{*}{$\downarrow$} & \multirow{3}{*}{$\uparrow$} & \multirow{3}{*}{$\downarrow \downarrow \mathrm{HCO}_{3}^{-}$} & $\downarrow$ Acidez titulable \\
\hline & & & & & $\downarrow \mathrm{N}^{+} \mathrm{H}_{4}$ \\
\hline & & & & & $\downarrow \mathrm{HCO}_{3}^{-}$ \\
\hline
\end{tabular}

La acidosis metabólica altera la liberación y función de varias hormonas la hormona del crecimiento (GH), IGF-1, insulina, glucocorticoides, hormona tiroidea, hormona paratiroidea (PTH) y vitamina D. Las consecuencias clínicas de estas respuestas metabólicas anormales incluyen un deterioro del crecimiento infantil y del niño y una pérdida de masa ósea y muscular en el adulto. El desarrollo de resistencia a la insulina puede estimular la degradación de proteína muscular por activación de mecanismos proteolíticos.

a. Hormonas:

A. Glucocorticoides: El aumento de la $\left[\mathrm{H}^{+}\right]$aumenta la secreción de cortisol en la corteza suprarrenal. El cortisol en el túbulo proximal de la nefrona incrementa el transporte celular de ion $\mathrm{H}^{+}$, al aumentar la transcripción del gen del intercambiador $\mathrm{Na}^{+}-\mathrm{H}^{+}$y la translocación del RNAm de este transportador.

Los glucocorticoides aumentan la disponibilidad de glutamina para la amoniogénesis a través de aumentar la expresión del transportador de glutamina SNAT3. SNAT3 está localizado en la membrana basolateral de las células epiteliales del túbulo proximal y transporta una molécula de glutamina y un $\mathrm{Na}^{+}$en intercambio con un $\mathrm{H}^{+}$. El transportador media el flujo de glutamina en ambos sentidos, dependiendo del gradiente de sustrato.

B. GH e IGF-1: la GH o el factor de crecimiento semejante a la insulina (IGF-1) en humanos tienen la capacidad de estimular la excreción neta de $\mathrm{H}^{+}$a nivel renal y por lo tanto de aumentar la concentración de $\mathrm{HCO}_{3}^{-}$en el plasma en presencia de un exceso de $\mathrm{Na}^{+}$de la dieta para la reabsorción tubular. GH/IGF-1 regulan la excreción renal de $\mathrm{NH}_{4}^{+}$en humanos por un efecto en el túbulo proximal de aumentar la producción de $\mathrm{NH}_{3}$ renal (amoniogénesis) y distalmente por estimular un mecanismo dependiente del transporte de $\mathrm{Na}^{+}$en el túbulo colector (acidificación dependiente de voltaje)

C. PTH: cuando aumenta la $\left[\mathrm{H}^{+}\right]$disminuye la sensibilidad de los receptores sensibles al calcio extracelular, esto disminuye la activación del receptor sensible a calcio a un nivel dado de $\mathrm{Ca}^{2+}$ y aumenta de esta forma la secreción de PTH.

- De forma aguda la PTH inhibe la secreción de $\mathrm{H}^{+}$en el túbulo proximal mediante la inhibición de la actividad del intercambiador $\mathrm{Na}^{+}-\mathrm{H}^{+}$(NHE3) presente en la membrana apical y también causando la endocitosis de dicho intercambiador desde la membrana apical. La PTH reduce los niveles del RNAm del NHE3 debido a un efecto sobre el promotor de NHE3 y una pequeña reducción de la vida media de su RNAm y 
disminución de la cantidad de proteína que es precedida por endocitosis del NHE3 de la superficie apical. Recordemos que dos tercios de la reabsorción de $\mathrm{NaHCO}_{3}$ transcelular está mediada por la secreción de $\mathrm{H}^{+}$a través del NHE3 y que la mayoría de la reabsorción de $\mathrm{ClNa}$ está indirectamente relacionado con ella. Por ello la disminución de la expresión de NHE3 es probablemente responsable de la reducción de $\mathrm{Na}^{+}, \mathrm{HCO}_{3}^{-}$y reabsorción de líquido en el túbulo proximal percibido en modelos experimentales la $\mathrm{PTH}$ inhibe la actividad del cotransportador $\mathrm{Na}^{+}-\mathrm{HCO}_{3}^{-}$en la membrana basolateral del túbulo proximal.

- A largo plazo, la PTH estimula la secreción renal de $\mathrm{H}^{+}$actuando sobre la parte gruesa de la rama ascendente del asa de Henle y en el túbulo distal. Este efecto estimulador de la PTH sobre la excreción de ácido se debe en parte a que la PTH inhibe la reabsorción de Pi por el túbulo proximal. Así, más Pi llega a los segmentos más distales de la nefrona donde está disponible para la titulación y excreción como ácido titulable.

b. Iones $\mathrm{H}+$ :

Un aumento en la $\left[\mathrm{H}^{+}\right]$estimula un sensor potencial de $\mathrm{pH}$, PyK2 que es una tirosina quinasa dependiente de calcio, no receptor. Entonces este sensor se autofosforila. Al mismo tiempo el aumento de la $\left[\mathrm{H}^{+}\right]$activa una quinasa regulada por señales extracelulares (ERK). La activación de PyK2 y de ERK parecen converger en la transcripción del receptor de endotelina 1. Dicha transcripción activa el receptor de endotelina B (ET-B). La activación de ET-B induce una reorganización del citoesqueleto dependiente de RhoA lo cual induce la acumulación de NHE3 en la membrana, lo cual a su vez aumenta la eliminación de iones $\mathrm{H}^{+}$en las células epiteliales del túbulo proximal.

De las tres endotelinas (ET) comunicadas (ET 1-3), la ET-1 es la más importante para la función renal con expresión en células endoteliales renales, mesangio, túbulo proximal y túbulo colector. Los efectos biológicos de la ET-1 están mediados por receptores ET (ET-A). ET-A está presente en la vascularización renal y sistémica y también en el túbulo proximal y colector. ET-B se expresa en células endoteliales renales y a lo largo de la nefrona. ETs además de un efecto vasoconstrictor también modulan la reabsorción de $\mathrm{Na}^{+} \mathrm{y}$ la secreción de $\mathrm{H}^{+}$a nivel renal. ET-1, a través de la activación de ET-B, inhibe la reabsorción de $\mathrm{Na}^{+} \mathrm{y} \mathrm{H}_{2} \mathrm{O}$ en el túbulo colector. ET-1 a través de la activación de ET-B estimula la acidificación en el túbulo proximal aumentando el intercambio $\mathrm{Na}^{+} / \mathrm{H}^{+}$(NHE3, vía activación c-src). La ET es un mediador fisiológico del aumento de acidificación en el túbulo proximal y distal de la nefrona en respuesta a una carga ácida, como una dieta con alto contenido en proteínas.

\subsection{Alcalosis metabólica}

1. Etiología

La alcalosis metabólica es un proceso causado bien por un aumento de la [SID] o una disminución en la [Атот]. Un aumento en la SID puede ser causado por la pérdida de más aniones fuertes $\left(\mathrm{Cl}^{-}\right)$que cationes fuertes como en la terapia con diuréticos de asa, como la tiazida o pérdida de $\mathrm{Cl}^{-}$tras vómitos prolongados por estenosis pilórica o por aspiración nasogástrica que se reduce la concentración de $\mathrm{Cl}^{-}$plasmático (hipocloremia) en relación al $\mathrm{Na}^{+} \mathrm{o}$ por la administración de más cationes fuertes $\left(\mathrm{Na}^{+}\right)$que aniones fuertes (como la infusión de $\mathrm{NaHCO}_{3}$ o grandes volúmenes de sangre conteniendo citrato sódico) o un exceso de aporte nutricional de $\mathrm{Na}^{+}$, en cualquier una hiperatremia. Una disminución en la [Атот] se puede presentar en la hipoalbuminemia crónica por síndrome nefrótico o fracaso hepático. Con el aumento de la SID (se hace más positivo) hay menos disociación del $\mathrm{H}_{2} \mathrm{O}$ y la concentración de ion $\mathrm{H}^{+}$está reducida ( $\mathrm{pH}$ aumentado) en orden a mantener la neutralidad eléctrica. De acuerdo con el modelo de Stewart la alcalosis no está causada por la pérdida de $\mathrm{H}^{+}$dado que la disociación del agua proporciona una fuente inagotable de $\mathrm{H}^{+}$.

Una disminución en la concentración total de ácidos débiles no volátiles [Атот] también produce una alcalosis metabólica. El ejemplo principal es la hipoalbuminemia debida a malnutrición, cirrosis hepática o síndrome nefrótico. Dado que la concentración de fosfato sérico normal es 
relativamente pequeña, la hipofosfatemia sola no produce una alcalosis metabólica significativa. La reducción en la concentración de proteínas plasmática reduce [Атот] у equivale a una caída de carga negativa. Los efectos son comparables a un aumento de la SID.

2. Amortiguación de los iones $\mathrm{H}^{+}$.

Ante una disminución de la concentración de iones $\mathrm{H}^{+}$se produce una desviación hacia la derecha y el resultado es una disminución de la $\mathrm{pCO}_{2}$ y un aumento del $\mathrm{HCO}_{3}^{-}$:

$$
\mathrm{CO}_{2}+\mathrm{H}_{2} \mathrm{O} \rightarrow \mathrm{H}_{2} \mathrm{CO}_{3} \rightarrow \mathrm{H}^{+}+\mathrm{HCO}_{3}^{-}
$$

Los amortiguadores celulares actúan inmediatamente y liberan $\mathrm{H}^{+}$. Cerca de la tercera parte de la amortiguación es intracelular, sobre todo, por intercambio iónico, con salida de $\mathrm{H}^{+}$de las células, que se compensa con la entrada de $\mathrm{Na}^{+}$y $\mathrm{K}^{+}$.

3. Compensación respiratoria.

La caída de la concentración de $\mathrm{H}^{+}$deprime el centro respiratorio, disminuyendo la ventilación alveolar lo cual eleva la $\mathrm{pCO}_{2}$ y disminuye la $\mathrm{pO}_{2}$. Esto hace regresar al $\mathrm{pH}$ hacia la normalidad aumentando la concentración de bicarbonato plasmático todavía más. La magnitud de esta compensación está limitada por los mecanismos quimiorreceptores carotídeo y aórtico, que estimulan el centro respiratorio si hay una caída apreciable de la $\mathrm{pO}_{2}$ arterial. $\mathrm{La}_{\mathrm{pCO}}$ rara vez se eleva por encima de 55 a $60 \mathrm{mmHg}$.

4. Compensación renal.

a. Disponibilidad de $\mathrm{H}^{+}$por la célula epitelial tubular. Al estar aumentada la $\mathrm{pCO}_{2}$ plasmática tras la compensación respiratoria, difunde un mayor número de moléculas de $\mathrm{CO}_{2}$ desde el capilar peritubular a las células epiteliales tubulares. La anhidrasa carbónica del citoplasma de estas células cataliza la formación del ion $\mathrm{H}^{+}$para ser secretados a la luz tubular.

b. Carga filtrada de bicarbonato. La concentración de $\mathrm{HCO}_{3}^{-}$plasmático está aumentada por el desplazamiento hacia la derecha de la ecuación: $\mathrm{CO}_{2}+\mathrm{H}_{2} \mathrm{O}<->\mathrm{H}_{2} \mathrm{CO}_{3}<->\mathrm{HCO}_{3}^{-}+\mathrm{H}^{+} \mathrm{y}$ tras la compensación respiratoria. La carga filtrada de $\mathrm{HCO}_{3}^{-}$supera a la secreción de $\mathrm{H}^{+}$a la luz tubular $\left(\left[\mathrm{H}^{+}\right]<\left[\mathrm{HCO}_{3}^{-}\right]\right)$.

c. Reabsorción del $\mathrm{HCO}_{3}^{-}$filtrado. Como está más aumentado el número de moléculas de $\mathrm{HCO}_{3}^{-}$plasmático que el de $\mathrm{H}^{+}$secretados no puede reabsorberse todo el $\mathrm{HCO}_{3}^{-}$filtrado y esa parte es excretada por la orina.

d. Excreción de protones. Como hay más moléculas de bicarbonato filtradas que protones secretados a la luz, no hay excreción de protones y por lo tanto no hay acidez titulable ni excreción de amonio y por ende no hay generación de bicarbonato por el riñón.

e. Intercambio de $\mathrm{Na}^{+}$en el túbulo distal, $\mathrm{Al}$ no haber excreción de protones el intercambio del $\mathrm{Na}^{+}$se hará con el $\mathrm{K}^{+}$. El $\mathrm{Na}^{+}$se reabsorbe y el $\mathrm{K}^{+}$se excreta a la luz tubular y por lo tanto en la orina. Se puede desarrollar una deficiencia de $\mathrm{K}^{+}$si la alcalosis se prolonga y no se administra suficiente $\mathrm{K}^{+}$.

En la corrección de una alcalosis, la reabsorción de $\mathrm{Cl}^{-}$por las células tubulares renales reduciría la SID plasmática, se hace positivo y por lo tanto aumentaría la $\left[\mathrm{H}^{+}\right]$en el plasma (caída del $\mathrm{pH}$ ). En la tabla $\mathrm{V}$ se muestra la concentración de $\mathrm{HCO}_{3}^{-}$y de $\mathrm{H}^{+}$en el plasma así como la respuesta compensatoria y la compensación esperada en trastornos primarios del equilibrio ácido-base. 
8. Principios teóricos de la fluidoterapia en trastornos del equilibrio ácido-base según el modelo de Stewart

El motivo de incluir este epígrafe en el presente tema reside exclusivamente en que su comprensión facilita entender las bases fisicoquímicas del modelo de Stewart para el equilibrio ácidobase, puede despertar el interés y la imaginación del estudiante, así como estimular su deseo por comprender lo básico de este tema. [19-21]

1. Infusión de salino (0,9\%). (Fig. 14)

La infusión de salino causa acidosis porque disminuye la [SID] debido a la hipercloremia que se crea. El salino $(0,9 \%)$ tiene concentraciones iguales de $\mathrm{Na}^{+}(154 \mathrm{mEq} / \mathrm{L})$ y Cl $\mathrm{Cl}^{-}(54 \mathrm{mEq} / \mathrm{L})$ y el plasma tiene una concentración de $\mathrm{Cl}^{-}(102 \mathrm{mEq} / \mathrm{L})$ mucho menor que la del $\mathrm{Na}^{+}(140 \mathrm{mEq} / \mathrm{L})$. Así, cuando se administran grandes cantidades de salino el $\mathrm{Cl}^{-}$aumenta mucho más que la de $\mathrm{Na}^{+}$y se desarrolla una hipercloremia. Al aumentar la [ $\left.\mathrm{Cl}^{-}\right]$disminuye la SID, al disminuir la carga positiva aumenta la disociación del agua plasmática y con ello la concentración de $\mathrm{H}^{+}$lo cual mantiene la electroneutralidad, si bien se produce una acidosis. Las infusiones grandes de salino inducen más acidosis.

Infusión de gran volumen de salino $0,9 \%$ en condiciones normales de $\mathrm{pH}$

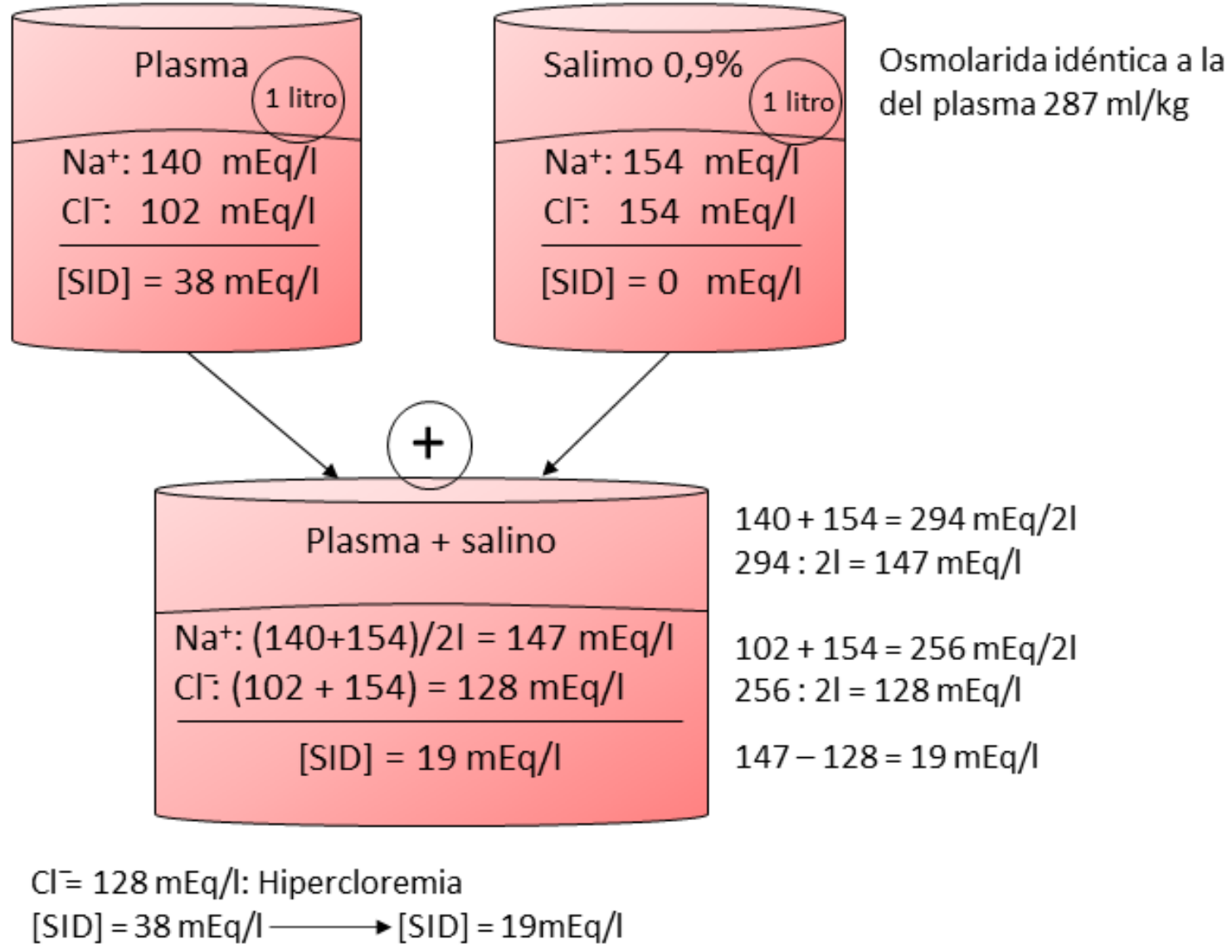

La infusión de salino $(0,9 \%)$ disminuye la [SID] de $38 \mathrm{mEq} / \mathrm{l}$ (fisiológica del plasma) a $19 \mathrm{mEq} / \mathrm{l}$, induciendo una acidosis hipercloremica.

Figura 14 Infusión de un gran volumen de salino 0,9\% en cndiciones normales de pH 
2. $\quad$ Infusión de Ringer-lactato (Fig. 15)

La solución de Ringer-lactato tiene una concentración de lactato orgánico (ion fuerte) de 28 $\mathrm{mEq} / \mathrm{L}$, de Cl-109 mEq/L y de cationes de $137 \mathrm{mEq} / \mathrm{L}$ por lo que la SID de esta solución contenida en el recipiente para su infusión es $0 \mathrm{mEq} / \mathrm{L}(137-(109+28)=0)$. El lactato es un anión orgánico fuerte que experimenta un rápido metabolismo después de la infusión del Ringer-lactato desapareciendo del plasma, y por lo tanto ahora habrá $0 \mathrm{mEq} / \mathrm{L}$ de lactato. Considerando la [SID] del plasma de $38 \mathrm{mEq} / \mathrm{L}$ ha pasado a un valor muy próximo de $34 \mathrm{mEq} / \mathrm{L}$ tras la infusión del Ringer lactato. Por lo tanto, la infusión de un Ringer-lactato produce una [SID] próxima al valor normal.

\section{Ringer lactato}

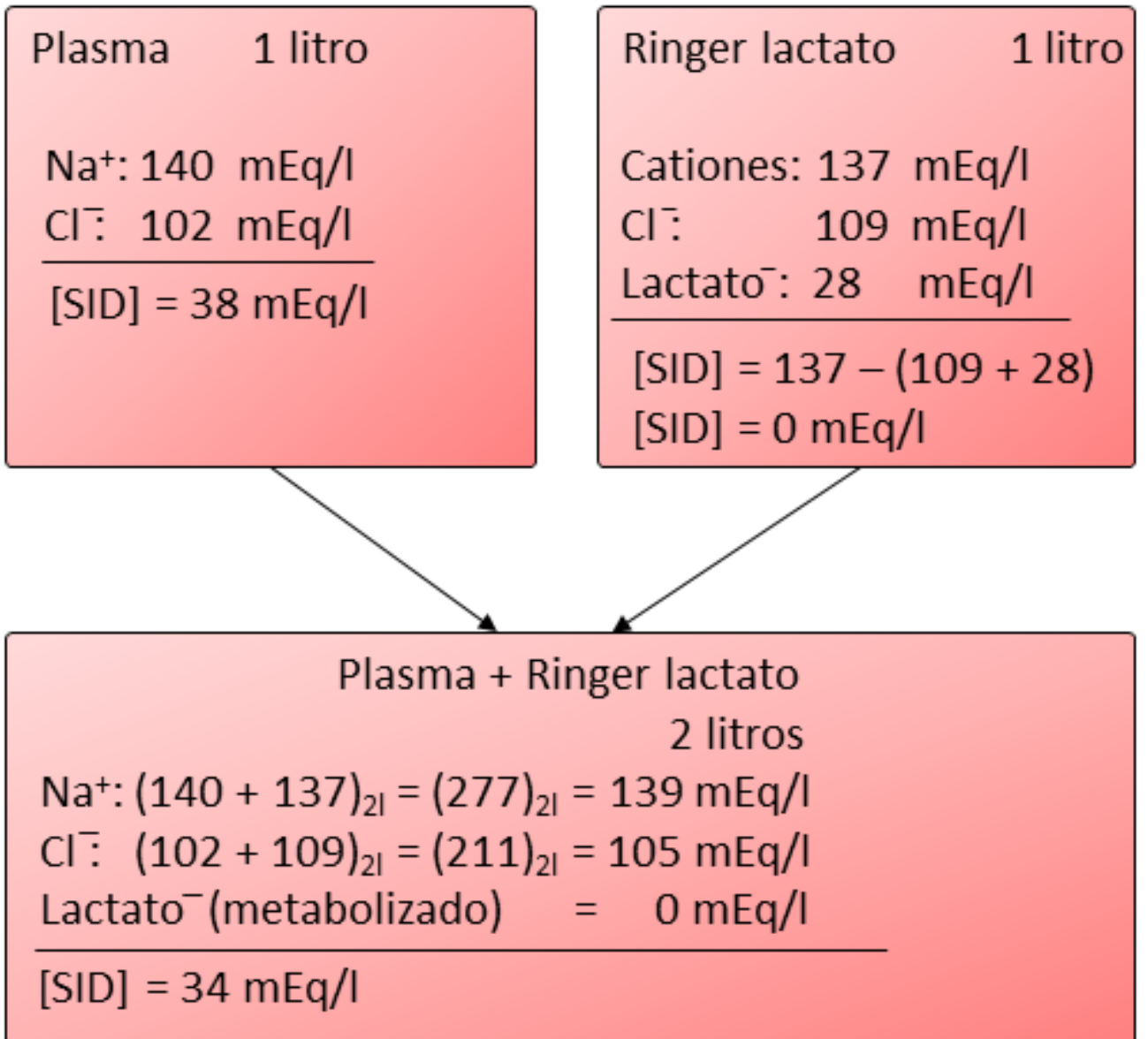

Figura 15 Infusión de Ringer - lactato

3. Infusión de bicarbonato sódico (Fig. 16)

Según Stewart el $\mathrm{HCO}_{3}^{-}$es una variable dependiente, y como tal no determina el $\mathrm{pH}$. Para Stewart la fuente de $\mathrm{H}^{+}$es la disociación del agua. Así la alcalinización del plasma tras la

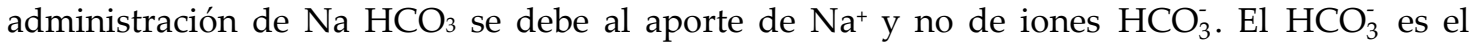
acompañante del ion $\mathrm{Na}^{+}$. El ion $\mathrm{HCO}_{3}^{-}$reacciona con los $\mathrm{H}^{+}$formando $\mathrm{CO}_{2}$ más $\mathrm{H}_{2} \mathrm{O}$. El CO $\mathrm{CO}_{2}$ es rápidamente excretado sino se acumularía y difundiría a las células. 


\section{Bicarbonato}

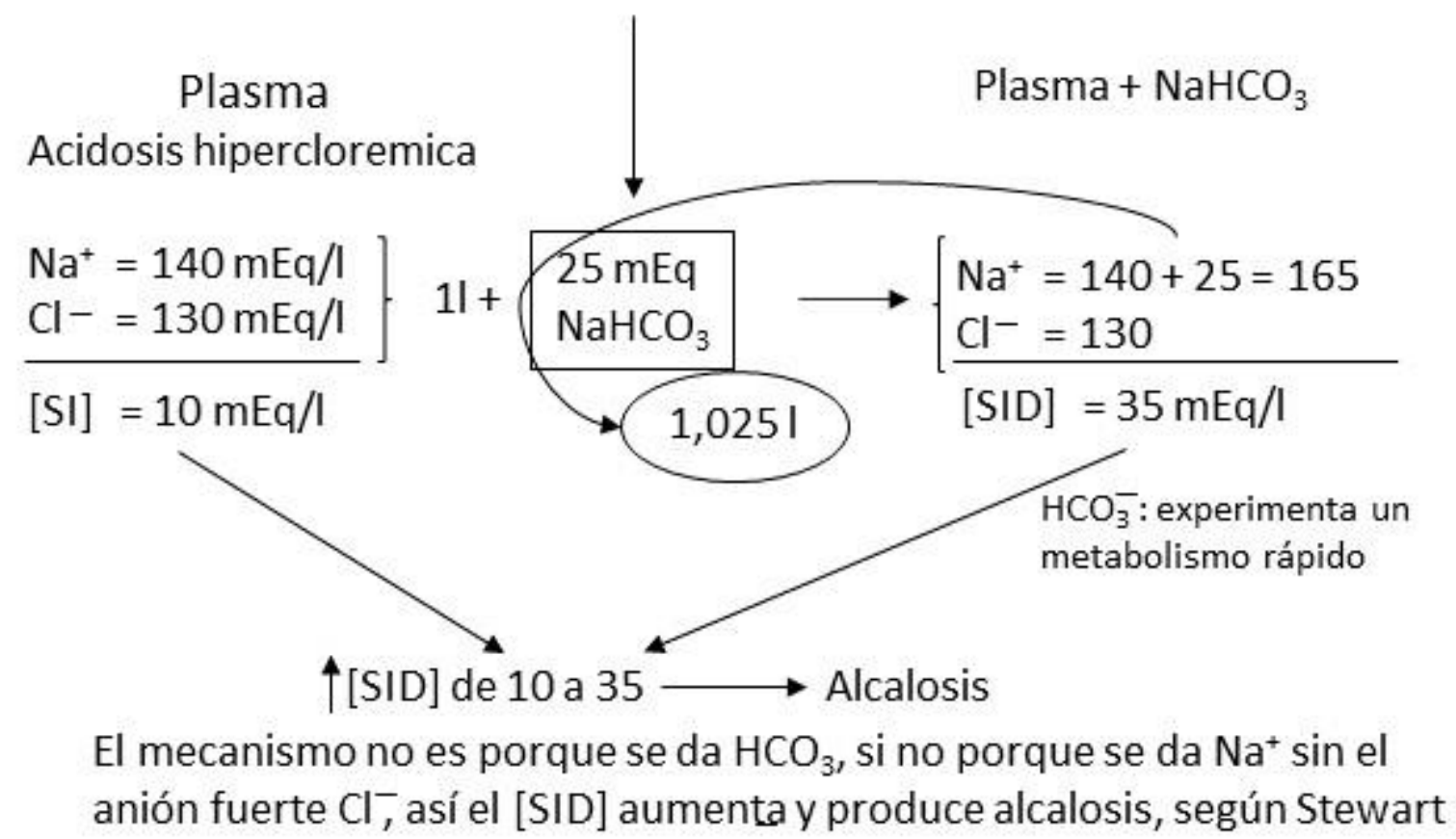

Figura 16 Infusión de bicarbonate sódico

4. Soluciones equilibradas

Soluciones intravenosas equilibradas es un término general para describir diferentes soluciones con diferente composición de electrolitos próximas a la composición del plasma, comparado con soluciones previamente disponibles. Las soluciones equilibradas usando aniones orgánicos tales como acetato, gluconato, lactato, malato o piruvato tienen una SID igual a cero en condiciones in vitro similar al salino isotónico, pues la suma de cargas positivas es igual a la suma de cargas negativas. In vivo, el metabolismo de estos aniones implica su desaparición y por lo tanto al tener carga negativa y perderse esta, ello supone un aumento de la SID y también una disminución de la osmolaridad de la solución. Otro modo de interpretarlo (R.D.Cahen), ya expuesto, es que supongamos carboxilatos en aniones organicos metabolizables con su carga negativa. $\mathrm{Al}$ ser neutralizados con $\mathrm{H}^{+}$procedentes de la hidratación del $\mathrm{CO}_{2}$ por la anhidrasa carbónica, se genera simultáneamente $\mathrm{HCO}_{3}^{-}$. 


\section{Referencias Bibliográficas}

1. Stewart. P. A. Modern quantitative acid-base chemistry. Can J Physiol Pharmacol. 1983; 61: 1444-1461.

2. Adeva-Andany MM, Carneiro Freire N, Donapetry-Garcia C, Rañal- Muiño E, Lopez- Pereiro.The importance of the Ionic Product for Water to understand the Physiology of the Acid-Base Balance in Humans.

3. Sirker AA, Rhodes A, Grounds RM, Bennett ED. Acid-base physiology: the traditional and the modern approaches. Anaest. 2002; 57: 348-356.

4. Kishen R, Honoré P M, Jacobs R, Joannes-Boyau O, De Waele E, De Regt J, Van Gorp V, Boer W, Spapen HD. Facing acid-base disorders in the third millennium - the Stewart approach revisited. Int J Nephrol Ren Dis. 2014; 7: 209-217.

5. Greenbaum J, Nirmalan M. Acid-base balance: Stewart's physiochemical. Curr Anaesth Crit Care. 2005; 16: 133135.

6. Quintard H, Hubert S, Ichai C. What is the contribution of Stewart's concept in acid-base disorders analysis. Ann Franç Anesth Réanim. 2007; 26: 423-433.

7. Jones N L. A quantitative physicochemical approach to acid-base physiology. Clin Biochem. 1990; 23: 189-195.

8. Rajkumar P, Pluznick JL. Acid-base regulation in the renal proximal tubules: using novel $p H$ sensors to maintain homeostasis. Am J Physiol Renal Physiol. 2018; 315 (5): F1187-F1190.

9. Kaunitz JD, Akiba Y. Review article: duodenal bicarbonate-mucosal protection, luminal chemosensing and acid-base balance. Aliment Pharmacol Therapeut. 2006; 24 (Suppl 4): 169-176.

10. Mizumori M, Meyerowitz J, Takeuchi T, Lim S, Lee P, Supuran CT, Guth PH, Engel E, Kaunitz JD, Akiba Y. Epithelial carbonic anhrdrases facilitate PCO2 and pH regulation in rat duodenal mucosa. J Physiol. 2006; 573 (3): 827-842.

11. Arilla Ferreiro E. Alteraciones del equilibrio ácido-base. Bioquímica Clínica. González de Buitrago JM, Arilla Ferreiro E, Rodríguez Segade M y Sánchez Pozo A. McGraw Hill Interamericana. 1998: 529-552.

12. Gomez H, Kellum JA. Uderstanding acid base disorders. Crit Care Clin. 2015; 31: 849-860.

13. Rastegar A. Clinical utility of Stewart's method in giagnosis and management of acid-base disorders. Clin J Am Soc Nephrol. 2009; 4: 1267-1244.

14. Seifter JL, Chang HY. Disorders of acid-base balance: new perspectives. Kidney Dis. 2016; 2 : 170-186.

15. Ruiz de Garibay AP, Kellum JA, Honigschanabel J, Kreymann B. Respiratory and metabolic acidosis correction with advanced organ support system. Intens Care Med Ext. 2019: 7 (56): 1-17.

16. Kellum JA. Metabolic acidosis in the critically ill: Lessons from physical chemistry. Kidney Int. 1998; 53 (Suppl. 66): S81-S86.

17. Fidkowski C, Helstrom J. Diagnosing metabolic acidosis in the critically ill: bridging the anion gap, Stewart, and base excess methods. Can J Anesth. 2009; 56: 247-256.

18. Adeva-Andany MM, Fernández-Fernández C, Mouriño-Bayolo D, Castro-Quintela E, DomínguezMontero A. Sodium bicarbonate therapy in patients with metabolic acidosis. Scient World J. 2014; 1-13.

19. Kilic O, Gultekin Y, Yazici S. The impact of intravenous fluid therapy on acid-base status of critically III adults: a Stewart approach-based perspective. Int J Nephrol Ren Dis. 2020; 13: 219-230.

20. Smuszkiewicz P, Szrama J. Theoretical principles of fluid management according to the physicochemical Stewart approach. Anaesthesiol Int Ther. 2013; 45 (2): 99-105.

21. Langer T, Santini A, Scotti E, Regenmortel NV, Malbrain MLNG, Caironi P. Intravenous balanced solutions: from physiology to clinical evidence. Anaesthesiol Int Ther. 2015; 47: s78-s88.

22. I. D. Weiner and J. W. Verlander Ammonia transporters and their role in acid-base balance. Physiol Rev. 2017, 97, $465-494$

23. D. Eladari and Y. Kusmai. Renal acid-base regulation: new insights from animal models. Pflugers Arch. Eur. J. Physiol DOI 10.1007/100424-014-1669-x

24. J. D. Kaunitz and Y. Akiba. Duodenal- carbonic anhydrase: mucosal protection, luminal chemosensing, and gastric acid disposal. Keio J. Med 2006, 55, 3, 96-106. 